\title{
ESTUDO DAS HABILIDADES DO PROCESSAMENTO \\ AUDITIVO, EM ESCOLARES NA CIDADE DE BAURU - SP
}

SILVANA MARIA BRUNO DA COSTA

Tese apresentada como exigência para a obtenção do Grau de Doutor na área de concentração Epidemiologia da Faculdade de Saúde Pública da Universidade de São Paulo.

Área de Concentração: Epidemiologia

Orientadora: Prof.a. Dra. Maria Regina Alves Cardoso Co-Orientador: Prof. Dr. Orozimbo Alves Costa

Filho

São Paulo 
Comissão Julgadora

Prof. a Dra. Maria Regina Alves Cardosos (orientadora)

Prof. Dr. Orozimbo Alves Costa Filho (co-orientador)

Prf. ${ }^{a}$ Dra. Doris Ruth Lewis

Prof. ${ }^{a}$ Dra. Eliane Schochat

Prof. a Dra. Iêda Chaves Pacheco Russo

Prof: ${ }^{a}$ Dra. Kátia de Freitas Alvarenga 
"Existem duas formas de viver a vida

Uma é acreditar que não existe milagre,

A outra é acreditar que todas as coisas

são um milagre"

Albert Einstein 
A

Prof. a Maria Regina Alves Cardoso

Incentivadora, amiga e orientadora desta minha realização profissional. 
Ao

Prof.Dr. Orozimbo Alves da Costa Filho

O grande mestre ensinando os verdadeiros caminhos para seu aprendiz. 
Aos meus pais Rubens e Maria Thereza, que proporcionaram todas as oportunidades para a realização dos meus sonhos e foram meus exemplos de vida e sabedoria. 


\section{AGRAdECIMENTOS}

$\dot{A}$ Profa. Dra. Maria Cecília Bevilacqua, por toda ajuda e incentivo recebidos.

À Profa. Dra. Iêda Chaves Pacheco Russo pelo carinho, atenção e dedicação recebidos na elaboração desta tese.

À Profa. Dra. Doris Ruth Lewis, Profa. Dra. Eliane Schochat e a Profa. Dra. Kátia de Freitas Alvarenga pelas valiosas sugestões, atenção e carinho na leitura deste trabalho no momento da qualificação.

À secretária e amiga Márcia pela disponibilidade em ajudar no agendamento das crianças e nos momentos dificeis.

À Fga.Regina Bortoleto, pelo apoio durante a coleta desta tese.

Às amigas Fga. Aline Epiphanio Wolf e Fga.Adriana A. de Paula e Silva, pela amizade, paciência, atenção e apoio, nos momentos mais dificeis de minha vida. Obrigado.

À equipe do Departamento de Epidemiologia da USP-FSP, as amigas Camile, Carol e Patrícia, pelo carinho e atenção que me tratavam sempre que precisei. 
Ao Tio Líbero, Tia Zenaide e família, pelo carinho com que sempre me receberam em seu lar.

Às minhas irmãs, Adriana $\mathbf{M}^{\mathrm{a}}$.B.C.Hinds de Palma e Fabiana M.B. da Costa, por estarem sempre presentes e pelo apoio que recebi. Obrigado.

Ao meu cunhado Rafael Hinds de Palma, pelo incentivo, carinho e amizade recebidos.

Aos pais e as crianças que colaboraram para a realização desta tese.

A FAPESP, pelo auxílio financeiro concedido para a realização desta tese.

A todos aqueles que de alguma forma colaboraram para a realização desta dissertação. Obrigado. 


\section{RESUMO}

$\mathrm{O}$ distúrbio do processamento auditivo tem sido relacionado a um baixo desempenho escolar em crianças. $\mathrm{O}$ objetivo do presente estudo foi identificar a prevalência de alterações nas habilidades auditivas, os fatores de risco e as características comportamentais associadas a estas alterações. Duzentos e dez crianças em idade escolar foram submetidas a testes do processamento auditivo e medidas eletrofisiológicas. Os resultados mostraram 32,38\% (IC95\%: $24,59 \%$ a $40,18 \%$ ) de prevalência. Foi realizada regressão logística múltipla que mostrou que os principais fatores de risco foram: hipóxia perinatal, infecção de orelha média, latência de $\mathrm{Pa}$ no Potencial Evocado Auditivo de Média Latência e latência do P300 alteradas, e limiar auditivo maior que 10dBNA em uma ou mais frequêencias. As características comportamentais encontradas nas crianças em idade escolar foram baixo desempenho escolar, dificuldade de localização sonora, vocabulário pobre e problemas de obediência à regras. 


\section{SUMMARY}

The auditory processing disorders has been related to a low school progress at school-aged children. The aim of the present work was to identify the prevalence of alterations on auditory abilities and the risk factors and behavioural characteristics associated to these alterations. Two hundred ten school-aged children were submitted auditory processing tests and eletrophysiological measures. The results showed 32,38\% (IC95\%: 24,59\% A 40,18\%) of the prevalence. It was carried on multiply logistic regression it showed that the main risk factors were perinatal hypoxia, middle ear infection, $\mathrm{Pa}$ latency of the Middle Latency Response and P300 latency were altered, and hearing level higher than 10dBHL in one or more frequency. Behavioural characteristics founded in the schoolaged children were low school progress, difficulty in sound localization, poor vocabulary and problems with obedience to rules. 
1. INTRODUÇÃO 1

2. REVISÃO DE LITERATURA 5

2.1. ANATomia E Fisiologia do Sistema Nervoso Auditivo Central (SNAC) 5

2.1.1. O nervo auditivo (VIIl par craniano) e os núcleos cocleares 6

2.1.2. Complexo Olivar Superior (CÓS) 8

2.1.3. Lemnisco Lateral (LL) 10

2.1.4. Colículo Inferior $(\mathrm{CI}) \quad 11$

2.1.5. Como Geniculado Medial (CGM) 12

2.1.6. Formação Reticular (FR) 12

2.1.7. O Corpo Caloso (CC) 13

2.1.8. O Cérebro 14

2.2. O Process AMENTO Auditivo (PA) E O DistúRBio do Processamento

AUDITIVO(DPA) $\quad 18$

2.2.1. Definições 18

2.2.2. Fatores de risco

2.3. Os Testes COMPortamentais para Avaliação do Processamento Auditivo 28

2.5. AvaliaÇão do Distúrbio do Processamento Auditivo útllizando as MEdidas 37

ELETROFISIOLÓGICAS

2.4.1. Potenciais Auditivos Evocados de Curta Latência - BERA

2.4.2. Potenciais Evocados de Média Latência - MLR 45

2.4.3. Potenciais Evocados de Longa Latência - P300 50

3. OBJETIVOS 55

4. MÉTODO 56

4.1. Populaç̃o

4.2. Amostra 56

4.3. Definição de Caso $\quad 58$

4.4. Procedimentos 59

4.5. Equipamentos $\quad 65$

4.6. Registro dos Resultados $\quad 66$

4.7. Análise dos Dados $\quad 66$

5. RESULTADOS 70

6. DISCUSSÃO 90

7. CONCLUSÕES $\quad 98$

8. CONSIDERAÇÕES ÉTICAS 100

9. REFERÊNCIAS BIBLIOGRÁFICAS 101 
ANEXOS

Anexo 1

Anexo 2

Anexo 3

Anexo 4

Anexo 5 


\section{Lista de Tabelas}

TABELA 1 - TIPOS DE FUNÇŌEs ATRIBUIDAS AOS HEMISTERIOS CERERRAIS

TADELA 2 - IMPORTANTES HADILIDADES DO PROCESSAMENTO AUDITIVO CENTRAL

TABELA 3 - TESTES PARA AVALIAÇÃo do PROCESSAMENTO AUDITIVO

TABELA 4 - TESTES PARA AVALIAÇÃO DO PROCESSAMENTO AUDITIVO TRADUZIDOS PARA O PORTUGUÊS

TABELA 5 - ESTRUTURAS ANATÔMICAS RESPONSÁVEIS PELAS ONDAS DA ABR E OS DIFERENTES TEMPOS DE LATÊNCIA, EM INDIVÍDUOS ADULTOS, COM AUDIÇÃO NORMAL

TABELA 6 - ParÃmetros do REgistro da ABR

TABELA 7 - PARÂMETROS DO ESTÍMULO DA ABR

TABELA 8 - PARÂMETROS DO REGISTRO PARA MLR 63

TABELA 9 - PARÂMETROS dO ESTÍMULO PARA MLR 63

TABELA 10 - ParÂMETros do Registro para P300 64

TABela 11 - Parâmetros do estímulo para P300

TABELA 12 - DISTRIBUIÇÃo DAS CRIANÇAS DE $3^{x}$ A $5^{x}$ SÉRIE, SEGUNDO A IDADE NO MOMENTO DA 70 AVALIAÇĀo. BaURU 2000-2001

TABELA 13 - Distribuição das CrianÇas de $3^{a}$ a $5^{a}$ SÉrie, SEgundo a Categoria da escola. 71 BAURU 2000-2001

TABELA 14 - Distribuição das CRIANÇAS de $3^{x}$ A $5^{a}$ SÉRIE, SEgundo A HISTÓRIA GESTACIONAL 72 NASCIMENTO. BAURU 2000-2001

TABELA 15 - Distribuição das CRIANÇAS de $3^{*}$ a $5^{*}$ SÉRIE, SEgundo dados da história MÉDICA. BAURU 2000-2001

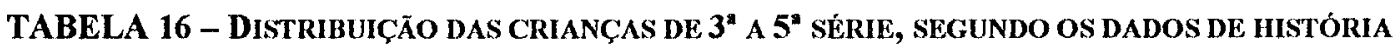
AUdiológica. BAURU 2000-2001

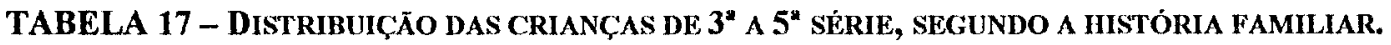

BAURU 2000-2001

TABELA 18 - DISTRIBUIÇÃo dAS CRIANÇAS de $3^{*}$ A $5^{x}$ SÉRIE, SEGUNDO AS CARACTERÍSTICAS EMOCIONAIS. BAURU 2000-2001

TABELA 19 - Distribuiç̃̃o das CrianÇAS de $3^{*}$ a $5^{*}$ SÉRIE, SEgundo CaRACterístiCas RELACIONAdAs a Problemas de fala/LINGUaGem. Bauru 2000-2001

TABELA 20 - DisTRIBUIÇÃo dAS CRIANÇAS DE $3^{*}$ A $5^{a}$ SÉRIE, SEGUNDO OS RESULTADOS DO TESTE SSI EM PORTUGUÊS, NAS RELAÇÕES DE SINAL/COMPETIÇÃO UTILIZADAS. BAURU 2000 - 2001

TABELA 21 - DISTRIBUIÇÃo DAS CRIANÇAS DE $3^{a}$ A $5^{a}$ SÉRIE, SEGUNDO FALHA NO TESTE SSI EM PORTUGUÊs. BAURU 2000-2001

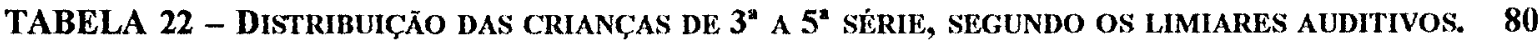
BAURU 2000-2001. 


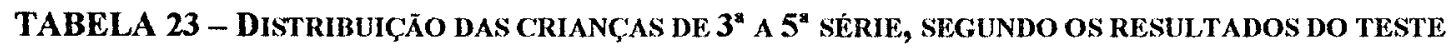
ELETROFisiológico MLR. BAURU 2000-2001

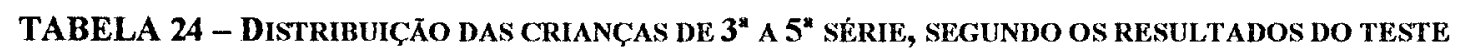
ELETRofisiológico P300. Bauru 2000-2001

TABELA 25 - DistribuiÇÃo das CRIANÇAS de $3^{a}$ A $5^{*}$ SÉRIE, SEGUNDO a IDADE E DESEMPENHO NO TESTE SSI. BAURU 2000-2001

TABELA 26 - DistribuiÇĀo das CRIANÇAS de 3" A 5* SÉRIE, SEgundo A CATEGoRIa da ESCOLA E O DESEMPENIO NO TESTE SSI. BAURU 2000- 2001

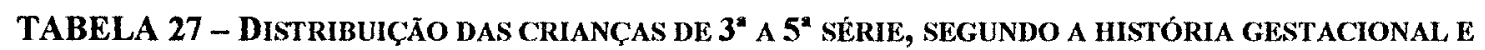
83 DESEMPENHO NO TESTE SSL. BAURU 2000-2001

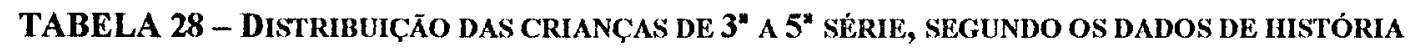
84 AuDIOLógICA E DESEMPENHO NO TESTE SSI. BAURU 2000-2001

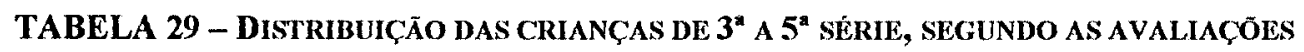
85 AUDIOLÓGICA E ELETROFISIOLÓGICA COMPARARADAS COM O DESEMPENHO NO TESTE SSI. BAURU 2000-2001

TABEla 30 - DistribuiÇĀo das CRIANÇAs de $3^{*}$ a $5^{*}$ SÉrie, SEgundo as Características COMPORTAMENTAIS E DESEMPENHO NO TESTE SSI. BAURU 2000-2001

TABELA 31 - Distribuição das Crianças de 3* a 5* SÉrie, Segundo as Caracteristicas de FALA/LINGUAGEM E DESEMPENHO NO TESTE SSI. BAURU 2000-2001.

TABELA 32 - RAZÕES DE CHANCES AJUSTADAS (RC) E RESPECTIVOS INTERVALOS DE $95 \%$ DE CONFIANÇA (IC95\%) PARA CARACTERÍSTICAS DA CRIANÇA, HISTÓRIA CLÍNICA E ALTERAÇÕEs NAS hABILIDAdEs do PROCESSAMENTO AUdITIVO. BAURU 2000-2001

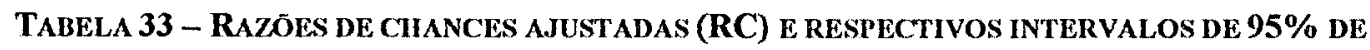
CONFIANÇA (IC95\%) PARA CARACTERÍSTICAS DA CRIANÇA, HISTÓRIA CLÍNICA E ALTERAÇÕES NAS HABILIDADES DO PROCESSAMENTO AUDITIVO. BAURU 2000-2001 
List A DE Figuras

FIGURA 1 - ESTRUTURAS DO SISTEMA AUDITIVO PERIFÉRICO E CENTRAL

FIGURA 2 - SISTEMA INTERNACIONAL $10 / 20$.

FIGURA 3 - REPRESENTAÇ̃̃o GRÁFICA DOS POTENCIAIS EVOCADOS 47 DE MÉDLA LATÊNCIA (MLR)

FIGURA 4 - MODELO de INTERPRET AÇÃo da LATÊNCIA P300.

FIGURA 5. MODELO CONCETTUAL DOS FATORES DE RISCO ASSOCIADOS Às ALTERAÇŌES NAS HABILIDADES DO PROCESSAMENTO AUDITIVO EM ESCOLARES.

FIGURA 6. MODEL O CONCEITUAL DAS CARACTERÍSTICAS EMOCIONAIS E DO COMPORTAMENTO 69 AUDITIVO ASSOCIADAS AS ALTERAÇÕES NAS HABILIDADES DO PROCESSAMENTO AUDITIVO EM ESCOLARES. 
Lista de Abreviaturas

ASHA-American Speech-Language- Hearing Association

C.C. - Corpo Caloso

C.G.M. - Corpo Geniculado Medial

C.I. - Colículo Inferior

C.O.S. - Complexo Olivar Superior

D.P.A. - Distúrbio do Processamento Auditivo

dB - deciBell

dBNA - deciBell Nível de Audição

dBNAn - deciBell Nível de Audição normatizado

dBNS - deciBell Nível de Sensação

F.R. - Formação Reticular

H.T.P.E. - Histograma de Tempo Pós-estímulo

L.L. - Lemnisco Lateral

M.C.I. - Mensagem Competitiva Ipsilateral

MCC - Mensagem Competitiva Contralateral

N.C.D. - Núcleo Coclear Dorsal

N.C.V.A. - Núcleo Coclear Ventral Anterior

N.C.V.P. - Núcleo Coclear Ventral Posterior

N.O.S.L. - Núcleo Olivar Superior Lateral

N.O.S.M. - Núcleo Olivar Superior Medial

P.E.A. - Potenciais Evocados Auditivos

P.E.A.M.L. - Potencial Evocado Auditivo de Média Latência

P.E.A.T.E. - Potencial Evocado Auditivo de Tronco Encefálico

P.S.I. - Pediatric Sentence Identification

S.A.R.A. - Sistema Ativador Reticular Ascendente

S.N.A.C. - Sistema Nervoso Auditivo Central

S.S.I. - Synthetic Sentence Identification

S.S.W. - Staggered Spondaic Word

T.E. - Tronco Encefálico

UNIFESP/EPM - Universidade Federal de São Paulo/Escola Paulista de Medicina 


\section{INTRODUÇÃO}

A habilidade de ouvir a fala depende de redundâncias intrínsecas (sistema auditivo periférico e central normais) e extrínsecas (pistas acústicas, sintáticas, semânticas, morfológicas e lexicais), que são influenciadas pela intensidade do ruido e/ou reverberação do ambiente, as quais prejudicam a percepcão auditiva, comprometendo a inteligibilidade em individuos com ou sem alterações auditivas. Existem evidências do esforço que o ouvinte faz para entender a fala na presença de ruido e/ou reverberação, podendo afetar a cognição, especialmente pela falta de estímulos discriminativos ou pistas (redundâncias extrínsecas) que permitam recuperar na memória as informações relevantes para a compreensão da fala (BOCCA 1958).

Existem condições básicas necessárias para que a criança ingresse em uma escola primária. Nos primeiros anos de vida, as habilidades e destrezas importantes para o aprendizado são adquiridas; entretanto, é necessário atingir a maturidade em nivel neurológico, psíquico, lingüístico, perceptual e de estruturas lógicas do pensamento para que seja possivel garantir a aquisição da leitura e escrita de forma adequada (TARNOPOL e TARNOPOL 1981)

A identificação de distúrbios do processamento auditivo (D.P.A.) em crianças tem recebido atenção especial nas últimas duas décadas devido às evidências de que esses distúrbios podem estar relacionados ao desempenho escolar (LASKY e KATZ 1983).

As crianças desenvolvem as habilidades perceptuais auditivas juntamente com a maturidade neurológica, que ocorrem geralmente até os nove anos. Porém, algumas crianças não adquirem as habilidades necessárias para o aprendizado em uma sala de aula, tais como: discriminação, memória, atenção auditiva, entre outras (PAGE 1985). 
Sabe-se, também, que três fatores interagem para caracterizar a atividade fisiológica de ouvir: (1) atividade periférica das orelhas externa, média e interna; (2) atividade auditiva central e (3) processos ou habilidades do sistema nervoso auditivo central (S.N.A.C.). A ruptura em qualquer um desses mecanismos, no processo de reconhecimento da fala, pode provocar prejuízos que resultem em um prejuizo da percepção auditiva da fala (HUMES 1990).

Dentre as condições mencionadas anteriormente, o desenvolvimento das habilidades do processamento auditivo tem sido apontado como importante para o aprendizado da leitura e escrita. Portanto, as alterações nessas habilidades tornam-se um fator de risco para o desempenho escolar. A evasão e a repetência escolar, principalmente nas séries de primeiro grau, vêm gerando preocupações, pois podem estar relacionadas com essas dificuldades (PERISSINOTO e col. 1997).

Algumas crianças com distúrbio de processamento auditivo não compreendem a fala em ambiente desfavorável, dispersam-se facilmente com o ruído de fundo, não acompanham uma conversação com mais de dois interlocutores, precisando que a informação seja repetida (MACHADO e PEREIRA 1997, JERGER e MUSIEK 2000).

Outras situações comuns nos escolares são as alterações auditivas que acometem o funcionamento da orelha média, como a otite média recorrente que geralmente provoca flutuação da audição, podendo causar efeitos adversos sobre a aquisição e o desenvolvimento da linguagem (ORTIZ e PEREIRA 1997).

A otite média, considerada uma das doenças mais comuns na infância, deveria ser encarada como um problema básico de saúde (HUBIG e COSTA FILHO 1997), a fim de prevenir os períodos de privação sensorial que podem influenciar negativamente $o$ 
desenvolvimento das estruturas e função do sistema nervoso auditivo central (S.N.A.C.) (WEBSTER D. e WEBSTER M. 1980).

Procedimentos de identificação, diagnóstico e tratamento das alterações da orelha média deveriam ser adotados, o mais cedo possível, devido aos efeitos adversos na deteç̧ão dos sons. Essa condição pode impedir o aprendizado eficiente da linguagem, podendo restringir o processo de organização e categorização da informação acústica (processamento auditivo) da fala (BAMFORD e SAUNDERS 1995).

Os testes para avaliar a audição periférica já foram pesquisados e validados, porém atualmente vem crescendo o interesse pelo estudo das alterações auditivas centrais.

A avaliação das vias auditivas centrais deve ser realizada por meio de procedimentos eletrofisiológicos e testes comportamentais especiais (CHERMAK e MUSIEK 1997).

Os testes especiais para avaliação do processamento auditivo utilizando a observação comportamental, fornecem informações sobre como o indivíduo faz uso das habilidades auditivas, possibilitando a localização dentre as diversas vias neurais do S.N.A.C. e as perspectivas terapêuticas a serem utilizadas (CARVALLO 1997).

Vários procedimentos eletrofisiológicos podem ser utilizados para avaliar o S.N.A.C., como os Potenciais Evocados Auditivos (P.E.A.), utilizando o registro de potenciais de ação da via auditiva central, evocados por uma fonte sonora, entre eles: o Potencial Evocado Auditivo de Tronco Encefálico (P.E.A.T.E.), o Potencial Evocado Auditivo de Média Latência (P.E.A.M.L.) e Potenciais Evocados de Longa Latência (entre eles, o Potencial Cognitivo ou Endógeno - P300). Outra medida fisiológica que vem sendo estudada atualmente é o registro das emissões otoacústicas evocadas (EOAE), na presença 
de ruido contralateral, com o intuito de avaliar o sistema olivococlear, situado no tronco encefálico (CHERMAK e MUSIEK 1997).

As medidas eletrofisiológicas como o P.E.A.T.E., P.E.A.M.L. e P300 tornam a avaliação global da função auditiva cada vez mais viável. A avaliação pode combinar testes eletrofisiológicos com a audiometria tonal liminar, medidas da imitância acústica, emissões otoacústicas e avaliação comportamental da função auditiva central, proporcionando o diagnóstico de alterações periféricas e centrais (KRAUS e McGEE 1999).

Ainda que avanços importantes tenham ocorrido no uso da bateria de testes para processamento auditivo em escolares com dificuldades perceptuais, é necessário conhecer as características de cada avaliação, a fim de compará-las e melhorar a sensibilidade da bateria de testes a ser utilizada. Considerações quanto ao tempo empregado, número de testes, características da população avaliada, devem ser analisadas.

A validação de testes auditivos centrais em crianças com problemas de aprendizado não é uma tarefa simples, pois nem todas apresentam os mesmos prejuizos nas habilidades auditivas centrais e, portanto, não há um padrão ouro para medir a precisão do teste. Comparações entre os vários testes, na população com problemas de aprendizado, podem ajudar a determinar quais são mais sensiveis na definição dessa população. Parece que essa população tem dificuldade na avaliação do processamento auditivo, similares àquelas encontradas em indivíduos com lesões já confirmadas (CHERMAK e MUSIEK 1997).

Embora o trabalho aqui apresentado não possa abordar todas essas questões, esperamos que constitua uma tentativa no sentido de aprimorar o conhecimento das características clínicas e comportamentais, a fim de auxiliar na avaliação do processamento auditivo em escolares. 


\section{REVISÃO DE LITERATURA}

\subsection{Anatomia e fisiologia do Sistema nervoso Auditivo Central}

(S.N.A.C.)

O tronco encefálico (T.E.) é formado de importantes estruturas que compõem a via auditiva ascendente. $\mathrm{Na}$ direção caudal para rostral temos os núcleos cocleares, o complexo olivar superior e o lemnisco lateral situado na ponte, o colículo inferior no mesencéfalo e o corpo geniculado medial, no tálamo (CARPENTER e SUTIN 1983).

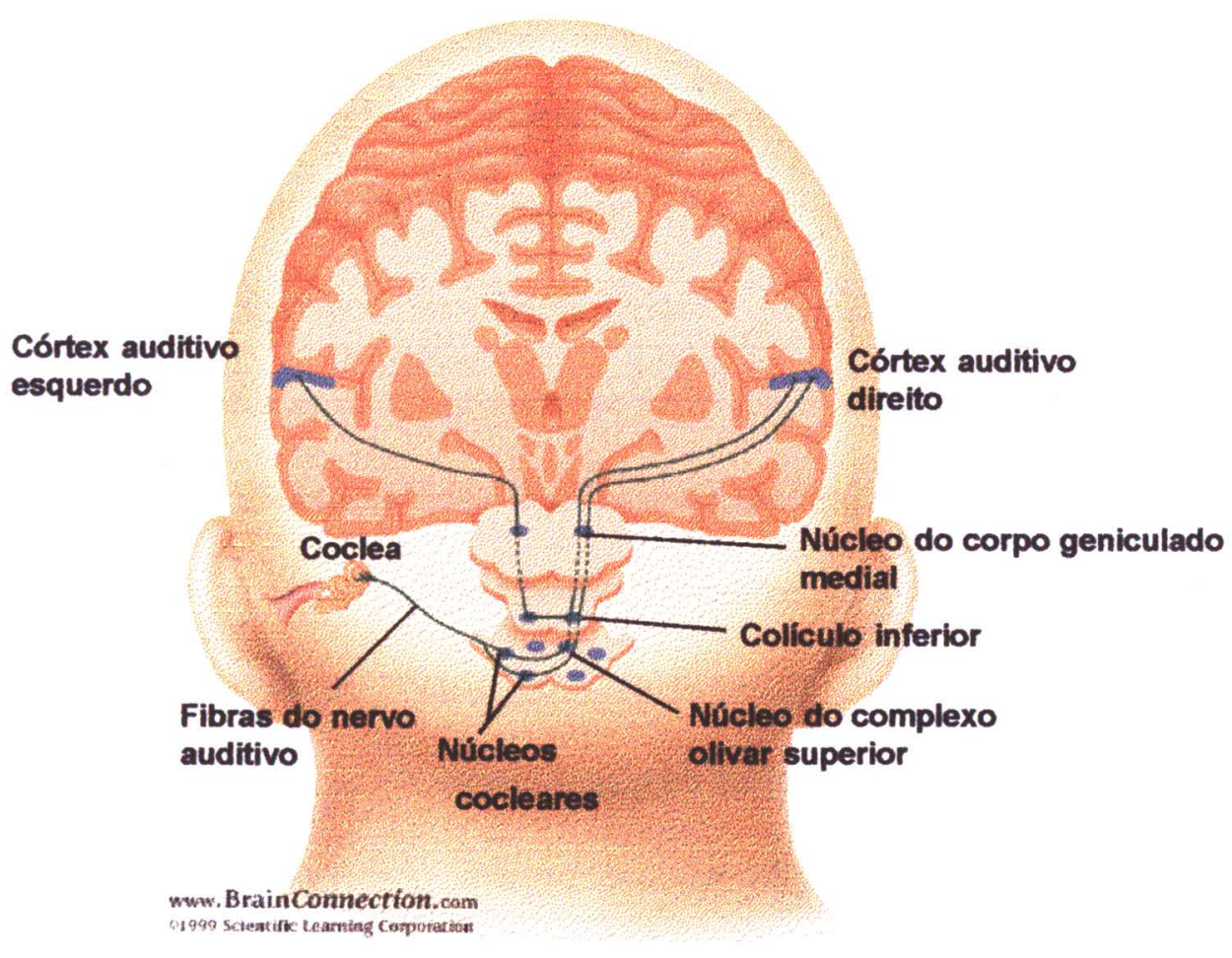

FIGURA 1 - ESTRUTURAS DO SISTEMA AUDITIVO PERIFÉRICO E CENTRAL

(Fonte: Figura modificada do site www.brainconnection.com)

Outras estruturas situadas no tronco encefálico (T.E.), na região posterior, apresentam função auditiva. A formação reticular se estende do mesencéfalo à corda 
espinhal e é composta da união de células nervosas, estando posicionada no meio de um denso trato de fibras nervosas (WADDINGTON 1984). A formação reticular parece estar relacionada às funções de alerta auditivo, reflexo e habituação auditiva (CARPENTER e SUTIN 1983).

\subsubsection{O Nervo Auditivo (VIII PAR CRANIANo) E OS NúCleos CoCleares}

MUSIEK e col. (1994) observaram que o entendimento das alteraçães e dos resultados dos testes para o sistema nervoso auditivo central depende do conhecimento da neuroanatomia e neurofisiologia, chave para o estudo da neuroaudiologia.

Esses autores relataram que a representação neuroanatômica descreve que os nervos auditivo e vestibular formam o VIII par craniano. $\mathrm{O}$ nervo auditivo consiste de fibras que começam nos terminais aferentes das células ciliadas, na cóclea, e terminam no núcleo coclear. $95 \%$ das 30.000 fibras do nervo auditivo estão ligadas às células ciliadas internas e as fibras remanescentes estão conectadas as células ciliadas externas. $\mathrm{O}$ nervo auditivo tem um arranjo em torno de si, específico de suas fibras, que na periferia do nervo auditivo são formadas por fibras da base da cóclea, portanto específicas para altas freqüências. No centro, encontram-se fibras do ápice, específicas para baixas freqüências. $O$ nervo auditivo passa, então, pelo meato acústico interno juntamente com o nervo facial. Possui aproximadamente, de 22 a $25 \mathrm{~mm}$ de comprimento. O nervo auditivo e o facial recebem suprimento sangüíneo da artéria basilar.

O nervo auditivo ao sair da cóclea apresenta três divisões, que se comunicam com: o núcleo coclear ventral anterior (N.C.V.A.), ventral posterior (N.C.V.P.) e dorsal (N.C.D.). Os núcleos cocleares são as estruturas mais caudais do S.N.A.C., localizados 
na área do ângulo ponto-cerebelar (WHITFIELD 1967). Essa área está posicionada em um recesso formado pela junção da ponte, medula e cerebelo. Tumores nessa área podem afetar os núcleos cocleares, o tronco encefálico (T.E.) e o cerebelo, podendo provocar alterações auditivas centrais (MUSIEK 1986).

O núcleo coclear é composto por diferentes tipos de células, incluindo as piramidais, estreladas, fusiformes e esféricas. Cada tipo de célula parece ter a função de modificar o impulso nervoso auditivo que faz sinapse no núcleo coclear (PFEIFFER, 1966). A maneira como é modificado esse impulso depende da morfologia das células que produzem um padrão de resposta característico, de acordo com o "histograma de tempo pós-estímulo" (H.T.P.E.). O H.T.P.E. é a resposta média de uma unidade neural para uma série de tons curtos apresentados, na unidade de freqüência característica daquela célula nervosa (RHODE 1985).

As três divisões do núcleo coclear apresentam disposição tonotópica. Cada divisão responde a uma área especifica de freqüência característica, com as freqüências baixas representadas na região ventro-lateral e as altas, na região dorso-medial dentro de cada núcleo (WEBSTER 1971).

Dos núcleos cocleares partem três tratos neurais que se projetam para as estruturas auditivas do S.N.A.C. O trato de fibras originado no núcleo coclear dorsal (estria dorsal) é projetado principalmente para o complexo olivar superior (C.O.S.), lemnisco lateral (L.L.) e colículo inferior (C.I.) contralaterais (WHITFIELD 1967). A estria acústica intermediária, que provém do núcleo coclear ventral posterior (N.C.V.P.), faz comunicação com o L.L. e C.I. contralateral. 
As fibras do núcleo coclear ventral anterior (N.C.V.A.), que formam a estria ventral, faz conexão com o complexo olivar superior (C.O.S.) contralateral e com grupos de núcleos no lemnisco lateral (L.L.) (WHITFIELD 1967).

Todos os três grupos de núcleos cocleares enviam projeções ipsilateral e contralateral, porém as vias contralaterais possuem maior número de fibras nervosas (NOBACK 1985).

\subsubsection{COMPLEXO OLIVAR SUPERIOR (C.O.S.)}

O complexo olivar superior (C.O.S.) está localizado na porção mais caudal da ponte (NOBACK 1985).

É composto de vários grupos de núcleos, porém cinco grupos serão discutidos quanto a sua importância na função auditiva: 1) núcleo olivar superior lateral (N.O.S.L.), 2) núcleo olivar superior medial (N.O.S.M.), 3) núcleo do corpo trapezóide e os núcleos, 4) pré-olivar lateral e 5) pré olivar medial (CHERMACK e MUSIEK 1997).

O núcleo olivar superior lateral (N.O.S.L.) recebe estimulação bilateral, (STROMINGER e HURWITZ 1976) com fibras nervosas ipsilaterais advindas do N.C.V.A. e contralateral, do N.C.V.P. (WARR 1966).

O núcleo olivar superior medial (N.O.S.M.) recebe inervação ipsilateral e contralateral do N.C.V.A. e o núcleo do corpo trapezóide parece receber vias do núcleo coclear contralateral (STROMINGER e STROMINGER 1971, STROMINGER e HURWITZ 1976). 
A entrada de vias neurais ipsilateral e contralateral proporciona ao C.O.S. uma base anatômica para a representação e interação binaural. Parece que o tempo e a intensidade de chegada do impulso ao C.O.S., vindos de cada orelha, são os principais determinantes da localização sonora.

Além disso, a convergência da atividade neural de cada orelha faz do C.O.S. uma estrutura importante na avaliação audiológica da função do T.E., pois apresenta um papel importante nas tarefas de escuta que necessitam da interação e interpretação de sinais apresentados bilateralmente. A normalidade nos testes especiais de fusão binaural e percepção da fala alternada dependem dessa interação (TOBIN 1985).

O C.O.S. também possui uma representação tonotópica em todos os grupos de núcleos. No N.O.S.L., as freqüências baixas são representadas lateralmente e as altas, medialmente. O N.O.S.M. apresenta, principalmente, uma representação das freqüências baixas (NOBACK 1985).

BORG (1973) comentou sobre a importância do C.O.S. no arco reflexo do músculo estapédio. $\mathrm{O}$ reflexo ocorre quando uma ou ambas as orelhas são estimuladas com intensidade sonora suficientemente forte. Impulsos neurais são conduzidos para o núcleo coclear por meio do nervo auditivo e depois para o C.O.S. e/ou núcleo do nervo facial. Os neurônios contornam o C.O.S. e terminam na região motora do núcleo do nervo facial, que envia fibras eferentes para o músculo estapédio, contraindo-o. Este reflexo parece ter importância na proteção da orelha para sons de forte intensidade. 


\subsubsection{LEMNISCO LATERAL (L.L.)}

O lemnisco lateral (L.L.) é uma via auditiva do T.E. que compreende fibras ascendentes e descendentes (GOLDBERG e MOORE 1967).

Os núcleos do L.L. são compostos por dois grupos de células neurais conhecidos como núcleo ventral e núcleo dorsal. Estes núcleos estão localizados mais superiormente na ponte, na região póstero-lateral do T.E. (WADDINGTON 1984).

O núcleo do L.L. recebe inervação aferente do N.C.D. contralateral e do N.C.V. de ambos os lados (JUNGERT 1958). Chegam, também, impulsos do C.O.S. ipsilateral e contralateral. Além disso, os núcleos dorsais do L.L. de ambos os lados estão interconectados por meio de um trato de fibras conhecido como comissura de Probst (NOBACK 1985).

A maior parte dos neurônios do núcleo dorsal do L.L. pode ser ativada bilateralmente. Entretanto, os neurônios do segmento ventral são ativados somente pela estimulação contralateral (KEIDEL e col. 1983).

BRUGGE e col. (1978) relataram que há uma organização tonotópica nos núcleos do L.L., sendo que o núcleo dorsal responde às freqüências baixas e o ventral, às frequêencias altas.

A secção bilateral do L.L. provoca uma elevação de até 80dBNA no limiar auditivo do indivíduo, não ocorrendo na secção unilateral. Lesões nessa estrutura podem alterar a localização sonora (MUNHOZ e col. 2000a). 


\subsubsection{COLÍCULO INFERIOR (C.I.)}

O colículo inferior (C.I.) está localizado na superficie dorsal do mesencéfalo e é claramente visivel como duas porções esféricas (MUSIEK e BARAM 1986).

O C.I. apresenta duas divisões principais que são o núcleo central do C.I., composto por fibras puramente auditivas, e o núcleo pericentral do colículo inferior (C.I.), o qual consiste de fibras somatossensorial e auditiva (KEIDEL e col. 1983).

O C.I. recebe inervação ipsilateral e contralateral dos N.C.D. e N.C.V., dos núcleos do C.O.S. medial e lateral, L.L. dorsal e ventral e do C.I. contralateral.

O C.I. é altamente tonotópico, sendo que as freqüências baixas estão localizadas dorsalmente e as altas ocorrem na região ventro-lateral. O C.I. possui os neurônios sensitivo, espacial e de tempo, sugerindo participação na localização sonora. Uma estrutura importante do C.I. é seu braço, que representa o grande trato de fibras que conecta ipsilateralmente o C.I. ao corpo geniculado medial, o qual é o principal núcleo auditivo do tálamo (MUSIEK e BARAN 1986).

Essa estrutura exerce importante função de audição direcional. Certas células desse complexo apresentam padrões de resposta bioelétricos em função da periodicidade dos estímulos, modificações da intensidade do estímulo em função da latência e efeitos binaurais. Foi demonstrado que a discriminação de intensidade e de frequêencia é finalizado no C.I. (MUNHOZ e col. 2000a). 


\subsubsection{Corpo Geniculado Medial (C.G.M.)}

O corpo geniculado medial (C.G.M.) está localizado na superficie inferior e dorso lateral do tálamo, a aproximadamente $1 \mathrm{~cm}$ do colículo inferior. O C.G.M. contém três divisões: ventral, dorsal e medial (MOREST 1964).

A divisão ventral é composta, principalmente por células neuronais que respondem ao estímulo acústico. As divisões dorsal e medial contêm neurônios que respondem a estimulos acústicos e somatossensoriais (KEIDEL e col. 1983). Parece estar relacionada à transmissão de informações sobre discriminação auditiva da fala para o córtex cerebral, da mesma forma que a divisão mantém e dirige a atenção seletiva, enquanto a medial tem função multissensorial (WINER 1984).

As vias aferentes para o C.G.M. surgem principalmente do braço do C.I., mas sugerem receber também vias diretamente dos núcleos e C.I. contralateral (CHERMAK e MUSIEK 1997).

Tem sido relatada uma organização tonotópica do C.G.M. O segmento ventral indica ter representação lateral, para as freqüências baixas e, medialmente, para as altas (AITKIN e WEBSTER 1972).

\subsubsection{FORMAÇÃo RETICULAR (F.R.)}

Denomina-se formação reticular (F.R.) um agregado de neurônios de tamanhos e tipos diferentes, separados por uma rede de fibras nervosas, que se encontram próximos à parte central do T.E. Trata-se de uma região do sistema nervoso, pertencente basicamente ao T.E., que faz conexão com vários núcleos e tratos. Porém, também se estende ao diencéfalo e aos níveis mais altos da medula (MACHADO A 1998). 
A F.R. é dividida em dois sistemas: 1) sistema ativador reticular ascendente (S.A.R.A.) e 2) sistema ativador motor. O S.A.R.A. tem a função de estimular o córtex cerebral, quando necessita ativar o estado de alerta e vigília (FRENCH 1957).

O sistema auditivo, assim como outros sistemas sensoriais, estão conectados à F.R. Esse pode ser um dos mecanismos que explicam a atenção seletiva e a habilidade de ouvir na presença de ruído de fundo (CHERMAK e MUSIEK 1997).

\subsubsection{O CORPo CALOSO (C.C.)}

O corpo caloso (C.C.) é representado por um grande número de comissuras interhemisféricas, formado por inúmeras fibras mielinizadas que cruzam o plano sagital mediano, unindo áreas do córtex cerebral de cada hemisfério (MACHADO A. 1998).

O corpo caloso é constituído por: 1) tronco do C.C., uma lâmina branca arqueada dorsalmente; 2) esplênio do C.C., uma dilatação posterior do tronco; 3) joelho do C.C., localizado numa porção mais anterior à base do cérebro; 4) rostro do C.C., uma continuação afinalada do joelho, e 5) comissura anterior (MUSIEK 1986b, MACHADO A.1998).

O lobo temporal apresenta projeções através do C.C. A porção posterior do lobo temporal, o giro temporal ântero-posterior e o sulco temporal superior enviam fibras para o hemisfério oposto, via comissura anterior do C.C. As áreas mediais e posteriores do giro temporal superior e plano supratemporal, que compreendem as principais áreas auditivas do cérebro, projetam fibras através do tronco do C.C. A porção inferior do lobo temporal envia fibras pela comissura anterior e pelo esplênio do C.C. (PANDYA e ROSENE 1985, PANDYA e SELTZER 1986). 
As pesquisas indicam que o segmento auditivo do C.C. situa-se na metade posterior dessa estrutura, pois individuos comissurectomizados na metade posterior apresentaram mudanças pós-operatórias nos testes da função central auditiva (MUSIEK e col.1985, MUSIEK e col.1984).

A área auditiva do C.C. foi praticamente descrita por completo, porém ainda há pouca informação sobre o caminho percorrido pelas fibras do C.C. ao córtex auditivo.

A via inter-hemisférica auditiva é conhecida como via auditiva transcalosal e é sabido que lesões nessa via provocam degradação na transferência inter-hemisférica da informação acústica (DAMASIO e DAMASIO 1979).

Alguns autores acreditam que o papel fundamental do C.C. pode ser o de igualar a atividade em ambos os hemisférios, a fim de permitir a integração da resposta cortical (BERLUCCHI 1983).

\subsubsection{O CÉREBRO}

O córtex cerebral, substância cinza na superfície do cérebro, é composto de bilhões de células nervosas, principalmente dos tipos: piramidal, estrelada e fusiforme. Ainda no córtex existem seis camadas, identificadas pelo tipo e densidade de arranjo das células (CARPENTER e SUTIN 1983).

$\mathrm{Na}$ camada IV é que encontramos a maior concentração de células sensoriais auditivas (CHERMAK e MUSIEK 1997).

As áreas auditivas do córtex envolvem o lobo temporal superior, o lobo frontal póstero-inferior e o lobo parietal inferior, onde encontramos estruturas auditivas importantes (CELESIA 1976, GALABURD e SANIDES 1980). 
O giro de Heschl (giros transversos) é considerado a área primária auditiva e se encontra na superficie lateral do córtex, no plano supratemporal, apresentando alta variabilidade entre as espécies. Além disso, existem diferenças entre o lado esquerdo e direito do mesmo individuo. O plano temporal é a área cortical que se estende da região posterior do giro de Heschl até a fissura silviana (no córtex auditivo, no lobo temporal). Esta região apresenta diferença entre os lados direito e esquerdo, sendo que o esquerdo é maior, talvez devido à dominância do hemisfério esquerdo para a fala, estando localizada próxima à área de Wernicke (CELESIA 1976).

A fissura silviana é uma importante área do córtex auditivo primário e, no homem, possui ainda ligação com a linguagem (MUSIEK 1986a).

A porção inferior do lobo parietal e frontal parece também responder à estimulação acústica (CELESIA 1976, GALABURDA e SANIDES 1980).

Outra área de grande importância do córtex auditivo é a ínsula que ocupa a porção medial do giro temporal superior. Apresenta vários giros e sulcos, respondendo às estimulações somática, gustativa, visual e, principalmente, à estimulação auditiva.

Existem várias estruturas de associação que proporcionam as conexões tálamocorticais (entre corpo geniculado medial e córtex) e inter e intra-hemisférica, como o globo pálido e putamem.

O córtex auditivo primário analisado apenas no giro de Heschl e na ínsula, também apresenta uma representação tonotópica, sendo que as altas freqüências são representadas caudo-medialmente e as baixas, rostro-medialmente. Possui função na localização sonora, devido a sensibilidade às diferenças de intensidade de chegada do estímulo sonoro entre os hemisférios (MUSIEK 1986a). 
No cérebro adulto normal, os dois hemisférios são complementares em relação à função. Um hemisfério pode ser dominante para um processo e o outro, para outras funções; por isso, a integração entre eles é necessária para o processamento ótimo da informação. O corpo caloso é a estrutura base para que isso ocorra (MUSIEK 1986b).

A TABELA 1 mostra um resumo das funções atribuídas aos hemisférios cerebrais.

\begin{tabular}{|c|c|}
\hline \multicolumn{2}{|c|}{ TABELA 1. TIPOS DE FUNÇŌES ATRIBUÍDAS AOS HEMISFÉRIOS CEREBRAIS. } \\
\hline HEMISFERIO ESQUERDO & HEMISFERIO DIRETTO \\
\hline Fala e linguagem & Percepção musical \\
\hline Ordenação temporal (sequencialização) & Percepção espacial/artística \\
\hline Reconhecimento de detalhes & Reconhecimento Geral \\
\hline Analítico & Gestalt \\
\hline Leitura e escrita & Reconhecimento de figuras e faces \\
\hline Concreto & Abstrato \\
\hline Controlado & Emocional \\
\hline Ativo & Receptivo \\
\hline
\end{tabular}

Fonte : MUSIEK, F.E.; (1986b) - Neuroanalomy, neurophysiology, and ceniral auditory assessment. Part III: Corpus callosum and efferent pathways. Ear and Hearing v. 7, n. 6, p. 349-58.

Alguns procedimentos podem ser usados para avaliar pacientes com cisão cerebral (separação). Os testes dicóticos de fala têm fornecido informações importantes da função do corpo caloso e dos hemisférios. Nos pacientes comissurectomizados, o teste dicótico de fala tem revelado um prejuízo nas respostas quando a orelha esquerda é estimulada. KIMURA (1961) explicou que o teste utilizando mensagem direcionada para a orelha direita é conduzido ao hemisfério esquerdo, o qual integra e processa o estímulo verbal a fim de propiciar uma resposta verbal. O estímulo de fala direcionado para a orelha esquerda será levado ao hemisfério direito; porém, se uma resposta verbal é requisitada, essa informação deve ser transferida para o hemisfério esquerdo, para o processamento lingüistico e de fala. Sendo assim, se o C.C. é seccionado ou danificado, o indivíduo 
apresenta resposta verbal apenas quando a estimulação de fala ocorre na orelha direita. Entretanto, $o$ indivíduo apresenta resposta na orelha esquerda se a tarefa solicitada não for verbal e sim apontar figuras correspondentes às palavras, pois o hemisfério direito reconhece o estimulo, mas não o interpreta lingüisticamente.

Outra pesquisa utilizando um estudo feito com dois pacientes com comissurectomia completa mostrou que no teste dicótico consoante-vogal e dicótico de digitos, no qual o paciente deve apresentar uma resposta verbal, ocorreu prejuizo na orelha esquerda e a resposta na orelha direita não foi afetada. Além disso, em testes monoaural de baixa redundância, como o teste de fala no ruído e fala filtrada, não foram encontradas alterações nos resultados, talvez devido a não supressão da via ipsilateral (MUSIEK e col. 1980).

O conhecimento da neuroanatomia e neurofisiologia são necessários para avaliar a utilização dos testes auditivos centrais. $\mathrm{O}$ valor da avaliação do processamento auditivo pode ser comprometido pela falta de conhecimento da morfologia e fisiologia do S.N.A.C. (MUSIEK 1986b).

CHERMAK e col. (1998) examinaram a conscientização de profissionais quanto à preparação e prática clínica no uso dos testes de processamento auditivo. Dentre os 183 audiologistas que responderam aos questionários (37\% dos questionários enviados), a maioria mostrou a necessidade de um estudo acadêmico e melhor preparação para a avaliação do sistema nervoso auditivo central. Os resultados da pesquisa sugeriram, portanto, a importância de melhorar a preparação profissional na avaliação da função auditiva central. 


\subsection{O Processamento Auditivo E o Distúrbio do Processamento}

\section{AUdiTIvo (D.P.A.).}

\subsubsection{DEFINIÇõES}

SLOAN (1991) definiu processamento auditivo como tudo o que ocorre desde que o som entra pelo meato acústico externo até o momento em que esse evento sonoro é experienciado pelo ouvinte. Para que isso ocorra é necessário um certo tempo, a fim de que a informação possa ser transformada, codificada e recodificada pelas vias auditivas. $\mathrm{O}$ processamento auditivo é freqüentemente usado em conjunção com a percepção auditiva, ou seja, esta é o resultado do processamento auditivo.

Segundo PHILIPS (1995), o processamento auditivo envolve a detecção de eventos acústicos, ou seja, a capacidade de discriminá-los quanto ao local, espectro de amplitude, tempo, a habilidade de agrupar e perceber os componentes do sinal acústico em figurafundo, bem como identificá-los por meio da associação semântica.

A American Speech-Language-Hearing Association - ASHA (1996) definiu o processamento auditivo central como sendo um conjunto de mecanismos e processos do sistema auditivo responsáveis pelo fenômeno comportamental auditivo como, localização e lateralização sonora, discriminação auditiva, reconhecimento de padrões auditivos, aspectos temporais da audição (resolução temporal, mascaramento temporal e integração temporal), performance auditiva com sinal acústico competitivo e percepção auditiva do sinal acústico degradado.

BREEDIN e col (1989) e MUSIEK e col. (1994) mencionaram que o distúrbio do processamento auditivo tem sido observado em várias populações na prática clínica, 
incluindo os distúrbios associados com lesões do sistema nervoso central como, tumores intracranianos, desordens cerebrovasculares, desordens degenerativas (esclerose múltipla, mal de Alzheimer e outras), distúrbios neuromorfológicos (déficit de atenção, distúrbio de aprendizagem, dislexia e outras) e mal-formações.

MUSIEK e col. (1994) comentaram que alguns pacientes com lesão auditiva central aparentemente não apresentam sintomas auditivos. Porém, estes podem ser referidos quando é realizada uma anamnese cuidadosa. Esses autores mencionaram, ainda, que os sintomas relacionados ao distúrbio do processamento auditivo (D.P.A.) são: (1) Dificuldade auditiva em ambientes ruidosos e/ou com muita reverberação; (2) zumbido subjetivo na cabeça; (3) dificuldade em localização sonora; (4) pobre utilização da prosódia; (5) pouca atenção e muita distração e (6) desinteresse musical. Além desses, outros sintomas são relatados de acordo com os diversos tipos de distúrbio do processamento auditivo.

Para KEITH (1995), o distúrbio do processamento auditivo na criança é uma alteração que afeta as habilidades auditivas, resultando na diminuição do aprendizado pela audição, apesar da desta apresentar-se dentro dos padrões de normalidade.

A TABELA 2 mostra um resumo das habilidades do processamento auditivo importantes para o aprendizado, descrito por Keith (1995). 
TABELA 2. HABILIDADES DO PROCESSAMENTO AUDITIVO.

\begin{tabular}{ll}
\hline Termos & Habilidade (descrição) \\
\hline Detecção & Diferenciar diferentes sons de diferentes frequências, duração ou intensidade. \\
Localização & Localizar a fonte sonora \\
Atenção auditiva & Prestar atenção aos sinais auditivos, especialmente a fala, por longo tempo \\
Figura-fundo auditiva & Identificar o falante principal na presença de nuido de fundo \\
Discriminação auditiva & Discriminar palavras e sons com caracteristicas acústicas semelhantes \\
Fechamento auditivo & Compreender toda a palavra ou sentenças, quando parte dela é suprimida \\
Síntesce auditiva & Unir fonemas isolados para formar palavras \\
Análise auditiva & ldentificar fonemas isolados na palavra \\
Associação auditiva & Identificar o som à sua fonte \\
Memória auditiva; & Guardar e resgatar estímulos auditivos e colocá-los na ordem correta de \\
Memória seqūencial & idéias
\end{tabular}

Fonte :KEIrH, R.W. (1995) - Tests of central auditory processing. In: Auditory Disorders in school children - The law identification - remediation. Thieme Medical Publishers, Inc, $3^{\prime \prime}$ ed.

Esse autor listou algumas características da criança com distúrbio do processamento auditivo:

1. A maioria é do sexo masculino.

2. Limiares tonais dentro dos padrões de normalidade.

3. Inconsistência ao estímulo auditivo, ora responde, ora parece não entender as instruções.

4. Atenção reduzida e fadiga em atividades longas e/ou complexas.

5. Distração a outros eventos auditivos ou visuais.

6. Dificuldade de localização sonora.

7. Dificuldade em seguir comandos verbais longos e/ou complexos.

8. Pede freqüentemente para repetir a informação. 
9. Dificuldade em lembrar informações apresentadas verbalmente (números de telefones, seqüências como meses do ano, etc.).

10. Algumas vezes apresenta história de otite média.

A American Spech-language-hearing Association - ASHA, em 1996, caracterizou o distúrbio do processamento auditivo como um prejuízo que interfere na habilidade do individuo em utilizar todo seu potencial auditivo. Pessoas com tal distúrbio podem apresentar dificuldade de entender a fala na presença de mensagem competitiva, ruído ou reverberação, necessitando que a mensagem seja repetida ou produzida com mais clareza, a fim de ser compreendida. Esses pacientes são vistos como desatentos ou facilmente distraídos.

PEREIRA (1996) declarou que os indivíduos com D.P.A. apresentam as seguintes manifestações comportamentais:

1. Quanto à comunicação oral:

- Dificuldades de produção de sons, principalmente $/ \mathrm{r} / \mathrm{e} / 1 /$.

- Problemas de linguagem expressiva envolvendo regras da língua.

- Dificuldade de compreensão em ambientes ruidosos.

- Dificuldade em entender palavras com duplo sentido, como por exemplo, "piada".

2. Quanto à comunicação escrita:

- Inversões de letras, orientação direita / esquerda.

- Disgrafias.

- Dificuldade de compreender leitura.

3. Quanto ao comportamento social:

- Agitados, hiperativos ou muito quietos.

- Distraídos. 
- Desajustados (brincam com crianças mais novas ou adultos tolerantes).

- Isolados (tendência), por frustrarem-se com as falhas na escola e em casa.

4. Quanto ao desempenho escolar:

- Problemas de leitura, gramática, ortografia, matemática.

- Desempenho escolar pode estar melhor ou pior, dependendo da posição do aluno na sala, do tamanho da classe, do nivel de ruído ambiental, da fala do professor.

5. Quanto à audição:

- Atenção ao som prejudicada.

- Dificuldade em escutar em ambiente ruidoso.

Além das manifestações comportamentais, a criança geralmente apresenta as seguintes características clínicas:

- Os limiares auditivos apresentam-se próximos da normalidade bilateralmente (1520dBNA) ou com uma discreta perda em freqüências isoladas.

- As medidas de imitância acústica podem apresentar timpanograma com configuração tipo "A" dentro dos padrões de normalidade e os reflexos acústicos podem estar presentes contralateral e ipsilateralmente, ou ausentes contralateral e presentes no ipsilateralmente, ou ausentes em $4.000 \mathrm{~Hz}$ ou, ainda, levemente elevados na captação contralateral.

- A avaliação comportamental do processamento auditivo pode mostrar prejuízo em localizar sons, memorizar sons em sequiência, reconhecer palavras decompostas acusticamente e identificar silabas, palavras e frases na presença de mensagem competitiva, tanto em tarefas monóticas como dicóticas.

KATZ e TILLERY (1997) listaram também algumas características comportamentais associadas ao D.P.A., porém a presença desses sintomas não deve 
descartar a existência de outras alterações, como distúrbio de atenção, alteração da percepção visual e autismo. Essa lista de características foi proposta inicialmente por FISHER em 1976 e incluía a investigação de história de otite média, principalmente nos primeiros anos de vida, pois pode indicar que o processamento auditivo foi prejudicado por essa alteração precoce. Outros fatores importantes são os relacionados com problemas de fala, linguagem e aprendizado, problemas com disciplinas escolares que exigem muita atenção, mesmo na presença de ruídos, como matemática e estudos sociais, pobre discriminação aos sons de fala, tempo de resposta retardada, distração aos barulhos, esquecimento de informações em poucos segundos, dificuldade em reter informações em sequêencia e em relacionar a informação auditiva com a visual.

PEREIRA (1997) descreveu o perfil do candidato à realização de procedimentos de avaliação do processamento auditivo como sendo todo aquele cuja história de vida sugere dificuldades de ouvir ou compreender em situações de grupo ou em lugares barulhentos, dificuldades em localizar sons, dificuldades de memória e distração. Além desses sinais sugestivos de prejuízo nas habilidades auditivas, insucessos em terapia fonoaudiológica devem ser investigados quanto ao processamento auditivo.

JERGER e MUSIEK (2000) comentaram que algumas crianças em idade escolar parecem ter problemas auditivos. Elas são descritas como tendo alguma dificuldade de escutar, principalmente na presença de ruído de fundo, em seguir ordens dadas oralmente e em entender a fala rápida ou degradada. Algumas apresentam problemas auditivos periféricos e outras, audição normal. Esses autores relatam que o termo usado no passado para essas crianças era "distúrbio do processamento auditivo central", porém essa denominação parece inadequada, pois se refere a um sítio anatômico e não à 
interação dos distúrbios periféricos e centrais que compõem esse quadro de alterações, sendo mais indicado o termo "distúrbio do processamento auditivo" (D.P.A.).

\subsubsection{FATORES DE RISCO}

A etiologia do D.P.A. pode estar associada a lesões nas áreas auditivas do tronco encefálico, córtex auditivo e nervo auditivo. Além disso, alterações periféricas também podem causar sintomas desse distúrbio, devido à privação sensorial que afeta o desenvolvimento das habilidades processamento auditivo, principalmente nos primeiros anos de vida.

RUPP, em 1978, relatou que 15 à $20 \%$ das crianças em idade escolar têm algum tipo de distúrbio de linguagem e/ou aprendizado e $70 \%$ dessas têm alguma forma de alteração auditiva.

Segundo MUSIEK e col. (1993), dentre as alterações que afetam áreas auditivas existem: os tumores intracranianos, os tumores extracranianos (schwanoma do acústico), alterações cérebro-vasculares, desordens degenerativas (esclerose múltipla, doença de Alzheimer e outras), traumas, mal-formação do S.N.C. e distúrbios neurológicos associados ao distúrbio de aprendizagem.

HALL e GROSE (1993), GRAVEL e WALLACE (1992) e BROWN (1994) relataram que o D.P.A. tem ocorrido associado à história de otite média crônica, que constitui uma alteração auditiva periférica muito comum na infância.

GRAVEL e col. (1996) analisaram 14 crianças, divididas em dois grupos, durante o primeiro ano de vida. Um grupo considerado positivo para a otite média e o segundo, negativo. Utilizaram a otoscopia pneumática e a P.E.A.T.E. As habilidades auditivas foram 
avaliadas aos quatro, seis e nove anos de vida, utilizando testes de processamento auditivo. Os resultados mostraram que as crianças com história de otite média no primeiro ano de vida apresentaram um prejuízo nas tarefas envolvendo o processamento auditivo. Esses autores concluíram que a performance dessas crianças poderia estar associada com perdas auditivas leves, causadas pela otite média, em um importante período do desenvolvimento. O grupo positivo para a otite apresentou dificuldades na leitura (habilidade visual-auditiva) e na habilidade de atenção na presença de ruído competitivo, situação presente nas escolas, o que prejudica a aquisição das informações orais. Eles comentaram que essas crianças experimentam uma dificuldade semelhante à das crianças com perda auditiva neurossensorial de mesmo grau.

ALMEIDA e col. (1997) estudaram a influência do nível sócio-econômico e cultural e concluíram que as crianças com nivel alto obtiveram resultados melhores nos testes comportamentais de processamento auditivo em comparação com as crianças de nivel baixo.

GONÇALVES e col. (2002) ressaltaram a importância da entrevista inicial que tem o intuito de levantar dados relevantes da história pregressa dos pacientes, a fim de relacioná-los aos distúrbios do processamento auditivo.

HUNGRIA (1991) mencionou que, em relação a hipóxia, a cóclea é sensível à insuficiência de oxigenação, pois o núcleo dorsal do nervo acústico possui vascularização capilar mais rica que o núcleo ventral, portanto, mais vunerável à insuficiência de oxigenação e podendo resultar em surdez seletiva para sons agudos. Na anóxia temporária, o núcleo ventral também está afetado, sobrevindo a surdez simultânea para sons graves.

FUESS (2000) estudou o retardo na maturação das vias auditivas, utilizando o P.E.A.T.E., analisando a existência de associação com distúrbios de aquisição da 
linguagem, concluindo que os fatores de risco encontrados freqüentemente entre as crianças com essa alteração são: hipóxia perinatal, convulsões e icterícia.

FELIPPE (2002) relatou que, ao abordar o aprendizado e os problemas de leitura e escrita devemos ter em mente que muitas questões estão envolvidas como: habilidades auditivas, visuais, cognitivas, da fala, da linguagem e motoras. Além disso, é necessário investigar outras variáveis contextuais obtidas durante a entrevista inicial: o meio sócioeconômico-cultural, maneira como o aprendizado está sendo conduzido na escola, as relações afetivas da criança, o seu estado e desenvolvimento emocional e a vivência com material escrito.

O sistema educacional que conduz o ensino fundamental atualmente nas escolas públicas e algumas privadas é a "progressão continuada", prevista pela LDB - Leis de Diretrizes e Bases da Educação Nacional (Lei $\mathrm{n}^{\circ}$ 9.394, artigo 32, parágrafo 2) e normatizado pela Deliberação 9/97 do Conselho Estadual de Educação de São Paulo, que define esse sistema de ensino em ciclos, que não comportam a retenção dos alunos nos três primeiros ciclos. (OLIVEIRA 2001). Esta metodologia foi aplicada a partir de 1998, a fim de cumprir os objetivos educacionais propostos pela Constituição da República Federativa do Brasil - 1988 e pelas Leis de Diretrizes e Bases da Educação Nacional de não exclusão de alunos e a erradicação do analfabetismo.

A progressão continuada prevê a aprovação contínua de todos os alunos durante todo o Ciclo I, que corresponde a primeira, segunda, terceira e quarta séries, podendo haver a retenção do aluno apenas no final de cada Ciclo completo, sendo que este aluno deveria voltar para a primeira, segunda ou terceira série, de acordo com a avaliação do professor. Da mesma maneira, ocorreria no Ciclo II (quinta, sexta, sétima e oitava séries) (MAINARDES 2001). 
STANOVICH (1994) relatou que as habilidades para identificar e manipular os sons da lingua (os fonemas em particular), constituem a consciência fonológica e fonêmica, fatores cruciais que permitem prever o sucesso da alfabetização, que deve começar portanto com o desenvolvimento dessas habilidades, a fim de propiciar o aprendizado da leitura e escrita.

Segundo NASCIMENTO (2003), o que ocorre atualmente nas escolas públicas, com a implantação deste sistema, desde 1998, foi que o aluno parece desestimulado a estudar pois sabe que ao final de cada ano será aprovado, os professores parecem ter perdido o controle dos alunos que não o respeitam e, principalmente houve um prejuízo no aprendizado da leitura e escrita. Alguns são aprovados para cursarem a série seguinte sem o domínio da leitura e escrita.

Após várias experiências fracassadas do atual sistema educação nas escolas públicas vemos algumas prefeituras o abandonarem, com o intuito de recuperar a imagem das escolas como ambiente de aprendizado. 


\subsection{Testes comportamentais para avaliação do processamento auditivo}

A avaliação das alterações do processamento auditivo surgiu da necessidade de atender a uma população que muitas vezes não tem outras queixas, apenas aquelas relacionadas à audição, e o fonoaudiólogo pode ser o primeiro profissional a ser procurado devido a sintomas anormais relacionados à função auditiva. Os testes para avaliar a função auditiva periférica e os por imagem para a avaliação da função auditiva central geralmente estão normais e, às vezes, somente a avaliação comportamental, por intermédio de testes especiais para avaliar o processamento auditivo, pode fornecer dados que não seriam obtidos por outros meios diagnósticos (MUSIEK 1989).

KEITH (1995) considerou que a interpretação dos testes para processamento auditivo em crianças pode ser útil para:

- Descrever o nível de maturação das vias auditivas centrais.

- Prover informações sobre uma possível origem neurológica relacionada aos problemas de aprendizado da criança.

- Avaliar os efeitos de medicamentos sobre as habilidades auditivas.

- Auxiliar na avaliação da predominância hemisférica.

- Pesquisar as habilidades do processamento auditivo.

A American Speech-Language-Hearing Association (ASHA) (1996) realizou uma categorização dos testes diagnósticos, como a seguir:

1. Monóticos (o estímulo é apresentado para cada orelha separadamente).

- Fala filtrada.

- Fala comprimida. 
- Reconhecimento de padrões (exemplo: padrão de freqüência).

- Sinal competitivo ipsilateral (tarefa de figura-fundo auditiva).

2. Dicótico (estímulos diferentes são apresentados simultaneamente para as duas orelhas, tarefas de separação binaural)

- Dígitos.

- Sílabas.

- Palavras e sentenças.

3. Diótico (o sinal é apresentado simultaneamente para as duas orelhas)

Existem circunstâncias nas quais cada um dos modos de avaliação do D.P.A. tornase mais apropriado. Os testes dicóticos são essenciais, porém os monóticos também o são, pois permitem avaliar a assimetria entre as orelhas (JERGER e MUSIEK 2000).

CHERMAK e MUSIEK (1997) afirmaram que os testes comportamentais são, ainda, o principal instrumento para avaliar o sistema nervoso auditivo central (S.N.A.C.). A bateria de testes comportamentais fornece informações quanto ao local da lesão, principalmente devido ao conhecimento das estruturas da via auditiva, e quanto a anatomofisiologia, responsáveis pelas várias tarefas. Para estes autores, as tarefas de escuta dicótica para a fala proporcionam o diagnóstico quando há um envolvimento do tronco cerebral baixo, pois os resultados mostram alteração ipsilateral à lesão; já nas mais difusas, essas alterações ocorrem bilateralmente. Quando as fibras do corpo caloso estão lesadas, a alteração para sons de fala ocorre na orelha esquerda e esta não é encontrada na direita, pois a informação não necessita passar pelo corpo caloso para chegar ao hemisfério esquerdo, onde são reconhecidos os padrões lingüísticos. Quando o envolvimento ocorre no córtex auditivo, no hemisfério direito, a alteração é percebida bilateralmente. Neste caso, 
deveriamos fazer uso de testes apresentados monoauralmente em tarefas de padrões de duração e/ou freqüência, a fim de localizar o hemisfério lesado, já que estes padrões são reconhecidos pelo hemisfério direito. Portanto, a avaliação comportamental do processamento auditivo deveria constar de uma bateria de testes selecionados segundo a necessidade de cada indivíduo.

A necessidade de avaliar o sistema nervoso auditivo central levou numerosos pesquisadores a desenvolverem testes comportamentais e eletrofisiológicos para a identificação de distúrbios do S.N.A.C. Tais testes demoraram a adquirir aceitação entre os clínicos, um dos motivos foi a complexidade anatômica e fisiológica do S.N.C. (MUSIEK e LAMB 1999). Os testes comportamentais fornecem informações importantes na avaliação do D.P.A. e as medidas eletrofisiológicas provêem evidência objetiva relacionada à integridade das vias auditivas centrais (PARTHASARATHY 2000).

MUELLER e BRIGHT (1999) observaram que quando uma bateria de testes é selecionada para um determinado paciente, três fatores devem ser considerados: 1) a correlação neuroanatomia para a qual o teste é mais sensível; 2) a tarefa exigida (monoaural, binaural, monótica, dicótica) e 3) dificuldade dos testes, pois os simples podem não ser úteis em alterações sutis do S.N.A.C.

Segundo JERGER e MUSIEK (2000) os testes comportamentais devem incluir as seguintes tarefas:

- Medidas de detecção (audiometria tonal liminar e tarefas de integração temporal).

- Medidas de discriminação supraliminar (testes para diferenciar padrões de freqüência, intensidade e duração, seqüencialização/ordenação, resolução, mascaramento temporal, localização sonora e espacial). 
- Medidas de identificação (reconhecimento de fonemas, silabas, palavras, frases e sentenças).

A TABELA 3 mostra as primeiras pesquisas realizadas com testes comportamentais para avaliação do S.N.A.C.

TABELA 3. TEstes PaRA AVAliaÇA do processamento auditivo

\begin{tabular}{|c|c|c|}
\hline Teste & Autor e ano & Procedimento \\
\hline Teste de fala filirada & $\begin{array}{l}\text { BOCCA e col. } 1954 \\
\text { WILLEFORD } 1976\end{array}$ & $\begin{array}{l}\text { - Repetiçäo de palavras filtradas (filtro } \\
\text { passa - baixa e passa-alta), para diminuir } \\
\text { redundincia extrisean. Tarefa monótica. }\end{array}$ \\
\hline Teste de fuszäo biaural & $\begin{array}{c}\text { MATZKER } 1959 \\
\text { PALVA E JOKINEN } 1975\end{array}$ & $\begin{array}{l}\text { - Uilizacia do sinal de fala em ambas as } \\
\text { orelhas de forma que cada orelha receba } \\
\text { uma porcio da palavra a ser repetida. } \\
\text { Tarefa biaural }\end{array}$ \\
\hline Teste dicólico de digitos & $\begin{array}{l}\text { KIMURA } 1961 \\
\text { SOMMERS C TAYLOR } 1972 \\
\text { (com criancas) }\end{array}$ & $\begin{array}{l}\text { Identificapjo de digitos em estimulapão } \\
\text { diótica. }\end{array}$ \\
\hline $\begin{array}{l}\text { Teste } S . S . W \text { - Staggered } \\
\text { Spondaic Word }\end{array}$ & KATZ 1962 & $\begin{array}{l}\text { - Idcontificar palavras espondaicas em tarefa } \\
\text { diótica. Tarefas com atengão livre e } \\
\text { atengão direcionada }\end{array}$ \\
\hline $\begin{array}{l}\text { Teste S.S.I. - Synthetic } \\
\text { Sentence Identification }\end{array}$ & SPEAKS E JERGER, 1965 & $\begin{array}{l}\text { Uniliza sentencas "artificiais" a fim de } \\
\text { controlar o contevido de informagio } \\
\text { expresso. }\end{array}$ \\
\hline $\begin{array}{l}\text { Teste consounte-vogal de } \\
\text { escuts direcionada }\end{array}$ & BERLJN E MCNEIL 1973 & $\begin{array}{l}\text { Uilização de silabas (PA, TA, CA, BA, DA, } \\
\text { GA), de maneira dicótica, para repetifäo. }\end{array}$ \\
\hline $\begin{array}{l}\text { Teste nja-verbal de escurts } \\
\text { direcionada }\end{array}$ & $\begin{array}{l}\text { BEVRE CHIARELLO } 1974 \\
\text { (sons musicais) } \\
\text { KATZ } 1985 \text { (sons ñ̃o verbais } \\
\text { ambientais) }\end{array}$ & $\begin{array}{l}\text { Teste dicótico, para identificação de sons } \\
\text { nĩo verbais diferentes apresentados em } \\
\text { cada orelha simultaneamente. }\end{array}$ \\
\hline Teste de Fala com Ruido & $\begin{array}{l}\text { OLSEN e col. } 1975 \\
\text { COHEN } 1980 \text { (com crianças) }\end{array}$ & $\begin{array}{l}\text { Repetição de monossilabos, na presenga } \\
\text { de nufdo mascarante. Tarefa monótica }\end{array}$ \\
\hline Teste P.S.I. & JERGER e col. 1980 & $\begin{array}{l}\text { Identificapão de frases, utilizando figuras } \\
\text { de apoio e mensagem competitiva. Teste } \\
\text { utilizado com crianças. Tarefa em escuta } \\
\text { monótica e dicótica }\end{array}$ \\
\hline
\end{tabular}

Fonte: KATZ J. (1999) Tratado de Audiologia Clinica. Ed. Manole

RINTELMANN (1985) relatou a importância da obtenção de dados normativos próprios para a utilização dos testes especiais de processamento auditivo em crianças e adultos, pois pode haver diferenças no material de fala utilizado, nas formas de resposta, 
nos métodos de correção e no sinal do teste, que poderiam interferir na fidedignidade dos resultados da avaliação.

MUSIEK e col. (1994) demonstraram que a eficiência de um teste (sensibilidade e especificidade) para avaliar o D.P.A. em crianças e adultos depende da alteração apresentada e relatada durante a anamnese, assim como da validação do teste a ser utilizado com a população escolhida para a avaliação central. Esses autores encontraram maiores déficits para a orelha esquerda quando submetida ao teste de sentenças competitivas, ao teste de dígitos e ao S.S.W. test (staggered spondaic words), nas crianças com problemas de aprendizagem, com história de otite média, mas sem alterações neurológicas e dificuldades auditivas características de distúrbio do processamento auditivo.

Alguns dos testes citados na TABELA 3 para avaliar o processamento auditivo foram padronizados em português, como mostra na TABELA 4.

TABELA 4. TESTE PARA AVALIAÇÃo do PROCESSAMENTO AUdITIVO TRADUZIdo PARA $O$ PORTUGURS, SEGUNDO SEUS AUTORES NO BRASIL.

\begin{tabular}{|c|c|c|}
\hline Texte & Autor e ano & Objetiva \\
\hline $\begin{array}{l}\text { Teste SSW-Staggered } \\
\text { Spondaic Word }\end{array}$ & BORGES 1986 & $\begin{array}{l}\text { Verifica algum impedimento na funçio } \\
\text { auditiva central. }\end{array}$ \\
\hline $\begin{array}{l}\text { Teste de Identificagĩo de } \\
\text { Sentengas Sintéticas (S.S.I.) }\end{array}$ & ALMEIDA E CAETANO 1988 & $\begin{array}{l}\text { - Utiliza sentenças "artificiais" a fim de } \\
\text { controlar o contevido de informaça } \\
\text { expresso. Tem a finalidade de avaliar a } \\
\text { atenção seletiva. }\end{array}$ \\
\hline Teste P.S.I. & ALMEIDA e col. 1988 & $\begin{array}{l}\text { Controla a influência da habilidade de } \\
\text { compreensão da linguagem }\end{array}$ \\
\hline Teste de Fala com Ruido & PEREIRA 1993 & $\begin{array}{l}\text { Utilizado para medir a atenção seletiva e } \\
\text { fechamento auditivo. }\end{array}$ \\
\hline $\begin{array}{l}\text { Teste de fala filtrada e fusia } \\
\text { biaural }\end{array}$ & PEREIRA e col. 1993 & $\begin{array}{l}\text { Medir a habilidade de fechamento } \\
\text { auditivo. }\end{array}$ \\
\hline $\begin{array}{l}\text { Teste consoante-vogal de } \\
\text { escula direcionada }\end{array}$ & TEDESCO e col. 1995 & $\begin{array}{l}\text { Auxilia na delimitaçäo da especializaçio } \\
\text { hemisférica para fungöes verbais. }\end{array}$ \\
\hline $\begin{array}{l}\text { Teste nao-verbal de escuta } \\
\text { direcionada }\end{array}$ & ORTIZ 1995 & $\begin{array}{l}\text { Verifica a atenço seletiva, por meio de } \\
\text { tarefa de separagüo biaural. } \\
\text { Avalia a habilidade em agrupar }\end{array}$ \\
\hline Teste dicótico de digitos & SANTOS E PEREIRA 1996 & $\begin{array}{l}\text { componentes do sinal acústico em figura- } \\
\text { fundo, e avalia em escuta direcionada } \\
\text { para cada orelha separadamente. }\end{array}$ \\
\hline
\end{tabular}

Fonte: PEREIRA LD., SCHOCHAT E. (1997) Processamento Auditivo Central Ed. Lovise . 
Para maior detalhamento de cada teste é aconselhável utilizar bibliografia específica (MUSIEK e col. 1994, KEITH 1995, CHERMAK \& MUSIEK 1997, KATZ e WILDE 1999).

Discutiremos a seguir o teste S.S.I. (Synthetic Sentence Identification test) e sua importância na avaliação do processamento auditivo.

SPEAKS e JERGER (1965) propuseram um teste para avaliar a compreensão da fala, utilizando sentenças "sintéticas" ou "artificiais", ou seja, estrutura de sentença, porém sem significado. Segundo os autores, a utilização dessa técnica proporcionou o aproveitamento da estrutura frasal e evitou o uso de palavras monossilábicas. $\mathrm{O}$ uso de sentenças com significado limitado e realização de teste fechado (close set) como maneira de resposta, reduziram a dependência de habilidades lingüisticas e de memória. Desta forma, o teste necessita somente da identificação (pelo número da frase) da sentença apresentada.

JERGER e JERGER (1974) utilizaram o teste S.S.I. em 11 pacientes portadores de lesões intra-axiais do tronco encefálico, acima dos núcleos cocleares. As performances na tarefa de M.C.C. e M.C.I. foram bastante diferentes. Todos os sujeitos apresentaram resultados alterados na condição M.C.I., sendo que seis falharam em ambas as orelhas e cinco, apenas na orelha contralateral. Nenhum paciente apresentou alteração na orelha ipsilateral à lesão. Os autores perceberam que na M.C.C., apenas três mostraram resultados insuficientes em uma das orelhas.

JERGER e JERGER (1975), em estudo posterior, compararam os resultados dos testes S.S.I. e S.S.W. em dois grupos de pacientes. Um dos grupos era composto por 10 
indivíduos com lesão do tronco encefálico e o outro grupo formado por 10 pacientes com lesão do lobo temporal. Os autores concluíram que o teste S.S.W. é mais consistente com os resultados alterados nos casos de lesão do lobo temporal e que pacientes com lesão do tronco encefálico apresentaram resultados alterados no teste S.S.I.-M.C.I.

JERGER e JERGER (1992) relataram que a utilização do teste S.S.I. com o teste S.S.W. oferece um dado efetivo na diferenciação de comprometimentos de lobo temporal e tronco cerebral. Segundo os autores, o teste S.S.W. auxilia no diagnóstico das alterações de lobo temporal, primordialmente, enquanto o teste S.S.I. com M.C.I. identifica consistentemente pacientes com alterações de tronco cerebral, sendo o SSI com MCC pouco consistente no diagnóstico de distúrbios do lobo temporal.

DECKER e NELSON (1981) levantaram a necessidade da normatização dos dados para o teste S.S.I. com mensagem competitiva ipsilateral, pois segundo seus estudos com grupos de indivíduos com audição normal, entre 8 e 25 anos de idade, houve melhora nos resultados desse teste com o aumento da idade e com a diminuição na intensidade da mensagem competitiva.

No Brasil, ALMEIDA e CAETANO (1988) adaptaram o S.S.I. para a língua portuguesa.

Uma pesquisa realizada por OSTERNE e col. (1994) em 50 mulheres de 17 a 22 anos, utilizou o Teste de Identificação de Sentenças Sintéticas (S.S.I.). Esses autores relataram que quando a mensagem competitiva foi apresentada contralateral, nos niveis de OdBNS (mensagem -M- a 40dB e competição-C- a 40dB), $-20(M=40 \mathrm{~dB}$ e $C=60 \mathrm{~dB})$, e -40 ( $M=40 \mathrm{dBNS}$ e $\mathrm{C}=80 \mathrm{dBNS}$ ) de relação sinal/competição, os indivíduos obtiveram $100 \%$ de acertos. $\mathrm{Na}$ apresentação ipsilateral, em $+10,0,-10$ e -20 de relação $\mathrm{S} / \mathrm{C}$, obtiveram 
respectivamente $100 \%, 96 \%, 74 \%$ e $34 \%$ de acertos, sem diferenças entre as orelhas direita e esquerda. A conclusão foi que a apresentação da competição ipsilateral é uma tarefa mais dificil.

KEITH (1995) relatou que o teste S.S.I. tem como idéia principal usar sentenças sintéticas, a fim de evitar problemas envolvendo o uso de sentenças "reais", as quais são identificadas facilmente por palavras chaves. As sentenças sintéticas são materiais que oferecem um grau de dificuldade maior, apesar de serem um material verbal, porém com o mínimo de pistas contextuais. A desvantagem do procedimento é que o indivíduo tem que saber ler e ter boa habilidade visual. $\mathrm{O}$ procedimento é realizado com mensagem competitiva ipsilateral (M.C.I.) e contralateral (M.C.C.). A mensagem competitiva é realizada com um texto apresentado durante toda a realização do teste. O S.S.I. mostrou ser um método efetivo para diferenciar sítios de lesão quando utilizado com outros testes para processamento auditivo. O S.S.I.-M.C.I. apresenta uma resposta insuficiente para a orelha oposta à lesão do tronco cerebral e o SSI-MCC detecta lesões no lobo temporal, na orelha contralateral à lesão.

KALIL e col. (1997) comentaram que o teste S.S.I. tem demonstrado ser um método importante no diagnóstico do D.P.A., pois permite avaliar as habilidades auditivas centrais, especialmente figura-fundo auditiva (atenção auditiva seletiva).

PEREIRA (1997) sugeriu que o teste S.S.I. fosse realizado em crianças a partir de 8 anos de idade, sendo este um dos procedimentos utilizados pelo Ambulatório dos Distúrbios da Audição da Universidade Federal de São Paulo (UNIFESP/EPM), para esta faixa etária. 
WILLEFORD e BURLEIGH (1999) comentaram que materiais como as sentenças têm sido utilizadas clinicamente, com o propósito de auxiliar na identificação do local da lesão em pacientes adultos que sofreram danos cerebrais. Além disso, têm sido usados para levantar a suspeita da presença e determinar a natureza das dificuldades de processamento auditivo, principalmente em crianças.

PENROD (1999) mencionou em seus estudos que a habilidade para compreender a fala deve ser considerada como um dos aspectos mais importantes a serem mensurados na função auditiva, pois é fundamental para avaliar a participação efetiva do indivíduo em nosso complexo mundo sonoro. 


\subsection{Avaliação do Processamento Auditivo E AS Medidas}

\section{ELETROFISIOLÓGICAS.}

ABRAMOVICH (1990) listou algumas das vantagens do uso dos potenciais evocados, como sendo testes não invasivos, pois utilizam eletrodos de superficie, e objetivos, ou seja, não necessitam da resposta do indivíduo.

Existe uma série de variáveis relacionadas aos aspectos técnicos (ambiente, parâmetros do estímulo e do registro) do sujeito/paciente (sexo, idade, nível de consciência) e do examinador que interferem na captação e interpretação dos potenciais auditivos evocados (P.E.A.).

As variáveis relacionadas com o estímulo são: tipo, polaridade e intensidade, velocidade de apresentação, transdutor utilizado (fone de ouvido, fone de inserção ou vibrador ósseo), que são características modificadas de acordo com o P.E.A. que se pretende captar e a razão pela qual a pesquisa está sendo realizada (avaliação audiológica versus neurológica) e calibração. As variáveis do registro estão associadas com a amplificação, utilização de filtros, rejeição de artefatos e características do ambiente, importantes para o registro dos P.E.A. (FERRARO e DURRANT 1999).

A captação dos potenciais de curta latência como a eletrococleografia e o P.E.A.T.E. é desencadeada por estímulos transitórios como o clique de $100 \mathrm{mV}$, por ser um sinal acústico de início rápido, com tempo de inicialização/finalização (rise/fall) de até $5 \mathrm{~ms}$ de duração e platô de 1 ciclo, o que propicia uma resposta sincronizada de um grande número de neurônios. Este tipo de estímulo proporciona a ativação de uma porção larga da cóclea, devido ao espectro relativamente largo. Geralmente é utilizado um pulso de $100 \mathrm{~ms}$, 
pois possibilita um espectro plano até $10.000 \mathrm{~Hz}$ (DURRANT e LOVRINIC 1984, JUNQUEIRA e FRIZZO 2002).

O limite superior da freqüência do clique geralmente varia de 5.000 a $10.000 \mathrm{~Hz}$; assim sendo, esse estímulo enfatiza a contribuição das freqüências altas no registro dos P.E.A. (GORGA e col. 1985).

RUTH e LAMBERT (1991), WOOD e col. (1995) recomendaram que para a captação da P.E.A.M.L. podem ser utilizados o clique, clique filtrado, toneburst e tonepips. Segundo esses autores, o toneburst é freqüentemente usado, pois permite a avaliação de freqüências especificas, pois é um estímulo mais longo, ou seja, com duração total (tempo de inicialização/finalização + platô) entre 1 e $10 \mathrm{~ms}$.

As respostas de regiões de freqüências relativamente estreitas podem ser eliciadas por pulsos senoidais como tonepips e toneburst. O toneburst pode ser criado utilizando uma variedade de funções que formam o envelope do estímulo, ou seja, tempo de inicilização/finalização pós-linear, funções de co-seno, co-seno-quadrado e outras funções matemáticas. A fórmula da função e a relação entre a duração do tempo de inicialização/finalização versus o platô, determinam a quantidade relativa de energia concentrada próxima da frequência da senóide e a energia distribuída nas frequêencias vizinhas (GORGA e col. 1988).

A duração total do estímulo, ou seja, a soma do platô com o tempo de inicialização/finalização são responsáveis pela resposta evocada. Estímulos mais curtos propiciam resposta com alta sincronização das células neurais, característica importante nos potenciais de curta latência, sendo que o clique é o estímulo mais recomendado, porém sem especificação de freqüência. Para os P.E.A.M.L. e potenciais de longa latência (ex: P300) o sincronismo neural não é um fator determinante, pois não há necessidade de ativar grande 
quantidade de células, devido a localização mais alta no S.N.A.C. O estímulo mais longo produz menor sincronia, porém maior especificidade de freqüência (JUNQUEIRA e FRIZZO 2002).

A polaridade do estímulo é definida pela direção inicial do diafragma do transdutor e é uma variável especialmente importante nos potenciais de curta latência. Quando o pulso elétrico produz um movimento inicial do diafragma para fora, a saída acústica é considerada como de condensação, porém se a deflexão é para dentro, existe a polaridade do clique de rarefação. A média da polaridade inicial de cliques sucessivos pode ser fixa (condensação ou rarefação) ou alternada.

A polaridade alternada é geralmente utilizada para suprimir o artefato elétrico produzido pelo estímulo durante o registro (FERRARO e DURRANT 1999).

Para registro de resposta neurogênica utilizando o P.E.A.T.E., o uso do estímulo de polaridade alternada tem sido defendido, pois a componente sensibilidade-polaridade pode ser afetada por artefatos e o uso desse parâmetro propicia o cancelamento desta interferência (ABRAMOVICH 1990).

A seleção dos parâmetros de registro dos P.E.A. varia de acordo com o equipamento utilizado, porém geralmente podemos selecionar: 1) número de canais, 2) configuração dos eletrodos, 3) ganho do amplificador, 4) filtros passa-alta e passa-baixa, 5) janela de análise (tempo), 6) número de estímulos repetidos, 7) tipo, polaridade, duração, freqüência, envelope, intensidade e velocidade do estímulo, 8) uso de mascaramento (FERRARO 1997). 
Os eletrodos que conectam o paciente ao equipamento são colocados em lugares anatômicos específicos no couro cabeludo, fronte, lóbulos da orelha, meato acústico externo, mastóide, membrana timpânica e promontório, seguindo o Sistema Internacional 10/20, de nomenclatura para cada região (JASPER, 1958). Assim sendo, as letras determinam as regiões anatômicas onde serão colocados os eletrodos, por exemplo: z, a linha média; $\mathrm{C}$, o plano coronal; F, o frontal; T, o temporal; $\mathrm{O}$, o occipital; M, a mastóide; A, a orelha; Fp, a fronte (Figura 2).

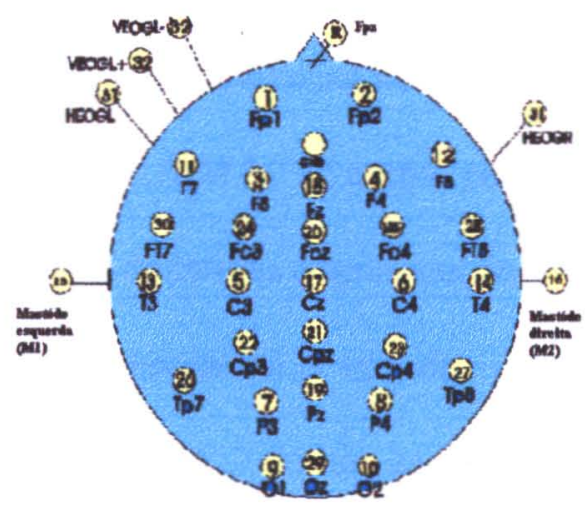

FIGURA 2. - SISTEMA INTERNACIONAL 10/20.

Fonte: Medical Technologies - URL < http://www.audios peech.ubs.ca.haplab/aep.htm

Os parâmetros de amplificação dependem dos tipos de P.E.A. que estão sendo pesquisados e da proximidade dos eletrodos em relação ao gerador coclear/neural. $\mathbf{O}$ ganho para a captação de um determinado potencial evocado é o número de vezes que o sinal de entrada é amplificado. Um ganho menor é utilizado para as respostas corticais (potenciais de longa latência), devido à proximidade dos eletrodos com o gerador do potencial, do que para as respostas de tronco encefálico (potenciais de curta latência). Portanto as captações de campo próximo requerem menos ganho que as de campo distante (FERRARO e DURRANT 1999). 
O objetivo da utilização de filtros na captação dos P.E.A. é possibilitar a detecção do sinal na presença de ruído, porém sem interferir no registro da freqüência do potencial. No P.E.A.T.E. é recomendado o filtro passa-banda $30-3.000 \mathrm{~Hz}$. No registro da P.E.A.M.L. a escolha do filtro depende da população, podendo ser utilizados filtros enfatizando frequêencias baixas (3-15 HZ, 10-300Hz), altas $(300-3.000 \mathrm{~Hz})$ ou, ainda, para crianças (30$1.500 \mathrm{~Hz}$ ) (MUSIEK e col. 1984b).

Para McPHERSON (1996), KRAUS e McGEE (1999) os potenciais podem ser divididos em dois tipos, segundo suas respostas. São classificados como potenciais "exógenos", aqueles influenciados pelas mudanças nas caracteristicas fisicas do estímulo, por exemplo, o P.E.A.T.E. e a P.E.A.M.L. e como potenciais "endógenos", aqueles altamente dependentes da atenção ou de tarefas cognitivas do indivíduo, como o P300.

JERGER e MUSIEK (2000) apoiaram o uso das medidas eletrofisiológicas para complementar o diagnóstico do D.P.A., como as emissões otoacústicas evocadas (E.O.A.E.) e o P.E.A.T.E., por serem as medidas mais conhecidas atualmente e incentivaram o estudo de outras já existentes como P.E.A.M.L. e P300. Esses autores acreditam que o P300, no futuro, poderá fornecer informações importantes, devido à possibilidade de avaliar tarefas de processamento temporal, por meio de estímulos visuais e auditivos e, assim, diferenciar os problemas auditivos/visuais dos puramente auditivos.

\subsubsection{Potencial Evocado Auditivo de Tronco ENCEFÁlico - P.E.A.T.E.}

SCHULMAN-GALAMBOS e GALAMBOS (1975) definiram os potenciais evocados auditivos de tronco encefálico (P.E.A.T.E.) como potenciais de ação que ocorrem nos primeiros dez milissegundos (ms), após o início da estimulação sonora. Esse registro é 
realizado por meio de uma série de características de onda, nomeadas por algarismos romanos - I, II, III, IV, V, VI, e VII - e refletem a ativação progressiva do nervo auditivo aos núcleos e tratos do tronco cerebral.

ALBERTI e col. (1985) comentaram que o P.E.A.T.E. é medido, geralmente, utilizando o estímulo clique, o qual abrange principalmente o espectro de freqüência entre $1.000 \mathrm{a} 4.000 \mathrm{~Hz}$, portanto pouca informação é obtida da audição nas freqüências baixa e alta. Esse estímulo apresenta a vantagem de propiciar a avaliação auditiva em menor intensidade de estimulação.

O uso do P.E.A.T.E. como um instrumento clínico para avaliar a audição desenvolveu-se rapidamente durante os anos 70 , devido à segurança e à especificidade desse procedimento, pois pode prover um método objetivo de avaliação da audição em crianças (NORTHERN e GERKIN 1989):

ABRAMOVICH (1990) relatou que as latências das ondas geradas no tronco encefálico não são limitadas a um único sítio de propagação. No homem, a onda I tem origem na parte distal do nervo acústico, enquanto que a onda II origina-se principalmente na parte proximal do nervo coclear, com contribuição do núcleo coclear. Os picos das ondas III, IV, V, VI e VII têm contribuição de mais de uma localização anatômica, portanto cada núcleo pode contribuir para mais de uma onda do P.E.A.T.E. A onda III origina-se principalmente no núcleo coclear ipsilateral ao complexo olivar superior contralateral. $\mathrm{O}$ complexo de onda IV-V tem origem nas estruturas ipsilateral e contralateral do lemnisco.

JACOBSON e HALL III (1992) observaram que a interpretação do P.E.A.T.E., por meio das respostas normativas, em indivíduos de sensibilidade auditiva normal e integridade neurológica, envolve a análise de três propriedades das ondas desse potencial: (1) medida da latência do pico da onda absoluta (duração em milissegundos, entre a 
apresentação do sinal e a medida do pico) e relativa (período relativo entre a latência de duas ondas); (2) a amplitude e (3) a morfologia do componente do pico da onda. Comprovaram também que, devido à facilidade de registro e precisão do P.E.A.T.E. como instrumento diagnóstico, esse teste tem sido muito difundido, principalmente por identificar e quantificar os prejuízos auditivos em crianças e adultos de dificil avaliação. Por isso, também, é muito recomendado na triagem auditiva de bebês.

COSTA e CELLANI (1993) mencionaram que o P.E.A.T.E. é eliciado por intermédio de um estímulo sonoro e está baseado na obtenção e registro dos potenciais auditivos precoces, originados nos neurônios de primeira ordem do nervo auditivo, dos núcleos e estruturas auditivas do tronco encefálico, como mostra a TABELA 5.

TABELA 5 - Estruturas anatômicas responsáveis pelas ondas c os diferentes Tempos de latência, $\mathrm{cm}$ indivíduos adultos, com audição normal

\begin{tabular}{|c|c|c|}
\hline Ondas & Estrutura anatômica & Variação do tempo \\
\hline & & De latência(ms) ${ }^{* \star}$ \\
\hline I & Nervo acústico & 1.5 a 1.9 \\
\hline 11 & Núcleo coclear & 2.5 a 3.0 \\
\hline III & Complexo olivar superior & 3.5 a 4.1 \\
\hline IV & Leminisco ipsilateral* & 4.3 a 5.2 \\
\hline $\mathrm{v}$ & Lemnisco contralateral* & 5.0 a 5.9 \\
\hline VI & Coliculo inferior & 5.8 a 6.7 \\
\hline VII & Corpo geniculado medial* & 6.5 a 7.6 \\
\hline
\end{tabular}

Fonte: Tabela modificada de COSTA OA. e CELANI AC. Audiometria de Respostas Elérricas de Tronco Encefálico. Caderno de ORL e Cirurgia da Cabeça e Pescoço 1993, 107 (1): 43-8.

* Existe a possibilidade de outras estruturas estarem envolvidas na geração dos potenciais.

** Resultados compilados de vários laboratórios internacionais.

DEHAN e JERGER (1993) constataram que o sexo afeta a latência da onda V, nos adultos, portanto tal fator deve ser considerado na avaliação.

MUSIEK e col. (1994) relataram que o uso do P.E.A.T.E. para o diagnóstico do D.P.A. é uma escolha que deve ser feita de acordo com o tipo de alteração encontrada. Em 
crianças com distúrbios de aprendizagem, os potenciais estão dentro da normalidade, porém em casos de privação auditiva como na otite média, principalmente nos primeiros anos de vida, é importante a avaliação por meio desse procedimento, a fim de avaliar possíveis comprometimentos na integridade das vias auditivas do tronco encefálico.

MUSIEK e col. (1999) comentaram que uma morfologia ruim da onda ou a presença/ausência de ondas pode indicar anormalidades. Contudo, a interpretação da morfologia anormal da onda é subjetiva e pode ser influenciada por muitas variáveis como problemas com os eletrodos e artefato elétrico ou muscular. A influência destas variáveis pode ser minimizada por modificações nos parâmetros de registro, mencionadas anteriormente. 


\subsubsection{Potencial Evocado Auditivo de Média LatênCIA - P.E.A.M.L.}

GEISLER e col. (1958) foram os primeiros a descrever a P.E.A.M.L. utilizando o estímulo clique, identificando um pico positivo com latência aproximadamente de $30 \mathrm{~ms}$. Estes autores mostraram que essa resposta correspondia a descargas neurais geradas pela via aferente para o córtex auditivo.

PICTON e col. (1974) descreveram os componentes dos potenciais evocados, incluindo a P.E.A.M.L., sendo caracterizados como picos positivos e negativos captados no couro cabeludo e identificados como: N18 (Na), P30 (Pa), P50 (Pb ou P1). Estes autores comentaram que as respostas do P.E.A.M.L. estão distribuídas pelas áreas fronto-centrais do couro cabeludo; portanto, podem ser captadas com uma montagem dos eletrodos semelhante a usada no P.E.A.T.E..

MENDELSON e SALAMY (1981), HOOD (1990), PALUDETTI e col. (1991) e KRAUS e col. (1994) concluiram que a morfologia e as latências das ondas são semelhantes quando comparadas em função da idade.

MENDELSON e SALAMY (1981) registraram o P.E.A.M.L. em 60 individuos de quatro faixas etárias diferentes (bebês prematuros, bebês a termo, crianças de 3 e 4 anos e adultos normais de 24 aos 39 anos). Esses autores concluiram que a morfologia das ondas era semelhante nos quatro grupos e que as latências não diminuem em função da idade.

OZDAMAR e KRAUS (1983) relataram que a amplitude $\mathrm{Na}-\mathrm{Pa}$ apresenta valores em torno de 0,5 a $2 \mu \mathrm{V}$, sendo que as maiores amplitudes foram observadas quando utilizado o estímulo toneburst na freqüência de $500 \mathrm{~Hz}$. Esses autores observaram ainda que 
as amplitudes também são influenciadas pela intensidade do estímulo e que as maiores foram conseguidas quando a intensidade encontrava-se acima de $60 \mathrm{dBNa}$.

MUSIEK e col. (1984) e ABRAMOVICH (1990) relataram em seus estudos que há uma grande variabilidade intra-individual e entre os indivíduos com relação às latências e amplitudes.

MUSIEK (1989b) sugeriu que a colocação dos eletrodos sobre o couro cabeludo, para a captação do P.E.A.M.L., deveria ser preferencialmente em cada hemisfério (C3 ou T3, C4 ou T4) e no vértex (Cz) quando há uma lesão confirmada, pois auxilia na indicação do prejuízo.

ABRAMOVICH (1990), KRAUS e col. (1999) definiram os potenciais evocados de média latência como potenciais neurogênicos registrados no couro cabeludo, com latências em tomo de 10 a $50 \mathrm{~ms}$, originados provavelmente no tálamo e suas projeções primárias e possivelmente no córtex primário. A interpretação do P.E.A.M.L. consiste na análise da morfologia das ondas e na identificação de picos positivos e negativos $\left(\mathrm{N}_{0}, \mathrm{P}_{0}, \mathrm{Na}, \mathrm{Pa}, \mathrm{Nb}\right.$ e $\mathrm{Pb}$ ). Os sítios geradores ainda não estão bem claros. Alguns autores sugerem que no ser humano, o componente No, Po e Na são gerados no gânglio geniculado medial ou ainda da atividade pós-sináptica do colículo inferior. O componente melhor identificado no traçado é o Na-Pa e é usado para estimar o limiar auditivo (Figura 3).

HOOD (1990), KRAUS e col. (1994) observaram que as latências dos picos dos componentes do P.E.A.M.L. variavam: Po, 10 a $13 \mathrm{~ms}$; Na, 15 a $25 \mathrm{~ms}$; Pa, 25 a $35 \mathrm{~ms}$; Nb, 35 a $50 \mathrm{~ms}$ e $\mathrm{Pb}, 55$ a $80 \mathrm{~ms}$. Essas variações dependiam de algumas características do registro como a freqüência do estímulo toneburst, o qual tendia a diminuir a latência com o 
aumento da freqüência. A intensidade influenciava levemente as latências, diminuindo quanto mais forte fosse o estímulo.

PALUDETTI e col. (1991) estudaram as latências do P.E.A.M.L. em idosos entre 60 e 80 anos de idade, concluindo que não houve diferença estatisticamente significante entre os intervalos estudados dentro dessa faixa etária para a latência $\mathrm{Pa}$ e que esta se apresentava entre os valores 26 a $35 \mathrm{~ms}$.

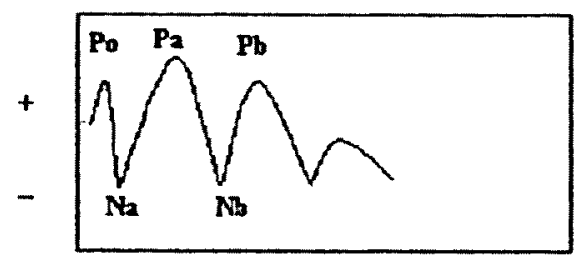

Janela de 50 ms

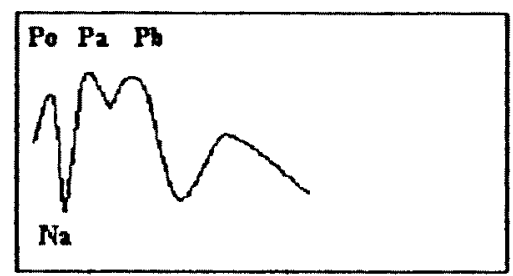

FIGURA 3 - REPRESENTAÇÃo GRÁFICA DOS POTENCIAIS EVOCADOS AUDITIVO DE MÉDIA LATÊNCIA (P.E.A.M.L)

MUSIEK e col. (1994) indicaram que na análise das ondas, quanto ao critério de anormalidade, devemos observar: 1) a ausência da onda $\mathrm{Pa}$, 2) uma diferença na amplitude entre os hemisférios direito e esquerdo maior que $50 \%$ para $\mathrm{Na}-\mathrm{Pa}, 3$ ) uma diferença na amplitude entre as orelhas direita e esquerda maior que $50 \%$ para $\mathrm{Na}-\mathrm{Pa}$ e 4) a latência de Pa maior que $35 \mathrm{~ms}$. 
KRAUS e col. (1999) comentaram que o sistema gerador do P.E.A.M.L. envolve a integração de muitas estruturas corticais, além de estruturas especificas centrais em relação ao mesencéfalo, bem como estruturas que estão fora da via auditiva principal tais como a formação reticular e divisões multi-sensoriais do tálamo. A ligação com a formação reticular tem sido comprovada, pois o estado de alerta afeta o registro dos potenciais. As lesões do lobo temporal têm apoiado a origem do pico Pa dos potenciais de média latência, no lobo temporal ou tálamo-cortical.

O ambiente utilizado para a captação do P.E.A.M.L. e a colocação dos eletrodos são similares aos usados para o P.E.A.T.E., facilitando o uso simultâneo dessas duas medidas, possibilitando um diagnóstico mais preciso.

MUNHOZ e col. (2000) recomendaram que na investigação neurológica deve ser utilizada uma intensidade de 70dBNA, a fim de obterem respostas neurais em pacientes que não apresentam perda auditiva.

TUCKER e col. (2001) realizaram um estudo com 11 sujeitos adultos, com audição normal, a fim de avaliarem o nível de intensidade do estímulo e o surgimento das ondas de resposta de média latência $(\mathrm{Pa}, \mathrm{Pb})$. Esses pesquisadores concluíram que a apresentação do estímulo a 90dBNAn propiciou o aparecimento das ondas em $100 \%$ das orelhas avaliadas, 86-95\% à 70dBNAn e 68-77\% à 50dBNAn.

HOOD (1987) estudou a simetria entre os potenciais captados entre as orelhas direita e esquerda entre indivíduos gagos e não gagos, a fim de obter a dominância hemisférica, por meio da comparação dos registros de latência e amplitude. Esse autor concluiu que a amplitude da onda $\mathrm{Pb}$ é maior em individuos gagos. 
HOOD (1990) relatou estudos entre indivíduos destros e canhotos, comparando os registros das orelhas direita e esquerda. Os estudos concluíram que houve um aumento na latência da onda $\mathrm{Pb}$ nos canhotos.

MUSIEK e col. (1994), CHERMAK e MUSIEK (1997), KRAUS e col. (1999), MUNHOZ e col. (2000b) alertaram quanto a alguns fatores não-patológicos que devem ser considerados como a influência do sono e da maturação da via neural, pois podem interferir no registro. Em crianças abaixo de 10 anos, o P.E.A.M.L. pode ser usado para monitorar a maturação do sistema nervoso central. Além disso, a utilização de uma intensidade de estímulo forte na captação do P.E.A.M.L. pode provocar respostas miogênicas que interferem no traçado.

AZUMI e col. (1995) observaram em seus estudos, com 51 indivíduos com audição normal, um aumento na amplitude de $\mathrm{Na}-\mathrm{Pa}$ e $\mathrm{Pa}-\mathrm{Nb}$ em relação à idade, porém não encontraram tal correlação para as latências $\mathrm{Na}, \mathrm{Pa}$ e Nb.

TUCKER e RUTH (1996) estudaram as respostas auditivas de média latência em 50 indivíduos, distribuídos entre recém-nascidos, crianças, pré-adolescentes, adolescentes e adultos, em relação à idade, local de captação do potencial, intensidade e velocidade do estímulo. Esses autores referiram que as variáveis como, idade, local de captação e intensidade afetaram significantemente a amplitude e a latência absoluta de $\mathrm{Pa}$.

MUSIEK e CHERMAK (1997) relataram que o interesse pelo P.E.A.M.L. aumentou após o advento do P.E.A.T.E. O P.E.A.M.L. é um instrumento útil no diagnóstico do distúrbio do processamento auditivo devido à possibilidade de localização dos sítios geradores dos potenciais auditivos de média latência. 


\subsubsection{Potencial COGNITIVo - P300}

Os potenciais auditivos tardios foram primeiramente observados por Pauline Davis em 1939, que observou essa ocorrência no EEG, sendo que as respostas obtidas apresentavam latências entre 70 e 500ms, após a estimulação (KRAUS e McGEE, 1999).

MUSIEK e col. (1994) observaram que a atividade neuroelétrica do P300 pode ser captada por meio de eletrodos colocados em várias combinações no couro cabeludo. Por exemplo, os invertidos podem ser colocados nas posições $\mathrm{C} 3, \mathrm{C} 4, \mathrm{Cz}, \mathrm{Pz}$ e $\mathrm{Fz}$, o não invertido, em cada lobo de orelha e o eletrodo "terra", na fronte. Os sítios geradores do P300 ainda não são bem conhecidos, porém acredita-se que esse potencial tenha contribuição do hipocampo e/ou lobo temporal posterior. Áreas do córtex auditivo também devem ser geradoras desse potencial cognitivo.

Esses autores definiram, também, as respostas anormais para adultos no P300. Uma latência maior de $350 \mathrm{~ms}$ seria considerada anormal para um adulto, porém devemos estar atentos ao fator idade. Devemos acrescentar ao valor de latência, em adultos com mais de 45 anos, $10 \mathrm{~ms}$ a cada década, por exemplo, de 46 a 55 anos, latências maiores de $360 \mathrm{~ms}$ seriam consideradas anormais.

McPHERSON (1996) relatou que os potenciais evocados de longa latência consistiriam de processos perceptuais e cognitivos resultantes de funções cerebrais altas em resposta a um evento auditivo. O P300 em particular estaria relacionado à cognição, pois ocorre quando o indivíduo reconhece, conscientemente, mudanças significativas no estimulo acústico. Esse autor comentou também que os sítios geradores desse potencial não estão totalmente conhecidos, porém existem algumas evidências de que o lobo temporal 
posterior e/ou hipocampo contribuem para a captação do potencial (áreas corticais auditivas).

McPHERSON (1996), KRAUS e McGEE (1999) descreveram que uma característica dos potenciais de longa latência é que são menos influenciados pelas propriedades físicas do estímulo e mais afetados pelo seu uso funcional pelo organismo do indivíduo.

GANANÇA e col. (1998) definiram o P300 como um potencial auditivo evocado relacionado a um determinado evento, gerado pela integração do estímulo auditivo com outras funções cognitivas. É um teste que avalia a percepção e a velocidade de integração do sistema central, muito utilizado na avaliação de crianças com dificuldades de aprendizado, na doença de Alzheimer, na epilepsia, na avaliação de situações de estresse profissional e outros.

KRAUS e col. (1999) relataram que em latências (pós-estímulo) maiores que 50ms, os potenciais evocados refletem principalmente a atividade do tálamo e córtex, estruturas envolvidas em funções de discriminação, integração e atenção do cérebro.

A interpretação do P300 deve ser realizada obedecendo alguns critérios de análise, a fim de diminuir a sua subjetividade de análise.

FRANCO (2001) recomendou a utilização da técnica descrita por Chiappa, para propiciar uma correta identificação da latência de P300, a qual consiste na determinação de um ponto de medida da latência, traçando-se linhas tangentes aos segmentos ascendente e descendente do componente. A latência corresponderia ao ponto onde estas duas linhas se cruzam, como mostrado na Figura 4. 


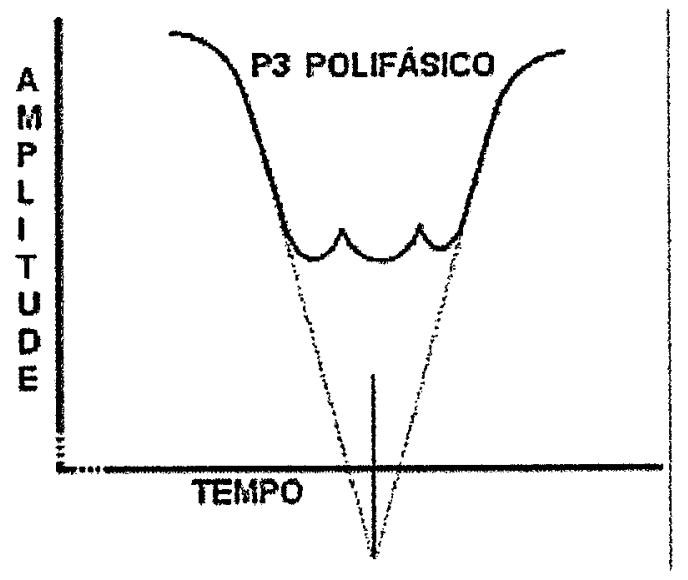

As hinhas pantilhadas sắo tangentes aas segmentos ascendente descendente de P3. A linha vertical partindo do ponto de encontro das tangentes determina, na linha horizontes (Tempo), o ponto onde se mede a latencia.

Figura 4 Modelo de interpretaÇÃo da latênCia P300.

Fonte: figura modificada de FRANCO G.M. O potencial evocado auditivo em adultos normais. Arq. Neuropsiquiatr., 2001, 59(2-A),p. 198-200.

ALONSO e col. (1990) relataram, em seus estudos com crianças normais e com dislexia, que houve uma diferença significativa entre esses dois grupos para a latência do componente P300.

JIRSA (1992) estudou as mudanças ocorridas nos potenciais de longa latência, antes e após intervenção terapêutica, em crianças com distúrbio do processamento auditivo, com e sem intervenção. Além disso, comparou esses resultados com um grupo-controle. Esse autor relatou que as medidas da amplitude aumentaram e a latência diminuiu, no P300, de forma significativa, nas crianças que realizaram trabalho terapêutico. Assim sendo, o autor concluiu que os componentes do P300 são sensíveis às mudanças clínicas ocorridas pósintervenção. 
Segundo JIRSA (1992), a avaliação do componente de longa latência P300, tem sido apontada como uma ferramenta eficaz para o monitoramento das crianças com distúrbio do processamento, pré e pós-intervenções terapêuticas.

Segundo CHERMAK e MUSIEK (1997) o uso dos testes eletrofisiológicos para a avaliação da função auditiva central provê informações importantes sobre a extensão da lesão do sistema nervoso auditivo central. O P.E.A.T.E. possibilita avaliar as vias do tronco encefálico, enquanto o potencial evocado auditivo de média latência (P.E.A.M.L.) e de longa latência (P300) revelam o funcionamento das áreas corticais e subcorticais do cérebro. Um dos mais importantes avanços na avaliação da D.P.A. foi compreender a interação entre os procedimentos eletrofisiológicos e testes comportamentais.

DINIZ Jr e col. (1997) estudaram os potenciais cognitivos ou P300 em 16 crianças com distúrbio de aprendizagem, a fim de correlacionar as respostas cognitivas com os testes comportamentais do processamento auditivo. Eles concluíram que as crianças apresentavam audição normal, segundo a avaliação auditiva periférica, resultados anormais em testes do processamento auditivo e as latências dos potenciais cognitivos ( $\mathrm{P} 300$ ) mostraram diferenças estatisticamente significantes com relação ao grupo controle.

SMEYERS (1999) evidenciou, em seus estudos com crianças portadoras da Síndrome do Déficit de Atenção e Hiperatividade (S.D.A.H.), a importância do uso do P300 como instrumento diagnóstico eficaz para monitorar o tratamento farmacológico dessa síndrome.

GIARD e col. (2000), em uma extensa revisão sobre os mecanismos neurofisiológicos da atenção auditiva seletiva no homem, comentaram que após 0 experimento pioneiro de HILLYARD e col. (1973) puderam comprovar a relação fisiológica e psicológica do potencial evento-relacionado (P300), os registros de imagens 
magneto-encefalográficos e a atenção seletiva, aumentando o interesse na utilização desse potencial na avaliação.

VISIOLI-MELO e ROOTTA (2000) pesquisaram a influência da epilepsia e o rendimento escolar, comparando um grupo de crianças normais a um grupo com quadro de epilepsia. Concluíram, após estratificação dos dois grupos pelo rendimento escolar, que houve diferença estatisticamente significante para a latência da onda P300 entre as crianças não epilépticas e com bom rendimento escolar (336ms) quando comparadas com os outros grupos, das crianças epilépticas com bom rendimento escolar e epilépticas ou não, com baixo rendimento escolar ( 363 a $400 \mathrm{~ms})$.

SCHOCHAT e col (2002) estudaram o P.E.A.T.E. e o P300 em crianças com transtorno do déficit de atenção e hiperatividade, medicadas e não medicadas, a fim de observarem diferenças entre esses dois grupos. Não foi encontrada diferença significativa entre eles, apesar de haver uma melhora na latência do P300 no grupo medicado. Estes autores revelaram que o P300 pode ser um instrumento útil para o estudo das funções cognitivas e de atenção, pois perceberam que o atraso na latência está provavelmente relacionado a alterações no processamento cognitivo. 


\section{OBJETIVO}

Esta pesquisa tem como objetivos:

1) Estimar a prevalência de alterações nas habilidades do processamento auditivo em escolares, que cursam terceira à quinta série, na faixa etária de 8 a 12 anos, utilizando o teste comportamental S.S.I.

2) Identificar possíveis associações entre as características da criança e as alterações nas habilidades do processamento auditivo, utilizando:

- Dados retirados da anamnese (lateralidade, história familiar, história gestacional, história médica, história audiológica e comportamental).

- Avaliação do sistema auditivo periférico e central (avaliação audiológica, comportamental do processamento auditivo e eletrofisiológica). 


\section{MÉTODO}

O desenho utilizado para o estudo foi um corte transversal.

\subsection{População}

A população estudada foi constituida por escolares que cursavam terceira à quinta série do ensino fundamental, abrangendo a faixa etária de 8 a 12 anos de idade, freqüentando as escolas públicas e privadas da cidade de Bauru - SP, durante o período do levantamento (Bauru 2000-2001).

Foram realizadas avaliações audiológicas, eletrofisiológicas e do processamento auditivo.

Um dos critérios para a realização dos testes propostos foi a presença de timpanograma tipo “A”, a fim de excluir as crianças com alterações de orelha média.

\subsection{AMOSTRA}

A fórmula utilizada para o cálculo do tamanho da amostra foi:

$$
n_{0}=\frac{p \times q \times z^{2}}{d^{2}}
$$

onde,

p: proporção de crianças com fator de risco para alteração do processamento auditivo, devido à prevalência estimada de distúrbio de linguagem e ou aprendizado nesta população (RUPP 1978).

q: $1-p$ 
z: percentil da Distribuição Normal

d: erro máximo

Foi estimado que a proporção de crianças com alteração nas habilidades do processamento auditivo seja próximo a $20 \%$ e admitindo-se como aceitável uma precisão tal que, em $95 \%$ das possíveis amostras, o erro máximo de amostragem (em valor absoluto) não ultrapasse a 6\%. Estimou-se a amostra em aproximadamente 170 crianças. Considerando-se possiveis perdas, o tamanho foi ajustado para 210 crianças.

Utilizou-se esse indice de alterações devido à falta de informações sobre a prevalência do distúrbio do processamento auditivo no momento de elaboração deste projeto (1999).

O procedimento para selecionar os escolares foi $o$ de amostragem por conglomerados, com probabilidade proporcional ao tamanho, em duas etapas. Na primeira foram sorteadas 10 escolas e, na segunda, 21 alunos da faixa etária estudada em cada escola sorteada.

A fração global de amostragem foi:

$$
f=0,0125=\frac{10 M_{i}}{\sum M_{i}} \times \frac{21}{M_{i}}
$$

onde,

$M_{i}$ : número de alunos na faixa etária estudada na escola $i$ na cidade de Bauru

$\sum \mathrm{M}_{\mathbf{i}}$ : número total de alunos na faixa etária estudada na cidade de Bauru 


\subsection{DEFINIÇÃo DE CASO}

Foi identificada como criança com alteração nas habilidades do processamento auditivo aquela que apresentou resultados alterados em pelo menos uma das relações sinal/competição do Testes S.S.I. em português.

Foi considerado resultado alterado no Teste S.S.I. para mensagem competitiva ipsilateral nas relações $\mathrm{S} / \mathrm{C}$ de 0 e $-10 \mathrm{dBNA}$, resultados abaixo de $90 \%$ e $70 \%$, respectivamente (OSTERNE e col. 1994). O teste S.S.I. foi utilizado nesta pesquisa, a fim de reproduzir as dificuldades enfrentadas pelos escolares em sala de aula, ou seja, avaliar a atenção em uma mensagem principal na presença de uma mensagem competitiva.

Além disso, foi possível avaliar a associação entre esse teste comportamental e o P300 (medida eletrofisiológica), quanto a atenção seletiva, função de ambos testes.

$\mathrm{Na}$ avaliação eletrofisiológica foram consideradas normais no P.E.A.T.E., latências para a onda I entre 1,3 a 1,8ms; III entre 3,3 e 3,9ms e para a onda $V$ valores entre 5,2 e 5,8ms. No P.E.A.M.L. foram utilizados os valores de $15-26 \mathrm{~ms}$ para a onda que representa Na, 25-36ms, para $\mathrm{Pa}$ e 0,4 à 2,0 $\mu \mathrm{V}$ para a amplitude Na-Pa. Para o P300, também avaliado pelo tempo de latência, foi considerado normal um valor de 270-350ms (MUSIEK e col. 1994, COSTA e col. - no prelo). Esses critérios foram estabelecidos após a normatização no equipamento utilizado. 


\subsection{Procedimentos}

\section{Agendamento e Anamnese}

Nas escolas sorteadas, foram realizadas reuniões com os pais, a fim de fornecer informações pertinentes quanto à realização de exames e orientações sobre questões que envolvem o processamento auditivo. Nessa ocasião, os pais responderam a um questionário (anamnese especifica - ANEXO 1) e receberam um cartão de agendamento, com informações que reforçavam a importância da avaliação para as crianças em fase escolar, além de assinarem a autorização para a realização dos testes.

\section{(ANEXO 2)}

A anamnese levantava dados pertinentes às crianças que seriam avaliadas pelos testes do processamento auditivo. A anamnese foi formulada utilizando um questionário de MARGOLIS 1997 (ANEXO 1). As informações levantadas eram referentes à história gestacional, médica, audiológica, familiar, características comportamentais da criança e aspectos relacionadas à fala e linguagem.

Os seguintes testes foram realizados em uma sessão de $1 \mathrm{~h}$ e 30 min para cada criança:

- avaliação audiológica completa;

- avaliação com teste especial do processamento auditivo;

- avaliação eletrofisiológica;

\section{Aplicação dos testes}

Avaliação audiológica completa compreendeu: 
1. Audiometria tonal limiar (adotamos o critérios propostos por DAVIS e SILVERMAN (1970), para classificação em dBNA, do limiar de normalidade.

2. Logoaudiometria.

3. Medidas de imitância acústica (timpanograma e medida do reflexo acústico) (JERGER 1970).

Estes procedimentos foram necessários para avaliar a audição periférica e obter dados para a realização da avaliação do processamento auditivo (a maioria dos testes para processamento auditivo utiliza níveis de sensação utilizando os limiares audiométricos).

Todos os escolares deveriam apresentar timpanometria tipo " $A$ ", no momento da realização dos testes, a fim de não comprometer a realização do teste S.S.I. A criança que apresentasse timpanometria tipo " $\mathrm{B}$ " ou " $\mathrm{C}$ " era encaminhada ao Posto de Saúde para diagnóstico e tratamento.

\section{Avaliação do Processamento Auditivo}

Foi utilizado para essa avaliação o CD 1, faixa 1 (calibração) e 6 (faixa teste) do "Manual de Avaliação do Processamento Auditivo Central" (PEREIRA e SCHOCHAT 1997) Os testes apresentados por meio de um compact disk (CD), que possibilita a preservação das condições ideais para a realização do teste.

1. Teste de Identificação de Sentença Sintética - S.S.I. em português

O material constou de listas de sentenças sintéticas como mensagem competitiva (história), de forma ipsilateral (tarefa de escuta monótica). O teste foi realizado por meio de fones de ouvido. Foi utilizada a intensidade de $40 \mathrm{dBNS}$ para a apresentação das frases e relação $\mathrm{S} / \mathrm{C} 0 \mathrm{~dB}$ e $-10 \mathrm{~dB}$ com mensagem competitiva ipsilateral (M.C.I.). (KALIL e col. 1997). 


\section{Avaliação eletrofisiológica da audição}

Esses procedimentos tornaram viável localizar possíveis alterações no sistema auditivo central e obter resultados que auxiliassem o diagnóstico das alterações das habilidades do processamento auditivo em escolares. Os testes objetivos não necessitam da participação efetiva do paciente.

Os exames foram realizados em sala silenciosa, com fones de inserção em ambas orelhas.

Foi utilizado eletrodo descartável e fio com garras tipo "pinça", a fim de possibilitar o uso desse tipo de eletrodo, facilitando o registro e diminuindo o tempo gasto na troca dos eletrodos em cada medida eletrofisiológica realizada. Foi condição obrigatória para iniciar a avaliação eletrofisiológica que o teste para impedância dos eletrodos apresentasse os seguintes parâmetros:

- Impedância individual dos eletrodos deveria ser menor que $5 \mathrm{kohms.}$

- Impedância entre os eletrodos, não ultrapassar 2kohms. (FERRARO 1997).

\section{Potencial Evocado Auditivo do Tronco Encefálico - P.E.A.T.E.;}

O exame foi realizado com a criança sentada, de olhos fechados e relaxada (sem sedação)

O estímulo utilizado foi o clique. Este estímulo foi apresentado numa intensidade de 80dBNAn e com polaridade alternada, sem mascaramento, sendo necessários 1024 a 2000 cliques promediados, a fim de obter melhor definição dos traçados (TABELAS 6 e 7).

O eletrodo "ativo" foi colocado em Fz e conectado a entrada 1 dos canais 1 e 2 (interligados) do amplificador. Os eletrodos "referência" foram posicionados nas mastóides direita e esquerda, conectadas na entrada 2 dos canais 1 e 2 , respectivamente, do 
amplificador. O eletrodo "terra" foi colocado na posição Fpz

$\mathrm{O}$ traçado foi realizado duas vezes para cada orelha, a fim de obter fidedignidade na reprodução das curvas.

\begin{tabular}{cc} 
TABELA 6 - PARÂMETROS DO REGISTRO DO P.E.A.T.E. \\
\hline Número de canais & 2 \\
Configuração dos & Canal 1 \\
eletrodos & $\mathrm{Fz}(+), \mathrm{M}_{1}(-)$ \\
& Canal 2 \\
& $\mathrm{Fz}(+), \mathrm{M}_{2}(-)$ \\
& $\mathrm{Fpz}(\mathrm{Terra})$ \\
Ganho do amplificador & $100.000 \mathrm{x}$ \\
Filtro passa-baixa & $100 \mathrm{~Hz}$ \\
Filtro passa-alta & $3000 \mathrm{~Hz}$ \\
Total de estímulos & $1.024 \mathrm{a} 2.000$ \\
& Fone de inserção- \\
Transdutor & $10 \mathrm{~ms}$ \\
Janela de análise & \\
\hline
\end{tabular}

TABELA 7 - PARÂMETROS do ESTÍMULO Do P.E.A.T.E.

\begin{tabular}{cc}
\hline Tipo & Clique \\
\hline Polaridade & Alternada \\
Duração & $100 \mathrm{~ms}$ \\
Intensidade & $80 \mathrm{dBNA}$ \\
Velocidade de repetiç̃o & $13 / \mathrm{s}$ \\
\hline
\end{tabular}

2. Potencial Evocado Auditivo de Média Latência - P.E.A.M.L.

O exame foi realizado com a criança sentada e em estado de alerta e relaxada.

O estímulo acústico utilizado foi o clique, apresentado numa intensidade de 70dBNAn, com polaridade alternada. Foram necessários 500 estímulos promediados para obtenção da resposta (TABELAS 8 e 9).

O eletrodo "ativo" foi colocado em Fz e conectado a entrada 1 dos canais 1 e 2 (interligados), do amplificador. Os eletrodos de "referência" foram posicionados nas mastóides esquerda $\left(\mathrm{M}_{1}\right)$ e direita $\left(\mathrm{M}_{2}\right)$, conectadas na entrada 2 dos canais 1 e 2 , respectivamente, do amplificador. O eletrodo "terra" foi colocado na posição Fpz. 
Foi solicitado ao paciente que permanecesse de olhos fechados e relaxado.

TABELA 8 - PARÂMETros do REgistro para P.E.A.M.L.

\begin{tabular}{cc}
\hline Número de canais & 2 \\
Configuração dos & Canal 1 \\
eletrodos & $\mathrm{Fz}_{(+), \mathrm{M}_{\mathrm{I}}(-)}$ \\
& $\mathrm{Canal} 2$ \\
& $\mathrm{Fz}_{\mathrm{Z}}(+), \mathrm{M}_{2}(-)$ \\
& $\mathrm{Fpz}_{(\mathrm{Terra})}$ \\
Gantho do amplificador & $75.000 \mathrm{x}$ \\
Filtro passa-baixa & $3 \mathrm{~Hz}$ \\
Filtro passa-alta & $100 \mathrm{~Hz}$ \\
Total de eslímulos & 500 \\
Transdutor & Fone de inserção \\
& \\
Janela de análise & $100 \mathrm{~ms}$ \\
\hline
\end{tabular}

\begin{tabular}{cc} 
TABELA 9-PARÂMETROS Do estimulo Para P.E.A.M.L. \\
\hline Tipo \\
Polaridade & Clique \\
& Altemado \\
Duração & $100 \mu \mathrm{s}$ \\
Intensidade & $70 \mathrm{dBNA}$
\end{tabular}

3. Potencial cognitivo - P300

O exame foi realizado com a criança sentada e de olhos abertos

Os eletrodos "ativos" foram colocados em $\mathrm{Cz}$ e Fz e conectados à entrada 1 dos canais 1 e 2 , respectivamente, do amplificador. Os eletrodos de "referência" foram posicionados nas mastóides direita e esquerda, interligadas e conectadas na entrada 2 dos canais 1 e 2, do amplificador, o eletrodo "terra", foi colocado na posição Fpz.

O estímulo acústico utilizado foi "toneburst", sendo apresentado numa intensidade de 75dBNAn, com polaridade alternada (COSTA e col. - no prelo). As freqüências utilizadas no teste foram: a freqüência de $1000 \mathrm{~Hz}$ para o "estímulo freqüente" e $2000 \mathrm{~Hz}$ para o "estímulo raro". Foram utilizados $20 \%$ de "estímulos raros" detectados, mesclados randomicamente aos "freqüentes", que correspondiam $80 \%$ do total de estímulos 
(TABELA 10 e 11 ).

Foi solicitado à criança que identificasse o estímulo raro, contando-o mentalmente. Ao término do teste foi pedido para ela dizer quantos estímulos contou, avaliando sua participação efetiva.

A condição obrigatória para aceitar o traçado foi o aparecimento da onda ou complexo $\mathrm{P} 300$ nas duas posições avaliadas $(\mathrm{Cz}$ e Fz) com pico positivo, quando presente. O valor da latência de P300 foi dada utilizando o método descrito por FRANCO 2001 (vide pág. 51)

TABELA 10 - PARÂMETROS DO REGISTRO PARA P300

$\begin{array}{cc}\begin{array}{c}\text { Número de canais } \\ \text { Configuração dos } \\ \text { eletrodos }\end{array} & 2 \\ & \mathrm{Canal} 1 \\ & \mathrm{Fz}(+), \mathrm{M}_{1}(-) \mathrm{M}_{2}(-) \\ & \mathrm{Canal} 2 \\ & \mathrm{Cz}(+), \mathrm{Ma}_{1}(-) \mathrm{MA}_{2}(-) \\ \text { Ganho do amplificador } & 30.000 \mathrm{x} \\ \text { Filtro passa-baixa } & 1 \mathrm{~Hz} \\ \text { Filtro passa-alta } & 100 \mathrm{~Hz} \\ \text { Total de estímulos } & 100 \text { estimulos raros } \\ & \\ \text { Transdutor } & \text { Fone de inserção- } \\ & \\ \text { Janela de análise } & 512 \mathrm{~ms}\end{array}$

TABEla 11 - ParÂmetros do estímulo para P300

$\begin{array}{cc}\text { Tipo } & \text { Toneburst } \\ \text { Duração } & 100 \mathrm{~ms}\end{array}$

Intensidade 75dBNA

Freqüência $\quad 1000 \mathrm{~Hz}-$ estímulo

freqüente

Envelope

$2000 \mathrm{~Hz}$ - estímulo raro

$10 \mathrm{~ms} \mathrm{r} / \mathrm{f}$

$30 \mathrm{~ms}$ plateau

Velocidade de repetição $\quad 1,1 / \mathrm{s}$ 


\subsection{EQUIPAMENTOS}

- Avaliação audiológica completa:

- Audiômetro, modelo UNITY - marca Siemens, calibrados segundos as normas contidas na ANSI 1969;

- Fones de ouvido TDH - 29;

- Cabina acústica construída segundo os padrões internacionais de construção de modo a controlar os valores máximos de ruído interno.

- Analisador de orelha média - AZ26 da marca Interacoustics, para realização das medidas de imitância acústica, com fone de ouvido TDH-39 e coxim MX-41, com tom da sonda em $226 \mathrm{~Hz}$.

- Avaliação eletrofisiológica:

- Os P.E.A. foram realizados utilizando o programa para computador BIOLOGYC que compreende os testes de P.E.A.T.E., P.E.A.M.L. e P300;

- Para a captação dos potenciais foram necessários cinco eletrodos de superficie e o fone de inserção, pasta abrasiva para limpeza da pele e pasta eletrolítica para diminuir a impedância;

- Avaliação comportamental com teste especial do PA:

- Um audiômetro de dois canais da marca Siemens, modelo UNITY.

- Cabina acústica construída segundo os padrões internacionais de construção de modo a controlar os valores máximos de ruido interno.

- Fones de ouvido TDH - 29.

- $C D$ com a gravação dos testes (PEREIRA e SCHOCHAT 1997).

- CD player, marca Sony. 


\section{- Equipamentos acessórios}

- Microcomputador da marca Intel.

- Impressora, da marca Hewlett Packard, modelo Deskjet 640C.

\subsection{REGISTRO DOS RESULTADOS}

1. A avaliação audiológica foi registrada em modelo internacional para registro das respostas ao tom puro, logoaudiometria e medidas de imitância acústica (Anexo 3).

2. A avaliação eletrofisiológica, pelo equipamento e enviada à impressora.

3. A avaliação comportamental do processamento auditivo foi anotada em protocolo de resposta proposto para cada um dos procedimentos, segundo PEREIRA e SCHOCHAT (1997) (Anexo 4).

4. Os resultados dos exames foram entregues aos pais em folha especifica de resultado (Anexo 5).

\subsection{ANÁLISE DOS RESULTADOS}

Após a verificação dos possíveis erros, todos os questionários (anamnese) e resultados dos testes audiológicos, comportamentais e eletrofisiológicos foram digitados em um microcomputador com o programa STATA, versão 7.0.

Foi calculada a prevalência de alteração nas habilidades do processamento auditivo em escolares na cidade de Bauru, utilizando os resultados do desempenho no teste de identificação de sentenças sintéticas - SSI, em português. Um intervalo de confiança de $95 \%$ foi calculado para essa prevalência levando-se em consideração o desenho do estudo, ou seja, amostragem por conglomerado. Foi utilizado o programa EPI-INFO, versão 6,0 para esse cálculo. 
Os resultados foram analisados adotando-se os seguintes procedimentos: 1) descrição univariada de todas as variáveis; 2) análise bivariada utilizando o Teste de QuiQuadrado e o Teste Exato de Fisher, quando necessário.

A análise bivariada possibilitou avaliar as variáveis que poderiam estar associadas como possiveis fatores de risco para a falha no teste S.S.I., ou seja, explorar associações entre potenciais fatores de risco para a alteração das habilidades do processamento auditivo.

$\mathrm{Na}$ Figura 5 é apresentado o modelo conceitual do relacionamento entre os fatores de risco para as alterações nas habilidades do processamento auditivo em escolares.

Essa análise também foi realizada entre as características comportamentais da criança e a alteração das habilidades do processamento auditivo. Na Figura 6 é apresentado um modelo conceitual das características emocionais e do comportamento auditivo associadas às alterações nas habilidades auditivas, em escolares.

Após as análises bivariadas, foram realizadas análises multivariadas (regressão logística) para estimar as razões de chances ajustadas para as variáveis de interesse.

No modelo de regressão logística foi considerada a falha no teste SSI como variável dependente e o conjunto das variáveis utilizadas na análise bivariada como variáveis independentes.

Os modelos de regressão logística múltipla foram construídos incluindo-se primeiramente as variáveis que na análise bivariada apresentaram $p<0,05$. Posteriormente, todas as outras variáveis foram testadas no modelo e em caso de ocorrência de alguma alteração importante nas estimativas de razão de chances, as variáveis permaneciam no modelo (CLAYTON e HILLS 1993).

As análises univariadas, bivariadas e multivariadas fora realizadas com o programa STATA versão7,0. 


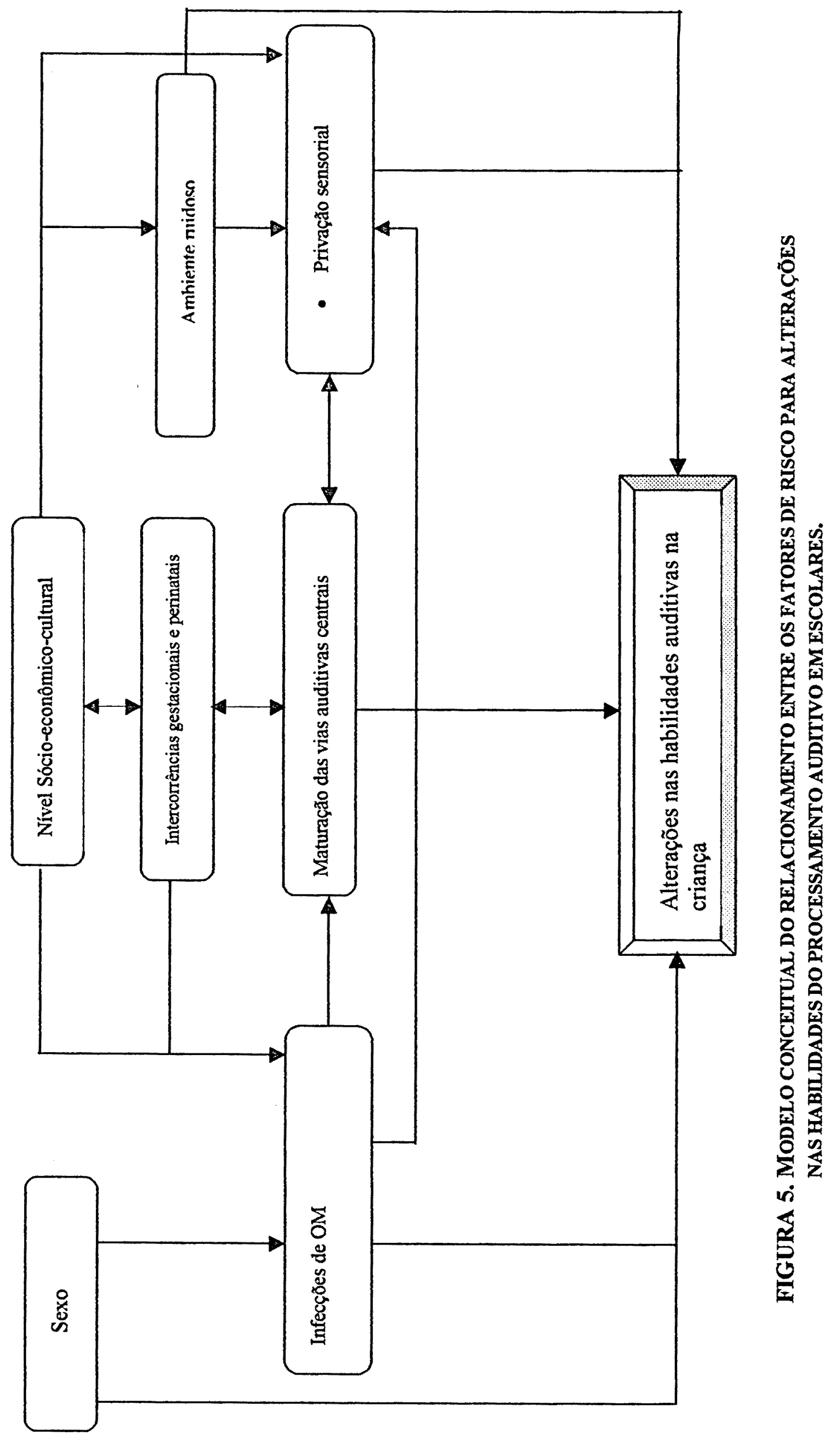




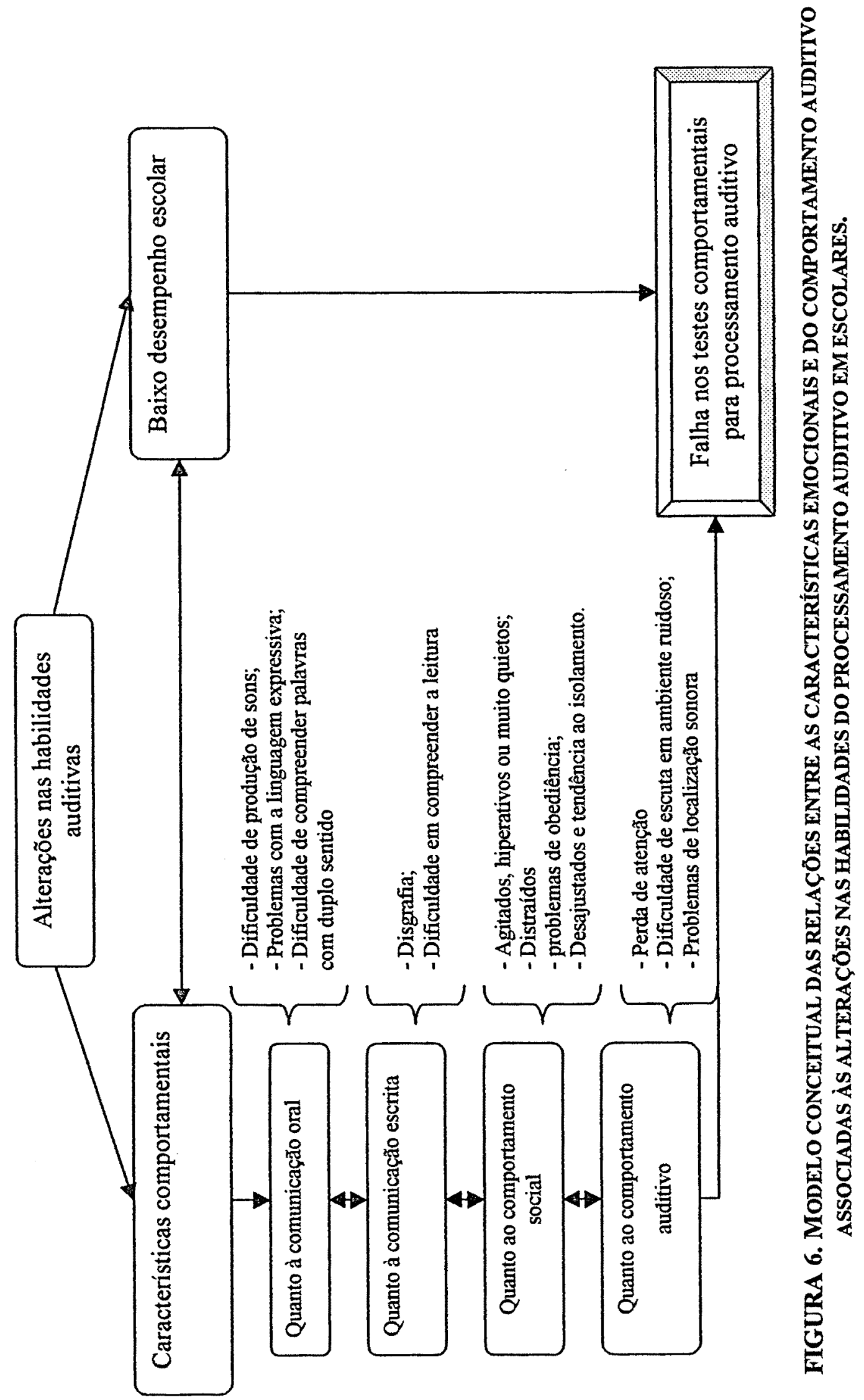




\section{RESULTADOS}

\subsection{CaRacteristicas da amostra estudada}

Foram sorteadas inicialmente dez escolas para esta pesquisa, porém duas escolas foram retiradas do estudo por não haverem manifestado interesse na realização dos testes auditivos em seus alunos. Foi necessário sortear novamente duas, a fim de totalizar dez escolas.

Segundo o planejamento da amostra e o acordo firmado com as escolas, seriam sorteadas 21 crianças de $3^{\mathrm{a}}$ a $5^{\mathrm{a}}$ série em cada uma delas. Assim sendo, foi necessário sortear 293 crianças para se poder obter uma amostra final de 210 escolares. Das 293 crianças, $56(19,1 \%)$ não compareceram na data agendada e $27(9,2 \%)$ não foram autorizadas pelos pais para realizarem a avaliação audiológica.

A amostra avaliada nesta pesquisa, composta pelas 210 crianças, apresentava 127 $(60,5 \%)$ do sexo feminino e $83(39,5 \%)$ do sexo masculino.

A TABELA 12 mostra a distribuição das crianças segundo a idade.

TABELA 12. Distribuiçáo das Crianças de 3" a $5^{*}$ SÉrie, SEgundo a IDAde No MOMENTO dA AVALIAÇÃo. BAURU 2000-2001.

\begin{tabular}{lcc}
\hline Idade & $\mathbf{n}$ & $\%$ \\
\hline 8 anos & 25 & 11,9 \\
9 anos & 67 & 31,9 \\
10 anos & 57 & 27,1 \\
11 anos e mais & 61 & 29,1 \\
\hline Total & 210 & 100 \\
\hline
\end{tabular}

Foram avaliadas $2(20,0 \%)$ escolas privadas e $8(80,0 \%)$ escolas públicas, sendo que 9 escolas (90\%) adotavam o sistema de "progressão continuada", sendo uma escola 
particular beneficente e 8 escolas públicas) e 1 (10\%) sistema tradicional de ensino (Tabela 13).

TABELA 13. DISTRIBUIÇÁ DAS CRIANÇAS DE $3^{2}$ A $5^{*}$ SÉRIE, SEGUNDO A CATEGORIA DA ESCOLA. BAURU 2000-2001.

\begin{tabular}{lcc}
\hline Categoria & $\mathrm{n}$ & $\%$ \\
\hline Beneficente & 22 & 10,5 \\
Pública & 166 & 79,0 \\
Particular & 22 & 10,5 \\
\hline Total & 210 & 100 \\
\hline
\end{tabular}

Noventa e duas $(43,8 \%)$ crianças cursavam a $3^{\mathrm{a}}$ série, $70(33,3 \%)$ escolares estavam na $4^{a}$ série e $48(22,9 \%)$ na $5^{a}$ série do ensino fundamental.

\subsubsection{Dados DE ANAMNESE}

\section{HistóRIA GESTACIONAL}

A TABELA 14 mostra os dados relacionados com a distribuição dos escolares, segundo a história gestacional.

Podemos observar um número importante de problemas no Pré-Natal $(11,4 \%)$ e peso abaixo de 2500 gramas $(12,2 \%)$. O índice de icterícia no nascimento foi de $(18,3 \%)$, sendo que uma criança necessitou exsanguíneo transfusão. A tabela também mostra um elevado número de cesarianas na cidade de Bauru $(76,6 \%)$ 


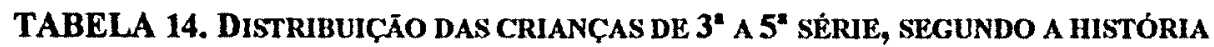
GESTACIONAL. BAURU 2000-2001

\begin{tabular}{|c|c|c|}
\hline História gestacional & $\mathbf{n}$ & $\%$ \\
\hline \multicolumn{3}{|c|}{ Problemas no Pré-Natal } \\
\hline Não & 164 & 88,6 \\
\hline Sim & 21 & 11,4 \\
\hline Total & 185 & 100 \\
\hline \multicolumn{3}{|l|}{ Uso de álcool } \\
\hline Não & 183 & 99,5 \\
\hline Sim & 1 & 0,5 \\
\hline Total & 184 & 100 \\
\hline \multicolumn{3}{|c|}{ Uso de drogas ou medicamentos } \\
\hline Não & 175 & 95,6 \\
\hline Sim & 8 & 4,4 \\
\hline Total & 183 & 100 \\
\hline \multicolumn{3}{|l|}{ TORCH } \\
\hline Não & 185 & 98,9 \\
\hline Sim & 2 & 1,1 \\
\hline Total & 187 & 100 \\
\hline \multicolumn{3}{|l|}{ Tempo gestacional } \\
\hline A termo & 174 & 93,1 \\
\hline Pré-Termo & 13 & 0,9 \\
\hline Total & 187 & 100 \\
\hline \multicolumn{3}{|l|}{ Tipo de parto } \\
\hline Normal & 44 & 23,4 \\
\hline Cesariana & 144 & 76,6 \\
\hline Total & 188 & 100 \\
\hline \multicolumn{3}{|l|}{ Hipóxia perinatal } \\
\hline Não & 180 & 96,3 \\
\hline Sim & 7 & 3,7 \\
\hline Total & 187 & 100 \\
\hline \multicolumn{3}{|l|}{ Icterícia } \\
\hline Não & 152 & 81,7 \\
\hline Sim & 34 & 18,3 \\
\hline Total & 186 & 100 \\
\hline \multicolumn{3}{|l|}{ Internação } \\
\hline Não & 171 & 91,9 \\
\hline Sim & 15 & 8,1 \\
\hline Total & 186 & 100 \\
\hline \multicolumn{3}{|l|}{ Incubadoura } \\
\hline Não & 177 & 94,7 \\
\hline Sim & 10 & 5,3 \\
\hline Total & 187 & 100 \\
\hline \multicolumn{3}{|c|}{ Exsanguíneo transfusão } \\
\hline Não & 186 & 99,5 \\
\hline $\operatorname{Sim}$ & 1 & 0,5 \\
\hline Total & 187 & 100 \\
\hline \multicolumn{3}{|c|}{ Peso abaixo de $2500 \mathrm{~g}$ no nascimento } \\
\hline Não & 151 & 87,8 \\
\hline Sim & 21 & 12,2 \\
\hline Total & 172 & 100 \\
\hline \multicolumn{3}{|c|}{ Presença de mal-formação } \\
\hline Não & 185 & 97,9 \\
\hline Sim & 4 & 2,1 \\
\hline Total & 189 & 100 \\
\hline
\end{tabular}




\section{HISTÓRIA MÉDICA}

A TABELA 15 apresenta os dados de história médica dos escolares avaliados nessa pesquisa.

Observamos na Tabela 15 que um grande número de pais relataram que suas crianças já apresentaram episódios de dores de cabeça $(27,4 \%)$. Observamos também que $14(7,4 \%)$ tiveram pelo menos uma convulsão (por motivos diversos: febre alta, problemas neurológicós e outros).

TABELA 15. DistrubuiçĀo das CRIANÇAS de 3" A 5" SÉRIE, SEGundo dados DA História MÉDICA. BAURU 2000-2001.

\begin{tabular}{lcc}
\hline História médica & $\mathrm{n}$ & $\%$ \\
\hline Convulsões & 175 & \\
Não & 14 & 92,6 \\
Sim & 189 & 7,4 \\
Total & & 100 \\
Dor de cabeça & 138 & \\
Não & 52 & 72,6 \\
Sim & 190 & 27,4 \\
Total & & 100 \\
Problema neurológico & 186 & \\
Não & 3 & 98,4 \\
Sim & 189 & 1,6 \\
Total & & 100 \\
\hline
\end{tabular}

\section{Histórla Audiológica}

Na Tabela 16 é mostràda a distribuição das crianças segundo a história audiológica.

Nessa tabela é observado que as infecções de orelha afetaram 74 crianças $(38,5 \%)$, sendo que da amostra, $33(18,7 \%)$ já realizaram testes auditivos e $23(13,1 \%)$ algum tipo de avaliação de fala/linguagem.

Os testes auditivos e as avaliações de fala/linguagem foram realizados por motivo diagnóstico ou por serviços fonoaudiológicos prestados às escolas (triagem). 
TABELA 16. Distribuição das CRIANÇAS de $3^{2}$ A $5^{2}$ SÉRIE, SRGundo os DADOS DE HISTÓRIA AUDIOLÓGICA. BAURU 2000-2001.

\begin{tabular}{|c|c|c|}
\hline História audiológica & $\mathbf{n}$ & $\%$ \\
\hline \multicolumn{3}{|l|}{ Seu filho ouve bem? } \\
\hline Não & 21 & 11,1 \\
\hline Sim & 168 & 88,9 \\
\hline Total & 189 & 100 \\
\hline \multicolumn{3}{|l|}{ Presença de zumbido } \\
\hline Não & 172 & 90,5 \\
\hline Sim & 18 & 9,5 \\
\hline Total & 190 & 100 \\
\hline \multicolumn{3}{|c|}{ Alterações de equilibrio } \\
\hline Não & 169 & 89,0 \\
\hline Sim & 21 & 11,0 \\
\hline Total & 190 & 100 \\
\hline \multicolumn{3}{|l|}{ Infeccões de orelha } \\
\hline Não & 118 & 61,5 \\
\hline Sim & 74 & 38,5 \\
\hline Total & 192 & 100 \\
\hline \multicolumn{3}{|l|}{ Cirurgia de orelha. } \\
\hline Năo & 171 & 97,2 \\
\hline Sim & 5 & 2,8 \\
\hline Total & 176 & 100 \\
\hline \multicolumn{3}{|l|}{ Testes auditivos } \\
\hline Não & 143 & 81,3 \\
\hline Sim & 33 & 18,7 \\
\hline Total & 176 & 100 \\
\hline \multicolumn{3}{|c|}{ Avaliação de fala/linguagem } \\
\hline Não & 153 & 86,9 \\
\hline Sim & 23 & 13,1 \\
\hline Total & 176 & 100 \\
\hline \multicolumn{3}{|l|}{ Exame neurológico } \\
\hline Não & 159 & 90,3 \\
\hline Sim & 17 & 9,7 \\
\hline Total & 176 & 100 \\
\hline \multicolumn{3}{|l|}{ Testes psicológicos } \\
\hline Naัo & 161 & 91,5 \\
\hline Sim & 15 & 8,5 \\
\hline Total & 176 & 100 \\
\hline
\end{tabular}

\section{HISTÓRIA FAMILIAR}

A TABELA 17 mostra dados referentes à história familiar de problemas neurológicos, fala/linguagem, aprendizado, deficiência auditiva e doenças hereditárias.

Foi observado um indice de $21 \%$ de história de deficiência auditiva na família (pais, irmão e avós maternos e paternos), incluindo a presbiacusia. 
Foi observado também um índice de $15,2 \%$ de história problemas neurológicos na família (pais, irmão e avós maternos e paternos), incluindo o acidente vascular cerebral.

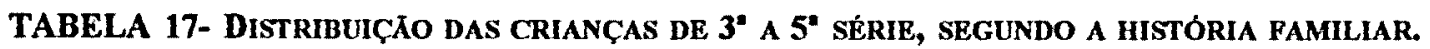
BAURU 2000-2001

\begin{tabular}{lcc}
\hline História familiar & $\mathbf{n}$ & $\%$ \\
\hline Problemas neurológicos & 26 & 15,2 \\
Sim & 145 & 84,8 \\
Não & 171 & 100 \\
Total & & \\
Problemas de fala/linguagem & 19 & 11,1 \\
Sim & 152 & 88,9 \\
Não & 171 & 100 \\
Total & & \\
Problemas de aprendizagem & 20 & 11,7 \\
Sim & 151 & 88,3 \\
Não & 171 & 100 \\
Total & & \\
Deficiência auditiva & 36 & 21,0 \\
Sim & 135 & 79,0 \\
Não & 171 & 100 \\
Total & & \\
Doenças hereditárias & 39 & 22,9 \\
Sim & 131 & 77,1 \\
Não & 170 & 100 \\
Total & & \\
\hline
\end{tabular}

\section{CARACTERISTICAS EMOCIONAIS E DO COMPORTAMENTO AUDITIVO DA CRIANÇA.}

Na Tabela 18 são mostrados os resultados relacionados à observação pelos pais quanto às caracteristicas emocionais e do comportamento auditivo das crianças.

As características emocionais levantadas estavam relacionadas às características descritas por KEITH (1995), para crianças com alteração do processamento auditivo (vide TABELA 2, pág. 21). 
$\mathrm{Na}$ tabela são observados índices importantes de queixas relacionadas ao comportamento auditivo das crianças: dificuldade de entender no ruido $(31,1 \%)$, distraido (39\%), esquece o que é dito $(40,1 \%)$, pede para repetir o que é dito $(37,3 \%)$, perda de atenção $(39,3 \%)$.

Os dados também mostram que as características emocionais observadas pelos pais apresentam número elevado de problemas relacionados à frustração $(37,3)$ e à autoconfiança $(38,4)$.

TABELA 18 DistribuiÇÃo das CRIANÇAS de 3" A 5" SÉRIE, SEgundo AS CARACTERISTICAS EMOCIONAIS E DO COMPORTAMENTO AUDTTIVO. BAURU 2000-2001.

\begin{tabular}{|c|c|c|}
\hline $\begin{array}{l}\text { Características emocionais e do } \\
\text { comportamento auditivo }\end{array}$ & $\mathbf{n}$ & $\%$ \\
\hline \multicolumn{3}{|l|}{ Desconforto a som intenso } \\
\hline Sim & 27 & 15,3 \\
\hline Não & 150 & 84,7 \\
\hline Total & 177 & 100 \\
\hline \multicolumn{3}{|l|}{ Dificuldade de entender no ruido } \\
\hline Sim & 55 & 31,1 \\
\hline Não & 122 & 68,9 \\
\hline Total & 177 & 100 \\
\hline \multicolumn{3}{|l|}{ Distraido } \\
\hline Sim & 69 & 39,0 \\
\hline Não & 108 & 61,0 \\
\hline Total & 177 & 100 \\
\hline \multicolumn{3}{|l|}{ Esquece o que the é dito } \\
\hline Sim & 71 & 40,1 \\
\hline Não & 106 & 59,9 \\
\hline Total & 177 & 100 \\
\hline \multicolumn{3}{|l|}{ Brinca com crianças mais jovens } \\
\hline Sim & 58 & 32,8 \\
\hline Não & 119 & 67,2 \\
\hline Total & 177 & 100 \\
\hline \multicolumn{3}{|l|}{ Cansa facilmente das atividades } \\
\hline Sim & 39 & 22,0 \\
\hline Não & 138 & 78,0 \\
\hline Total & 177 & 100 \\
\hline \multicolumn{3}{|l|}{ Pede para repetir o que foi dito } \\
\hline Sim & 66 & 37,3 \\
\hline Não & 111 & 62,7 \\
\hline Total & 177 & 100 \\
\hline \multicolumn{3}{|l|}{ Perda de atenção } \\
\hline Sim & 68 & 39,3 \\
\hline Não & 105 & 60,7 \\
\hline Total & 173 & 100 \\
\hline
\end{tabular}




\begin{tabular}{|c|c|c|}
\hline $\begin{array}{l}\text { Caracteristicas emocionais e do } \\
\text { comportamento auditivo }\end{array}$ & $\mathbf{n}$ & $\%$ \\
\hline \multicolumn{3}{|l|}{ Desobediente } \\
\hline Sim & 49 & 27,7 \\
\hline Não & 128 & 72,3 \\
\hline Total & 177 & 100 \\
\hline \multicolumn{3}{|l|}{ Agitado } \\
\hline Sim & 59 & 33,5 \\
\hline Não & 117 & 66,5 \\
\hline Total & 176 & 100 \\
\hline \multicolumn{3}{|l|}{ Irritado } \\
\hline Sim & 82 & 46,3 \\
\hline Não & 95 & 53,7 \\
\hline Total & 177 & 100 \\
\hline \multicolumn{3}{|l|}{ Gosta de ir à escola } \\
\hline Sim & 154 & 87,0 \\
\hline Não & 23 & 13,0 \\
\hline Total & 177 & 100 \\
\hline \multicolumn{3}{|l|}{ Dificuldade de localizar som } \\
\hline Sim & 8 & 4,5 \\
\hline Não & 169 & 95,5 \\
\hline Total & 177 & 100 \\
\hline \multicolumn{3}{|l|}{ Dificuldade com conceito tempo } \\
\hline Sim & 19 & 10,7 \\
\hline Não & 158 & 89,3 \\
\hline Total & 177 & 100 \\
\hline \multicolumn{3}{|l|}{ Problemas de obediência } \\
\hline Sim & 56 & 31,6 \\
\hline Não & 121 & 68,4 \\
\hline Total & 177 & 100 \\
\hline \multicolumn{3}{|l|}{ Frusta-se facilmente } \\
\hline Sim & 66 & 37,3 \\
\hline Não & 111 & 62,7 \\
\hline Total & 177 & 100 \\
\hline \multicolumn{3}{|l|}{ Problemas de autoconfiança } \\
\hline Sim & 68 & 38,4 \\
\hline Não & 109 & 61,6 \\
\hline Total & 177 & 100 \\
\hline
\end{tabular}

\section{ASPECTOS RELACIONADOS À FALA/LINGUAGEM.}

A TABELA 19 está relacionada a distribuição das crianças, segundo os problemas \ /linguagem, na população estudada. 
Nessa tabela é observado um índice elevado de queixas relacionadas ao vocabulário pobre (16,4\%), dificuldade de formar frases complexas (26\%) e baixo desempenho escolar $(19,4 \%)$ das crianças.

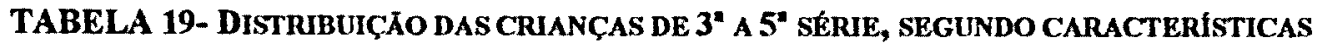
RELACIONADAS A PROBLEMAS DE FALALLINGUAGEM. BAURU 2000-2001.

\begin{tabular}{lcc}
\hline Características & $\mathrm{n}$ & $\%$ \\
\hline Atraso de fala/linguagem & 163 & 92,1 \\
Não & 14 & 7,9 \\
Sim & 177 & 100 \\
Total & 148 & \\
Vocabulário pobre & 29 & 83,6 \\
Não & 177 & 16,4 \\
Sim & & 100 \\
Total & 131 & \\
Problemas para formar frases complexas & 46 & 74,0 \\
Não & 177 & 26,0 \\
Sim & & 100 \\
Total & 26 & \\
Se a fala da criança é entendida & 151 & 14,7 \\
Não & 177 & 85,3 \\
Sim & & 100 \\
Total & 11 & \\
Se a criança entende quando outros falam & 166 & 6,2 \\
Não & 177 & 93,8 \\
Sim & & 100 \\
Total & 162 & \\
Se fez terapia fonoaudiológica & 15 & 91,5 \\
Não & 177 & 8,5 \\
Sim & & 100 \\
Total & 129 & \\
Lateralidade & 11 & 92,1 \\
Destro & 140 & 7,9 \\
Canhoto & & 100 \\
Total & 38 & 19,4 \\
Baixo desempenho escolar & 158 & 80,6 \\
Sim & 196 & 100 \\
Não & & \\
Total & & \\
\hline
\end{tabular}

\subsubsection{RESUltados de diagnóstico atUal.}

Os resultados parciais de cada teste realizado nesta pesquisa pode ser visualizado individualmente nos ANEXOS 6 e 7 . 
O teste de Identificação de Sentenças Sintéticas - S.S.I. - em português foi realizado com M.C.I., nas relações S/C em 0 e $-10 \mathrm{~dB}$, segundo os critérios estabelecidos no capítulo de material e método (vide pág. 58).

$\mathrm{Na}$ Tabela 20 são mostrados os resultados do teste S.S.I., nas relações sinal/competição 0dBNA e -10dBNA, nas orelhas direita e esquerda.

A análise dos resultados possibilitou observar que houve um número maior de falhas na situação de sinal/competição - $10 \mathrm{dBNA}(26,7 \%$ para a orelha direita e $24,3 \%$ para a esquerda).

TABELA 20- DistribuiçAo das CRIANÇAs de 3* A $5^{*}$ série (n=210), SEcundo os RESULTADOS dO TESTE SSI, FM PORTUGUES, NAS RELAÇOES DE SINAL/COMPETIÇÃO UTILIZADAS. BAURU 2000-2001.

\begin{tabular}{lcccc}
\hline Testes S.S.I & \multicolumn{3}{c}{ OD } & \multicolumn{3}{c}{ OE } \\
\hline M.C.I.= OdB & $\mathbf{n}$ & $\%$ & $\mathbf{n}$ & $\%$ \\
Normal & 181 & 86,2 & 179 & 85,2 \\
Alterado & 29 & 13,8 & 31 & 14,8 \\
& & & & \\
M.C.I. $=-10 \mathrm{~dB}$ & $\mathrm{n}$ & $\%$ & $\mathrm{n}$ & $\%$ \\
Normal & 154 & 73,3 & 159 & 75,7 \\
Alterado & 56 & 26,7 & 51 & 24,3 \\
\hline
\end{tabular}

Na Tabela 21 são apresentados os resultados da distribuição das crianças, segundo a falha no teste S.S.I., independente da orelha testada.

Os resultados mostram uma prevalência alta de crianças que falharam no teste S.S.I. de $32,4 \%$ com um intervalo de confiança de $95 \%$ de $24,59 \%$ a $40,18 \%$.

TABela 21- Distribuição das cruanças de 3" a $5^{2}$ série (n=210), segundo a falha no TESTE S.S.I. EM PORTUGUÊS. BAURU 2000-2001.

\begin{tabular}{lcc}
\hline Testes S.S.I & n & $\%$ \\
\hline Normal & 142 & 67,6 \\
Alterado & 68 & 32,4 \\
TOTAL & 210 & 100 \\
\hline
\end{tabular}


Na TAB. 22 são apresentados os resultados da audiometria tonal, analisados segundo os critérios referidos na bibliografia (vide p. PEREIRA 1996) para crianças com alterações nas habilidades auditivas.

TABELA 22- Distribuiça das CRIANÇAS de 3" a 5" série ( $n=210)$, sEgundo os limiares AUDITIVOS. BAURU 2000-2001.

\begin{tabular}{lcc}
\hline Audiometria tonal limiar & $\mathbf{n}$ & $\%$ \\
\hline Limiar auditivo até 10dBNA & 95 & 45,2 \\
Limiar auditivo acima de 10dBNA & 115 & 54,8 \\
TOTAL & 210 & 100 \\
\hline
\end{tabular}

Os dados referentes aos testes: Potencial Evocado Auditivo de Média Latência (P.E.A.M.L.) e Potencial Cognitivo (P300) são mostrados nas TABELAS 23 e 24, respectivamente.

Na Tabela 23 são apresentados os resultados das respostas evocadas de média latência.

Foi observado maior número de alterações na latência da onda $\mathrm{Pa}(8,6 \%)$ em relação a $\mathrm{Na}(2,4 \%)$.

Os resultados parciais de P.E.A.M.L. mostram que para a latência Na para a OD, 3 $(1,4 \%)$ das crianças apresentaram resultados alterados e para a $\mathrm{OE}, 2(1,0 \%)$. Para a latência Pa ocorreu um número maior de resultados alterados sendo, 11(5,2\%) para a OD e 10(4,8\%) para a OE, segundo os parâmetros estabelecidos.

TABELA 23- Distribuição das Crianças de 3* a 5" série (n=210), segundo os resultados DO TESTE ELETROPISIOLÓGICO P.E.A.M.L. BAURU 2000-2001

\begin{tabular}{lcc}
\hline P.E.A.M.L. & n & $\%$ \\
\hline Latência de Na (OD e/ou OE) & 205 & \\
Normal & 5 & 97,6 \\
Alterado & & 2,4 \\
& & \\
Latência de Pa (OD e/ou OE) & 192 & 91,40 \\
Normal & 18 & 8,60 \\
Alterado & & \\
\hline
\end{tabular}


Os resultados da TABELA 24 revelam a porcentagem de crianças que apresentaram latência da onda P300 alterada, ou seja, maior que $350 \mathrm{~ms}$ (vide p. 59). Os resultados analisados foram referentes ao valor da latência na posição $\mathrm{Cz}$.

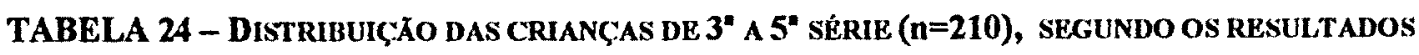
Do TESTE Eletrofisiológico P300. BauRu 2000-2001.

\begin{tabular}{lcc}
\hline P300 & n & $\%$ \\
\hline Normal & 181 & 86,2 \\
Alterado & 29 & 13,8 \\
TOTAL & 210 & 100 \\
\hline
\end{tabular}

Os resultados da avaliação eletrofisiológica realizada nos escolares mostraram que no Potencial Evocado Auditivo do Tronco Encefálico (P.E.A.T.E.), as repostas encontraram-se dentro dos parâmetros de normalidade estabelecidos para esta pesquisa para todas as crianças, tanto para as latências (I, III e V), quanto para os intervalos entre os picos (I-III, III-V, I-V).

\subsection{ANÁLISES BIVARIADAS}

A seguir são demonstrados os resultados das análises bivariadas para cada uma das variáveis a serem observadas quanto a possível associação como fator de risco para o desempenho no teste S.S.I.

Na TABELA 25 é observada associação estatisticamente significante entre o resultado do teste S.S.I. e a idade da criança no momento da avaliação $(p=0,005)$. 
TABEla 25. Distribuicão das CRIANÇAS de $3^{*}$ a 5* SÉrie ( $N=210$ ), SEGUNdo A IDAde $E$ DESEMPENHO NO TESTE S.S.I. BAURU 2000-2001.

\begin{tabular}{|c|c|c|c|c|c|c|}
\hline \multirow[t]{3}{*}{ Idade } & \multicolumn{4}{|c|}{ Testes S.S.I. } & & \\
\hline & \multicolumn{2}{|c|}{ Normal } & \multicolumn{2}{|c|}{ Altcrado } & \multicolumn{2}{|c|}{ TOTAL } \\
\hline & $\mathbf{n}$ & $\%$ & $\bar{n}$ & $\%$ & $\mathrm{n}$ & $\%$ \\
\hline 8 anos & 12 & 48,0 & 13 & 52,0 & 25 & 100 \\
\hline 9 anos & 44 & 65,7 & 23 & 34,3 & 67 & 100 \\
\hline 10 anos & 35 & 61,4 & 22 & 38,6 & 57 & 100 \\
\hline 11 anos e mais & 51 & 83,6 & 10 & 16,4 & 61 & 100 \\
\hline
\end{tabular}

A TABELA 26 apresenta os resultados da distribuição das crianças de $3^{a}$ a $5^{a}$ série, segundo a categoria em que as escolas estão enquadradas. Foi encontrada associação estatisticamente significante $(p=0,035)$

Nessa tabela é possível observar que houve maior índice de falhas no teste SSI, nas escolas beneficentes $(54,5 \%)$ e públicas $(31,3 \%)$. Estas seguem o sistema de "progressão continuada" (vide p.27).

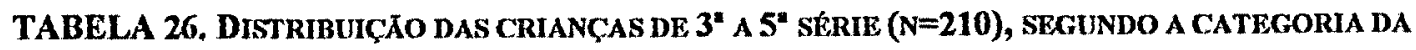
ESCOLA E O DESEMPENHO NO TESTE S.S.I. BAURU 2000-2001.

\begin{tabular}{|c|c|c|c|c|c|c|}
\hline \multirow[t]{3}{*}{ Categoria da escola } & \multicolumn{4}{|c|}{ Testes SSI } & & \\
\hline & \multicolumn{2}{|c|}{ Normal } & \multicolumn{2}{|c|}{ Alterado } & \multicolumn{2}{|c|}{ TOTAL } \\
\hline & $\mathrm{n}$ & $\%$ & $\mathrm{n}$ & $\%$ & $\mathbf{n}$ & $\%$ \\
\hline Beneficente & 10 & 45,5 & 12 & 54,5 & 22 & 100 \\
\hline Municipal e Estadual - Pública & 114 & 68,7 & 52 & 31,3 & 166 & 100 \\
\hline Particular & 18 & 81,8 & 4 & 18,2 & 22 & 100 \\
\hline
\end{tabular}

$\mathrm{Na}$ TABELA 27 são apresentados os resultados relacionados com a história gestacional e o desempenho no teste S.S.I. Observamos que hipóxia perinatal está associada com o desempenho nos testes S.S.I. $(p=0,008)$.

Os resultados demonstrados nessa tabela revelam que entre os 7 casos com história de hipóxia perinatal , $6(85,71 \%)$ falharam no teste S.S.I. 


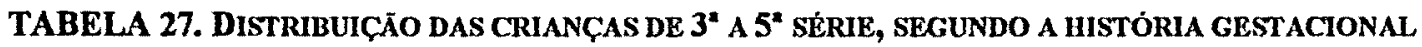
E DESEMPENIO NO TESTE S.S.I. BAURU 2000-2001.

\begin{tabular}{|c|c|c|c|c|c|c|c|}
\hline \multirow[t]{3}{*}{ História gestacional } & \multicolumn{4}{|c|}{ Testes S.S.I. } & & & \multirow{3}{*}{$p$} \\
\hline & \multicolumn{2}{|c|}{ Normal } & \multicolumn{2}{|c|}{ Altcrado } & \multicolumn{2}{|c|}{ TOTAL } & \\
\hline & $\mathrm{n}$ & $\%$ & $\mathbf{n}$ & $\%$ & $\mathbf{n}$ & $\%$ & \\
\hline Problemas no Pré-Natal. & & & & & & & 0,079 \\
\hline Sim & 110 & 67,07 & 54 & 32,93 & 164 & 100 & \\
\hline Não & 10 & 47,62 & 11 & 52,38 & 21 & 100 & \\
\hline Hipóxia perinatal & & & & & & & 0,008 \\
\hline Sim & 1 & 14,29 & 6 & 85,71 & 7 & 100 & \\
\hline Não & 121 & 67,22 & 59 & 32,78 & 180 & 100 & \\
\hline
\end{tabular}

A análise sobre a história médica das crianças mostrou resultado estatisticamente significante para queixa de dores de cabeça $(p=0,033)$.

A TABELA 28 apresenta os resultados da análise bivariada para associação entre os dados história audiológica e desempenho no teste S.S.I, sendo estatisticamente significante: queixa de que a criança não ouve bem $(p=0,023)$, alterações de equilíbrio $(p=0,006)$ e mais que um episódio de infecção de orelha média $(p=0,003)$, com o desempenho das crianças no teste S.S.I. 
TABELA 28. DistribuiçÃo das CRIANÇAS de $3^{\mathrm{a}}$ a $5^{\mathrm{a}}$ sÉrie, sEgundo os dados de mistóRia AUdIOLÓGICA E DESEMPENHO NO TESTE S.S.I. BAURU 2000-2001.

\begin{tabular}{|c|c|c|c|c|c|c|c|}
\hline \multirow[t]{3}{*}{ História audiológica } & \multicolumn{4}{|c|}{ Testes S.S.I. } & & & \multirow{3}{*}{$p$} \\
\hline & \multicolumn{2}{|c|}{ Normal } & \multicolumn{2}{|c|}{ Alterado } & \multicolumn{2}{|c|}{ TOTAL } & \\
\hline & $\bar{n}$ & $\%$ & $n$ & $\%$ & $\mathrm{~N}$ & $\%$ & \\
\hline Seu filho ouve bem? & & & & & & & 0,023 \\
\hline Não & 9 & 42,86 & 12 & 57,14 & 21 & 100 & \\
\hline Sim & 114 & 67,86 & 54 & 32,14 & 168 & 100 & \\
\hline Alteraçóes de equilíbrio. & & & & & & & 0,006 \\
\hline Não & 116 & 68,64 & 53 & 31,36 & 169 & 100 & \\
\hline Sim & 8 & 38,10 & 13 & 61,90 & 21 & 100 & \\
\hline Infecções de OM & & & & & & & 0,003 \\
\hline Não & 87 & 73,73 & 31 & 26,27 & 118 & 100 & \\
\hline $\operatorname{Sim}$ & 39 & 52,70 & 35 & 47,30 & 74 & 100 & \\
\hline
\end{tabular}

A comparação dos resultados da avaliação audiológica e eletrofisiológica com a avaliação comportamental (teste S.S.I.) revelou associações estatisticamente significantes, como pode ser observado na TABELA 29. 


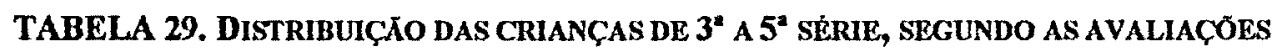
AUDIOLÓGICA E ELETROFISIOLÓGICA COMPARARADAS COM O DESEMPENHO NO TESTE S.S.I.

\begin{tabular}{|c|c|c|c|c|c|c|c|}
\hline \multirow[t]{3}{*}{ A valiação audiológica c eletrofisiológica } & \multicolumn{4}{|c|}{ Testes S.S.I. } & & & \multirow{3}{*}{$\begin{array}{c}p \\
0,000\end{array}$} \\
\hline & \multicolumn{2}{|c|}{ Normal } & \multicolumn{2}{|c|}{ Alterado } & \multicolumn{2}{|c|}{ TOTAL } & \\
\hline & $\mathbf{n}$ & $\%$ & $\mathbf{n}$ & $\%$ & $\mathbf{n}$ & $\%$ & \\
\hline \multicolumn{8}{|l|}{ Audiometria tonal liminar } \\
\hline Limiar auditivo até $10 \mathrm{dBNA}$ & 79 & 83,16 & 16 & 16,84 & 95 & 100 & \\
\hline Limiar auditivo acima de 10dBNA & 63 & 54,78 & 52 & 45,22 & 115 & 100 & \\
\hline Latência da onda Na no P.E.A.M.L.. & & & & & & & 0,021 \\
\hline Normal & 141 & 68,78 & 64 & 31,22 & 205 & 100 & \\
\hline Alterado & 1 & 20,00 & 4 & 80,0 & 5 & 100 & \\
\hline Latência da onda Pa no P.E.A.M.L.. & & & & & & & 0,000 \\
\hline Normal & 137 & 71,35 & 55 & 28,65 & 199 & 100 & \\
\hline Alterado & 5 & 27,78 & 13 & 72,22 & 11 & 100 & \\
\hline Potencial Cognitivo (P300) & & & & & & & 0,000 \\
\hline Normal & 139 & 76,80 & 42 & 23,20 & 181 & 100 & \\
\hline Alterado & 3 & 10,34 & 26 & 89,66 & 29 & 100 & \\
\hline
\end{tabular}

Não houve associação entre amplitude de Potencial Cognitivo - P300 e o desempenho no teste S.S.I. $(p=0,795)$.

Na TABELA 30 são mostrados os resultados das características comportamentais que apresentaram associação com o desempenho no teste S.S.I.

As caracteristicas relacionadas a seguir não estiveram associadas com os resultados dos testes S.S.I.: desconforto a som intenso $(p=0,146)$, dificuldade de entender fala na presença de ruído $(p=0,988)$, esquece o que lhe é dito $(p=0,414)$, prefere brincar com crianças mais jovens $(p=0,733)$, cansa facilmente das atividades $(p=0,552)$, pede para repetir o que foi dito $(p=0,461)$, desobediente $(p=0,071)$ e frusta-se facilmente $(p=0,682)$. 


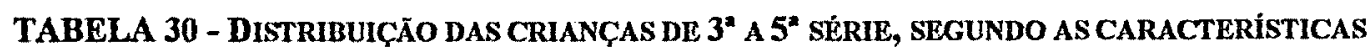
EMOCIONAIS E DO COMPORTAMENTO AUDITIVO E DESEMPENHO NO TESTE S.S.I. BAURU 2000-2001.

\begin{tabular}{|c|c|c|c|c|c|c|c|}
\hline \multirow{3}{*}{$\begin{array}{l}\text { Aspectos emocionais } \\
\text { comportamento auditivo }\end{array}$} & \multicolumn{4}{|c|}{ Testes SSI } & & & \multirow{3}{*}{$p$} \\
\hline & \multicolumn{2}{|c|}{ Normal } & \multicolumn{2}{|c|}{ Alterado } & \multicolumn{2}{|c|}{ TOTAL } & \\
\hline & $\mathrm{n}$ & $\%$ & $\mathrm{n}$ & $\%$ & $\mathrm{n}$ & $\%$ & \\
\hline Distraído & & & & & & & 0,028 \\
\hline Não & 52 & 75,36 & 17 & 24,64 & 69 & 100 & \\
\hline Sim & 64 & 59,26 & 44 & 40,74 & 108 & 100 & \\
\hline Agitado & & & & & & & 0,028 \\
\hline Não & 83 & 70,94 & 34 & 29,06 & 117 & 100 & \\
\hline Sim & 32 & 54,24 & 27 & 45,76 & 59 & 100 & \\
\hline Irritado. & & & & & & & 0,033 \\
\hline Não & 69 & 72,63 & 26 & 27,37 & 95 & 100 & \\
\hline Sim & 47 & 57,32 & 35 & 42,68 & 82 & 100 & \\
\hline Se gosta de ir à escola. & & & & & & & 0,017 \\
\hline Não & 10 & 43,48 & 13 & 56,52 & 23 & 100 & \\
\hline Sim & 106 & 68,83 & 48 & 31,17 & 154 & 100 & \\
\hline Problema de localização sonora. & & & & & & & 0,001 \\
\hline Não & 115 & 68,05 & 54 & 31,95 & 169 & 100 & \\
\hline Sim & 1 & 12,50 & 7 & 87,50 & 8 & 100 & \\
\hline Problemas com conceitos de tempo. & & & & & & & 0,005 \\
\hline Não & 109 & 68,99 & 49 & 31,01 & 158 & 100 & \\
\hline Sim & 7 & 36,84 & 12 & 63,16 & 19 & 100 & \\
\hline Problemas de obediência às regras & & & & & & & 0,009 \\
\hline Năo & 87 & 71,90 & 34 & 28,10 & 121 & 100 & \\
\hline Sim & 29 & 51,79 & 27 & 48,21 & 56 & 100 & \\
\hline Falta auto-confiança & & & & & & & 0,007 \\
\hline Não & 77 & 70,64 & 32 & 29,36 & 109 & 100 & \\
\hline $\operatorname{Sim}$ & 39 & 57,35 & 29 & 42,65 & 68 & 100 & \\
\hline Perda de atenção & & & & & & & 0,041 \\
\hline Não & 76 & 72,38 & 29 & 27,62 & 105 & 100 & \\
\hline Sim & 39 & 57,35 & 29 & 42,65 & 68 & 100 & \\
\hline
\end{tabular}

A TABELA 31 mostra os aspectos de fala /linguagem que estão associados com o desempenho no teste S.S.I: dificuldade para formar frases complexas $(p=0,027)$ e baixo desempenho escolar $(p=0,000)$.

As variáveis relacionadas aos aspectos de fala/linguagem que não apresentaram associação com os testes S.S.I. foram: atraso de fala $(p=0,629)$, vocabulário pobre 
$(p=0,998)$, se sua fala é entendida $(p=0,381)$, se entende o que os outros dizem $(p=0,428)$, se fez fonoterapia $(p=0,299)$ e lateralidade $(p=0,543)$.

TABELA 31 - DISTRIBUIÇÃo dAS CRIANÇAS de 3* A 5" SERIE, SEGUNdO AS CARACTERISTICAS dE FALNLINGUAGEM E DESEMPENHO NO TESTE S.S.L. BAURU 2000-2001.

\begin{tabular}{|c|c|c|c|c|c|c|c|}
\hline \multirow[t]{3}{*}{ Fala/linguagem } & \multicolumn{4}{|c|}{ Testes S.S.I. } & \multirow{2}{*}{\multicolumn{2}{|c|}{ TOTAL }} & \multirow{3}{*}{$P$} \\
\hline & \multicolumn{2}{|c|}{ Normal } & \multicolumn{2}{|c|}{ Alterado } & & & \\
\hline & $\mathbf{n}$ & $\%$ & $\mathbf{n}$ & $\%$ & $\mathbf{n}$ & $\%$ & \\
\hline Dificuldade de formar frases complexas & & & & & & & 0,027 \\
\hline Não & 92 & 70,23 & 39 & 29,77 & 131 & 100 & \\
\hline Sim & 24 & 52,17 & 22 & 47,83 & 46 & 100 & \\
\hline Baixo desempenho escolar & & & & & & & 0,000 \\
\hline Não & 118 & 74,68 & 40 & 25,32 & 158 & 100 & \\
\hline Sim & 12 & 31,58 & 26 & 68,42 & 38 & 100 & \\
\hline
\end{tabular}

\subsection{RESUlTAdO DA ANÁliSE MULTIVARIADA}

\subsubsection{FATORES DE RISCO PARA ALTERAÇõES NAS HABILIDADES DO P.A.}

A TABELA 32 apresenta os resultados do modelo final de regressão logística múltipla. Os fatores de risco relacionados ao desempenho nos testes S.S.I. foram: idade, latência no teste $\mathrm{P} 300$ maior que $350 \mathrm{~ms}$, latência de $\mathrm{Pa}$ maior que $35 \mathrm{~ms}$, limiar auditivo em uma ou mais freqüência acima de 10dBNA (vide PEREIRA 1996, p.23), infecções de OM, hipóxia perinatal e categoria da escola. 
TABEla 32. - RAZÕES DE CIANCES AJUSTADAS (RC) E RESPECTIVOS INTERVALOS DE 95\% DE CONFIANÇA (IC95\%) PARA CARACTERISTICAS DA CRIANÇA, HISTÓRIA CLÍNICA E ALTERAÇÕES NAS HABILIDADES DO PROCESSAMENTO AUDITIVO.

\begin{tabular}{|c|c|c|c|c|}
\hline VARIÁVEIS & $\mathbf{n}$ & RC & IC95\% & $p$ \\
\hline Sexo & & & & 0,87 \\
\hline Masculino & 83 & 1 & & \\
\hline Feminino & 127 & 0,94 & $0,41-2,11$ & \\
\hline Idade & & & & 0,04 \\
\hline 8 & 25 & 1 & & \\
\hline 9 & 67 & 0,37 & $0,11-1,27$ & \\
\hline 10 & 57 & 0,76 & $0,23-2,50$ & \\
\hline $11 \mathrm{e}^{+}$ & 61 & 0,20 & $0,05-0,78$ & \\
\hline Hipóxia perinatal & & & & 0,020 \\
\hline Não & 180 & 1 & & \\
\hline Sim & 7 & 10,98 & $1,05-115,13$ & \\
\hline Infeçã̃o de OM & & & & 0,040 \\
\hline Não & 118 & 1 & & \\
\hline Sim & 74 & 2,26 & $1,02-5,03$ & \\
\hline Audiometria tonal liminar & & & & 0,003 \\
\hline Limiar até 10dBNA & 115 & 1 & & \\
\hline Acima de $10 \mathrm{dBNA}$ & 95 & 3,36 & $1,47-7,66$ & \\
\hline Latência da onda $\mathrm{Pa}$ & & & & 0,030 \\
\hline Normal & 192 & 1 & & \\
\hline Alterado & 18 & 4,89 & $1,15-20,79$ & \\
\hline Potencial Cognitivo (P300) & & & & $<0,000$ \\
\hline Normal & 181 & 1 & & \\
\hline Alterado & 29 & 19,98 & $5,02-79,56$ & \\
\hline Categoria da escola & & & & 0,042 \\
\hline Beneficente & 22 & 1 & & \\
\hline Pública & 166 & 0,26 & $0,07-0,96$ & \\
\hline Particular & 22 & 0,11 & $0,02-0,70$ & \\
\hline
\end{tabular}




\subsubsection{Características COMPORTAMENTAis DA CRIANÇA COM ALTERAÇÃo NAS} HABILIDADES DO D.P.A.

As variáveis que caracterizavam o comportamento da criança e que mostraram associação com alteração das habilidades do P.A. foram: baixo desempenho escolar, dificuldade de localização sonora, vocabulário pobre e dificuldade de obediência às regras (TABELA 33).

TABELA 33. - RAZÖES DE CHANCES AJUSTADAS (RC) E RESPECTIVOS INTERVALOS DE 95\% DE CONFIANÇA (IC95\%) PARA CARACTERÍSTICAS DA CRIANÇA, HISTÓRIA CLINICA E ALTERACOESS NAS HABILIDADES DO PROCESSAMENTO AUDITIVO.

\begin{tabular}{|c|c|c|c|c|}
\hline VARIÁVEIS & $\bar{n}$ & $\mathbf{R C}$ & IC $95 \%$ & $p$ \\
\hline Sexo & & & & 0,16 \\
\hline Masculino & 83 & 1 & & \\
\hline Feminino & 127 & 0,58 & $0,28-1,24$ & \\
\hline Idade & & & & 0,02 \\
\hline 8 & 25 & 1 & & \\
\hline 9 & 67 & 0,39 & $0,13-1,18$ & \\
\hline 10 & 57 & 0,50 & $0,16-1,57$ & \\
\hline $11 e^{+}$ & 61 & 0,15 & $0,04-0,54$ & \\
\hline Baixo desempenho escolar & & & & $<0,000$ \\
\hline Não & 158 & 1 & & \\
\hline Sim & 38 & 6,37 & $2,16-18,81$ & \\
\hline Vocabulário pobre & & & & 0,02 \\
\hline Não & 148 & 1 & & \\
\hline Sim & 29 & 0,26 & $0,08-0,88$ & \\
\hline Probl. de localização sonora & & & & $<0,000$ \\
\hline Não & 169 & 1 & & \\
\hline Sim & 8 & 31,84 & $2,95-343,72$ & \\
\hline Probl. de obediência às regras & & & & 0,04 \\
\hline Não & 128 & 1 & & \\
\hline Sim & 49 & 2,44 & $1,04-5,76$ & \\
\hline
\end{tabular}




\section{DISCUSSÃO}

Neste capitulo, realizaremos uma análise crítica dos resultados obtidos no presente estudo, a fim de compará-los àqueles compilados por outros pesquisadores da literatura especializada sobre o assunto.

Os procedimentos utilizados nesta pesquisa foram realizados obedecendo à metodologia adequada para cada teste e após normatização e calibração de cada um dos equipamentos, seguindo as normas vigentes e com profissionais especializados, portanto acreditamos que não ocorreram erros sistemáticos que possam inviabilizar os resultados.

O estudo foi desenvolvido com o intuito de elucidar, aspectos importantes para a análise dos procedimentos utilizados no diagnóstico para a identificação de alterações nas habilidades do processamento auditivo em escolares. Além disso, havia a intenção de levantar algumas caracteristicas emocionais e do comportamento auditivo exibidas por essas crianças em idade escolar.

A avaliação do sistema nervoso auditivo central tem levado numerosos pesquisadores a desenvolver testes comportamentais e eletrofisiológicos para a identificação de distúrbios do S.N.A.C. Acreditamos que este estudo possa mostrar essaa necessidade, nas diversas populações que apresentam características de alterações nas funções do S.N.A.C. (MUSIEK e LAMB 1999).

O desenvolvimento das habilidades auditivas é primordial para o aprendizado de leitura e escrita, pois as alterações nessas habilidades podem prejudicar o desempenho 
escolar devido aos efeitos sobre o aprendizado pela audição (HUMES 1990, KEITH 1995, PERISSINOTO e col. 1997).

A identificação do D.P.A. tem sido realizada principalmente por testes comportamentais. Entretanto, nos últimos anos, a avaliação eletrofisiológica vem ganhando espaço no diagnóstico dessas alterações devido à possibilidade da avaliação global da audição; portanto, acreditamos ser importante a discussão sobre a utilização dos testes comportamentais unidos aos eletrofisiológicos na avaliação do processamento auditivo. (CHERMAK E MUSIEK 1997, PARTHASARATHY 2000).

O teste comportamental - Identificação de Sentenças Sintéticas (S.S.I.) foi utilizado nessa pesquisa para a análise da prevalência de alterações nas habilidades do processamento auditivo, pois fornece informações importantes de como o indivíduo faz uso da audição na comunicação, na presença de uma mensagem competitiva. O teste foi escolhido, devido à possibilidade de avaliar a habilidade de atenção auditiva seletiva, bem como observar as dificuldades enfrentadas pelos escolares no seu uso, em sala de aula, ou seja, prestar atenção a uma mensagem principal na presença de uma competitiva, situação comum nas escolas. (PEREIRA 1996, GRAVEL e col. 1996).

Além disso, este estudo possibilitou analisar aspectos importantes das crianças que falharam no teste comportamental para processamento auditivo. As que falharam no teste S.S.I. totalizaram 68 [32,38\% (IC95\%: 24,59\% a 40,18\%)] dos escolares avaliados, esse número elevado pode estar relacionado a alterações na atenção auditiva seletiva, que é uma das importantes habilidades do processamento auditivo, além de uma série de outras circunstâncias. A falha no teste de identificação de sentenças sintéticas - S.S.I. evidencia uma dificuldade nas habilidades do processamento auditivo, principalmente de atenção auditiva seletiva - figura-fundo auditiva (PEREIRA 1996, GRAVEL e col. 1996). 
Segundo a literatura compulsada, são necessários mais estudos para conhecer o desenvolvimento das habilidades auditivas para a realização da tarefa solicitada, pois os resultados demonstraram serem afetados pela idade, mostrando ser um importante fator para a falha no teste S.S.I. Obsrvamos uma melhora dos resultados com o aumento da idade (como pode ser observada na Tabela 25). Portanto, apesar do teste ter sido sugerido para utilização em crianças a partir de 8 anos (PEREIRA 1997) devemos levar em conta a maturação do sistema nervoso central (DECKER e NELSON 1981).

Além disso, devemos estar atentos às outras condições como distúrbios que exibem o mesmo comportamento que o D.P.A., por exemplo, a Síndrome do Déficit de Atenção e Hiperatividade e problemas de leitura e escrita, e outras características comportamentais que interferem na realização dos testes como: a falta de atenção, motivação, compreensão, cooperação durante o exame, meio sócio-econômico-cultural e sistema educacional que conduz o aprendizado da criança (KATZ e TILLERY 1997, JERGER e MUSIEK 2000, FELIPPE 2002).

O sistema educacional utilizado atualmente nas escolas públicas do estado de São Paulo, a "progressão continuada", define que o ensino deve ser realizado em ciclos, nos quais não há a reprovação dos alunos nos três primeiros anos de cada ciclo $\left(1^{\mathrm{a}}\right.$ a $4^{\mathrm{a}}$ série, $5^{\mathrm{a}}$ a $8^{\mathrm{a}}$ série e $1^{\circ}$ ao $3^{\circ}$ colegial). (OLIVEIRA 2001, MAINARDES 2001)

Essa pesquisa confirma algumas conclusões de pesquisadores da área da educação, de que o sistema educacional com a "progressão continuada" prejudica algumas crianças com alterações em habilidades (auditivas, visuais e motoras) importantes para a aprendizagem, pois são aprovadas sem que haja o desenvolvimento adequado dessas habilidades, além de não apresentarem o domínio da leitura e escrita. Esse estudo possibilitou levantar essa questão, pois os resultados do Teste S.S.I. mostraram alto índice 
de falhas no teste S.S.I. (32,38\%), que necessita de boa habilidade de leitura e escrita, sendo observada que as crianças nas idades afetadas estudaram em escolas com sistema de "progressão continuada" (categoria beneficente e pública) (STANOVICH 1994, NASCIMENTO 2003).

Portanto a utilização do teste S.S.I. na faixa etária estudada, deve ser realizada, obedecendo a alguns critérios de análise das características da criança a ser avaliada, a fim de tornar a avaliação útil para os propósitos a que se dispõe.

Esta pesquisa levantou os fatores de risco relacionados à falha no teste S.S.I. que são discutidos a seguir.

A audiometria tonal liminar revelou que as crianças com alteração nas habilidades auditivas apresentavam limiares auditivos piores que o grupo que não falhou, ou seja, maior número de crianças apresentavam limiares auditivos acima de 10dBNA em pelo menos uma freqüência, o que corrobora com o estudo de PEREIRA (1996). Este dado revela a importância da avaliação audiológica no processo de diagnóstico de alterações nas habilidades auditivas pois, apesar dos limiares apresentarem-se dentro ou próximo dos padrões de normalidade, esta característica pode indicar dificuldade de detecção auditiva.

A pesquisa também mostrou que os escolares que falharam no teste comportamental - S.S.I. estão associados com latências alteradas, segundo os critérios estabelecidos, para algumas medidas eletrofisiológicas.

O Potencial Evocado Auditivo Média Latência - P.E.A.M.L. apresentou associação com o desempenho no teste S.S.I. $(p=0,03)$; as latências de Pa apresentaram-se alteradas no grupo que falhou no teste S.S.I. A alteração deste componente pode estar relacionada com a atividade de transmissão de informações sobre discriminação auditiva, realizada por estruturas do tálamo e suas projeções para o córtex auditivo primário (WINER 1984), 
consideradas geradoras do componente Pa (ABRAMOVICH 1990, KRAUS e col. 1999). Portanto, essa medida pode ser um teste importante e complementar para o diagnóstico de alterações nas habilidades auditivas (PARTHASARATHY 2000).

O P.E.A.M.L. pode oferecer uma valiosa contribuição na avaliação das habilidades do processamento auditivo, acrescentando informações para o conhecimento anatomofisiológico das vias auditivas centrais, quando unidos à avaliação comportamental. Porém, estudos com este potencial devem ser incentivados, a fim de viabilizar sua utilização na prática clínica.

Foi observado resultado alterado do Potencial Cognitivo - P300, que confirma a falha na habilidade de atenção seletiva, avaliada no teste S.S.I. A presença de alteração na latência da onda $\mathrm{P} 300$, em crianças com distúrbio do processamento auditivo, concorda com outros estudos realizados por ALONSO e col. (1990), MUSIEK e col. (1992), DINIZ Jr e col. (1997), VISIOLI-MELO e ROOTTA (2000). Não foi encontrada associação estatisticamente significante para a amplitude deste potencial, corroborando com o estudo de SCHOSCHAT e col. (2002).

A utilização do P300 no diagnóstico do distúrbio de processamento auditivo tende a aumentar devido à sua relação com as funções de cognição, atenção e discriminação e às evidências de alterações em seu componente, na presença de distúrbios de processamento auditivo e aprendizado (ALONSO e col. 1990, DINIZ Jr. e col. 1997, GANAÇA e col. 1998, VISOLI-MELO e ROOTTA 2000, SCHOCHAT e col. 2002), além disso, constituise num importante teste eletrofisiológico que possibilita auxiliar o monitoramento das crianças em terapia de processamento auditivo (JIRSA 1992).

Atualmente, discute-se sua utilização unindo registros de potenciais eliciados por estimulos auditivos e visuais. Esta avaliação possibilitaria o diagnóstico diferencial dos 
distúrbios puramente auditivos e os distúrbios auditivo/visuais do processamento da informação cortical (JERGER e MUSIEK 2000, GIARD e col. 2000).

Não foram observadas alterações nas características do P.E.A.T.E., concordando com os estudos, de MUSIEK e col. (1994) e SCHOCHAT e col. (2002), que avaliaram esse potencial.

Outro fator de risco associado às alterações nas habilidades do processamento auditivo, evidenciado nessa pesquisa, foi história de infecções de orelha média, também discutida por outros pesquisadores como BROWN (1990), GRAVEL e WALLACE (1992), HALL e GROSE (1993), GRAVEL e col. (1996), KEITH (1995).

Várias pesquisas têm mostrado preocupação com a detecção de alterações de orelha média (BROWN 1990, GRAVEL e WALLACE 1992, HALL e GROSE 1993). Essas alterações poderiam ser prevenidas se fosse dada uma atenção especial aos programas de detecção e diagnóstico, adequados e efícientes, a serem realizados principalmente nos primeiros anos de vida, de forma a prevenir os periodos de privação sensorial que podem prejudicar o desenvolvimento das habilidades do processamento auditivo, acarretando prejuizos no desempenho escolar, principalmente relacionados às dificuldades de leitura/escrita e atenção na presença de ruído competitivo, também discutidas por outros estudiosos como KEITH (1995), GRAVEL e col. (1996), HUBIG e COSTA (1997).

A hipóxia perinatal foi revelada nesse estudo como outro importante fator de risco para as alterações nas habilidades do processamento auditivo, confirmando que provoca modificações importantes no S.N.A.C., também discutido por outros estudos que demonstraram haver associação com alterações que podem afetar a função e a maturação das vias auditivas (HUNGRIA 1991, FUESS 2000). 
As características emocionais e do comportamento auditivo associadas às alterações nas habilidades auditivas mostraram que as crianças que falharam no Teste S.S.I. apresentavam desempenho escolar baixo, dificuldade de localização sonora, vocabulário pobre e problemas de obediência às regras, o que concorda com os achados de outros estudos (MUSIEK e col. 1994, KEITH 1995, ASHA 1996, PEREIRA 1996, JERGER e MUSIEK 2000). Essas caracteristicas possibilitam traçar um perfil das crianças que apresentam alterações nas habilidades do processamento auditivo.

A queixa de baixo desempenho escolar, nesta pesquisa, pode estar relacionada às alterações nas habilidades auditivas devido ao sistema de ensino aplicado às crianças para aquisição da aprendizagem, discutidos anteriormente.

A associação da queixa dos pais de dificuldade de localização sonora e o desempenho no teste S.S.I. das crianças podem ser apresentadas como uma das características a serem levantadas na anamnese e na avaliação, o que leva à suspeita da existência de alteração nas habilidades auditivas.

Este estudo não pretende responder a todas as questões referentes ao uso dos testes no diagnóstico do D.P.A. em escolares e às características dessa população, mas pretende fornecer uma ajuda no sentido de conhecer as caracteristicas clínicas e comportamentais das crianças com alteração nas habilidades auditivas, em fase escolar, e incentivar novos estudos que se preocupem com essa questão.

JERGER e MUSIEK (2000) apoiaram a idéia da necessidade de mais pesquisas na área do D.P.A. Alguns pontos importantes levantados por esses autores para pesquisas futuras são: procurar melhorar os conhecimentos do desenvolvimento psicofísico normal da discriminação, reconhecimento e resgate de informações da memória auditiva e visual, a prevalência do D.P.A. em crianças, a idade apropriada para iniciar um trabalho de triagem 
do D.P.A., características de performance nos testes existentes para os diferentes grupos clínicos, a relação dos resultados dos testes com as estratégias de tratamento, resultados da intervenção precoce entre outras questões fundamentais ao assunto abordado, diagnóstico diferencial de outras alterações e o D.P.A., além da necessidade de mais estudos para melhorar a sensibilidade e especificidade dos instrumentos de diagnóstico atuais (JERGER e MUSIEK 2000, SCHOCHAT e col. 2002). 


\section{CONCLUSÕES}

A partir da análise crítica dos resultados que obtivemos na população estudada, é válido concluir que:

1) Houve uma prevalência de $32,38 \%$ de falha no teste de identificação de sentenças sintéticas - SSI, demonstrando dificuldade na habilidade de atenção seletiva (figurafundo auditiva) em escolares de $3^{\mathrm{a}}$ à $4^{\mathrm{a}}$ série, na faixa etária de 8 a 12 anos;

2) Os fatores de risco para as alterações nas habilidades do processamento auditivo relacionados com as características de história pregressa e as alterações no sistema auditivo, evidenciados pelos resultados da avaliação audiológica e eletrofisiológica foram:

- Infeç̧ão de orelha média.

- Hipóxia perinatal.

- Limiares auditivos acima de 10dBNA.

- Potencial Evocado Auditivo de Média Latência (P.E.A.M.L.) apresentou a latência da onda PA alterada, segundo os critérios estabelecidos nessa pesquisa;

- Potencial cognitivo (P300) apresentou latência alterada.

3) As características emocionais e do comportamento auditivo da criança com alterações nas habilidades do processamento auditivo foram:

- Baixo desempenho escolar.

- Vocabulário pobre.

- Problemas de localização sonora.

- Dificuldade de obediência às regras. 
Este estudo possibilitou concluir que existe a necessidade de mais pesquisas com a população de escolares e com os procedimentos utilizados na avaliação do processamento auditivo, comportamental e eletrofisiológico, a fim de viabilizar a utilização na prática clínica.

Além disso, o estudo evidencia a necessidade de programas que visem a prevenção de problemas de orelha média, nos primeiros anos de vida, por meio da intervenção precoce e prevenção das alterações de processamento auditivo, a fim de propiciar o desenvolvimento adequado para o aprendizado das crianças. 


\section{CONSIDERAÇÕES ÉTICAS}

Os procedimentos realizados nesta pesquisa, tanto o comportamental como os eletrofisiológicos, não representam qualquer risco para a criança. Os testes comportamentais foram realizados em cabina preparada acusticamente e os testes eletrofisiológicos utilizaram eletrodos de superficie, portanto métodos não invasivos e que não provocam desconforto ou constrangimento ao individuo. A bateria de testes foi realizada em aproximadamente uma hora e meia. Os exames foram realizados mediante autorização dos pais ou responsáveis (Anexo 2).

Os resultados foram entregues aos pais. As crianças com alteração receberam orientações e encaminhamentos para atendimento especializado, a fim de desenvolver as habilidades auditivas prejudicadas, identificadas pela bateria de testes utilizados nesta pesquisa. As escolas também foram orientadas quanto aos possiveis fatores de riscos associados ao distúrbio do processamento auditivo (D.P.A.) e como minimizar seus efeitos, bem como atitudes a serem tomadas diante das crianças identificadas com a alteração, a fim de propiciar o bom desempenho dessas crianças durante a fase escolar. 


\section{REFERÊNCIAS BIBLIOGRÁFICAS}

ABRAMOVICH S. Electric Response Audiometry in Clinical Practice. Churchill Livingstone 1990.

AITKIN LM., WEBSTER, WR. Medial geniculate body of the cat: organization response to tonal stimuli of neurons in the ventral division. J Neurophysiol 1972; 35: $365-80$.

ALBERTI P.W.; HYDE M.L.; RIKO, K.; CORBIN, H.; FITZHARDINGF,P.M. Issues in early identification of hearing loss. Laryngoscope, v.95, p.373-81, Apr.1985.

ALMEIDA C.I.R., CAETANO M.H.U. Logoaudiometria utilizando sentenças sintéticas. Rev Bras Otorrinol, 54:68-72, 1988.

ALMEIDA CC., LOPES CC., MACEDO LM., GADEL MT., COSTA MC., PEREIRA LD. Influência do nível sócio-econômico e cultural e da estimulação auditiva nas habilidades do processamento auditivo central. Fono atual 1997; 2:1217.

ALONSO TO., NAVARRO M., ABAD EV. P300 component of the auditory eventrelated potentials and dyslexia. Funct Neurol 1990; Oct-Dec; 5(4): 333-8

AMERICAN SPEECH-LANGUAGE-HEARING ASSOCIATION TASK FORCE ON CENTRAL AUDITORY PROCESSING CONSENSUS DEVELOPMENT Central auditory processing: Current status of research and implications for clinical practice. Am J Audiol 1996; 5(2): 41-54.

ASSESSORIA DE COMUNICAÇÃO E IMPRENSA - UNICAMP Respaldo 
Científico (Editorial - 03-01-2003) Unicamp na Midia [texto online] 30/01/2003.

Disponivel em $<$ URL:

http://www.unicamp.br/unicamp/canal_aberto/clipping/janeiro2003/clipping030103.

AZUMI T., NAKASHIMA K., TAKAHASHI K. Aging effects on auditory middle latency responses. Electromyogr.Clin.Neurophysiol. 1995; 35(7): 397-401.

BAMFORD J., SAUNDERS E. Hearing Impairment auditory perception and language disability - studies in disorders comunication. In: Hearing Impairment Auditory Percepption and Language Disability. Singular Publishing Group, San Diego 1991.

BAMFORD J., SAUNDERS E. Central auditory dysfunction. In: Hearing Impairment Auditory Percepption and Language Disability. Singular Publishing Group, San Diego 1995; cap. 10, p. 227-46.

BARAJAS J.J. (1991) The effects of age on human P3 latency. Acta Otolaryngol (Stockh). Suppl. 476:157-60.

BERLUCCHI G. Two hemispheres but one brain. Behav. Brain Science. 1983; 6: $171-2$.

BOCCA E. Clinical aspects of cortical deafness. Laryngoscope 1958; 68:301-9.

BORG E. On the organization of the acoustic middle ear reflex: A physiologic and anatomic study. Brain Reseach, 1973; 100: 113-16.

BORGES ACLC. Dissílabos alternados. In: PEREIRA, L.D.; SCHOCHAT, E. Processamento Auditivo Central. Ed. Lovise 1997; Parte 2, cap. 9, p.169-178.

BREEDIN SD., MARTIN RG., JERGER S. Distinguishing auditory and speech- 
specific perceptual deficits. Ear Hear. 1989; 10(5):311-16.

BRAIN CONNETION. 20/10/2002 - URL < http://brainconnection.com

BROWN DP. Speech recognition in recurrent otitis media: results in a set of identical twins. J. Am. Acad. Audiol, 1994; 5:1-6.

BRUGGE JF., GEISLER CE. Auditory mechanisms of the lower brainstem. Annn. Rev. Neurosci. 1978; 1:363-94.

CARPENTER M., SUTIN J. Human neuroanatomy. Baltimore: Williams \& Wilkins 1983.

CARVALLO RMM. Processamento auditivo: avaliação audiológica básica. In: SCHOCHAT, E.; PEREIRA, L.D. Processamento auditivo central: manual de avaliação. Ed. Lovise 1997; cap. 2, p. 27-35.

CELESIA G. Organization of auditory cortical areas in man. Brain. 1976; 99: 40314

CHERMAK GD., MUSIEK FE. Conceptual and historical foundations. In: Central Auditory Processing Disorders - New Perspectives. Singular Publishing Group San Diego 1997; cap.1, p. $1-25$.

CHERMAK GD., MUSIEK FE. Conceptual and historical foundations. In: Central Auditory Processing Disorders - New Perspectives. Singular Publishing Group San Diego 1997; cap. 2, p. 27-70.

CHERMAK GD., TRAYNHAM WA., SEIKEL JA., MUSIEK FE. Professional education and assessment practices in central auditory processing. J. Am. Acad. Audiol. 1998; 9:452-65. 
CLAYTON D., MICHAEL H. Statistical Models in Epidemiology Oxford University Press 1993.

COSTA, O.A. ; CELANI,A.C. Audiometria de respostas elétricas de tronco cerebral . Caderno de ORL e Cirurgia da Cabeça e Pescoço, v.107 (1), p.43$48,1993$.

COSTA S.M.B.; COSTA FILHO O.A., CARDOSO M.R.A. - Os efeitos da idade e sexo na latência do P300 Rev Bras Otorrinolaringol (no prelo)

DAMASIO H., DAMASIO A. Paradoxic ear extinction in dichotic listening: possible anatomic significance. Neurology 1979; 25(4): 644-53.

DECKER TN., NELSON PW. Maturation effects on the synthetic sentence identification-ipsilateral competing message. Ear Hear. 1981 Jul-Aug; 2 (4): 165-9.

DEHAN,C.P.; JERGER,J. The Jerger Perspective Clinical Audiology. Edited by Bobby R., p.403-09, 1993.

DIBI V., REZENDE A.G., PEREIRA L.D. Teste de escuta monótica de baixa redundância em indivíduos normais de 8 a 15 anos. Revista da Sociedade Brasileira de Fonoaudiologia. 1998 Jun.; 2(3): 48-50.

DINIZ Jr. J., MANGABEIRA-ALBERNAZ PL., MUNHOZ MSL. Cognitive potencials in children with learning disabilities. Acta Otolaryngol. 1997; 117:21113.

DURRANT J.D., LOVRINIC J.H. Bases of hearing science. Ed. Williams \& Wilkins. Baltimore, $2^{\mathrm{a}}$ ed., 1984.

FELIPPE A.C.N. Processamento auditivo e problemas de leitura-escrita In: 


\section{AQUINO A.M.C.M. Processamento auditivo - Eletrofisiologia \& Psicoacústica.}

Ed. Lovise 2002, cap. 6., p.101-10.

FERRARO J.A Laboratory Exercises in Auditory Evoked Potentials Singular Publishing Group, Inc. San Diego 1997.

FERRARO J.A., DURRANT J.D. Potenciais auditivos evocados: visão geral e princípios básicos. In: KATZ, J. Tratado de Audiologia Clínica. Ed. Manole 1999; cap. 22 , p. $315-36$.

FRANCO G.M. O potencial evocado auditivo em adultos normais.

Arq. Neuropsiquiatr., 2001, 59(2-A),p. 198-200.

FRENCH J. The reticular formation. Science America 1957; 66: 01- 08

FUESS V.L.R. Estudo do retardo da maturação das vias auditivas através dos potenciais evocados auditivos de tronco cerebral. Associação com distúrbios de aquisição de linguagem Revista Arquivos da Fundação Otorrinolaringologia [periódico online] 2000; 4(1). Disponivel em <URL: http://www.henet.usp/otorrino/arq $41 / \mathrm{mat}$.htm.

GALABURDA A., SANIDES F. Cytoarchitectonic organization of the human auditory cortex. J Comp Neurol 1980;190: 597-610.

GANANÇA MM., VIEIRA RM., CAOVILLA HH. A avaliação audiológica no exame otoneurológico. In: Princípios de otoneurologia. Ed. Atheneu. 1998; cap. 3, p. 7-21.

GEISLER C.D., FRISHKOPF L.S., ROSENBLITH W.A. Extracranial responses to acoustic clicks in man. Science $1958 ; 128 ; 1210-11$. 
GIARD M.H., FORT A., MOUCHETANT-ROSTAINY,, PERNIER J. Neurophysiological mechanisms of auditory selective attention in humans. Front Biosci, 2000; 5: 84-94

GONÇALVES A.S., SOUZA L.B., SOUZA V.M.C. Avaliação do Processamento Auditivo: relato de experiência clínica In: AQUINO A.M.C.M. Processamento auditivo - Eletrofisiologia \& Psicoacústica. Ed. Lovise 2002, cap. 8., p.121-28.

GORGA M.P., WORTHINGTON D.W., REILAND J.K., BEAUCHAINE K.L., GOLDGARD D.E. Some comparisons between auditory brainstem responses thresholds latencies, and the pure-tone audiogram. Ear Hear 1985, 6:105-12.

GORGA M.P., REILAND J.K., BEAUCHAINE K.L. Auditory brainstem responses from graduates of an intensive care nursery using an insert earphone. Ear Hear 1988,$9 ; 144-47$.

GRAVEL JS., WALLACE IF. Listening and language at four years of age: effects of early otitis media. J Speech Hear Res. 1992; 35:588-95

GRAVEL JS., WALLACE IF, RUBEN RJ. Early otitis media and later educational risk. Acta Otolaryngol (Stockh). 1995; 115:279-81.

GRAVEL JS., WALLACE IF, RUBEN RJ. Auditory consequences of early mild hearing loss with associated with otitis media. Acta Otolaryngol (Stockh), 1996; 116:219-21.

GOLDBERG JM., MOORE RY. Ascending projections of the lateral lemniscus in the cat and the monkey. J Comp Neurol 1967; 129:143-55.

HALL JW., GROSE JH. The effect of otitis media with effusion on the masking difference level and auditory brainstem response. J Speech Hear Res 1993; 36:210- 
17.

HILLYAR S.A., HINK R.F., SCHWENT V.L., PICTON T.W. Electrical sign of selective attention in the human brain Science, 1973; 182:177-180, citado em

GIARD M.H., FORT A., MOUCHETANT-ROSTAINY., PERNIER J. Neurophysiological mechanisms of auditory selective attention in humans. Front Biosci, 2000; 5: 84-94

HIRSCH, A. Behavioral tests: applications and limitations in comparison with brainstem response audiometry. Acta Otolaryngol (Stockh.), v.482 (Suppl.), p.118-24, 1991.

HOOD L.J. Middle latency response in stutterers . ASHA 1987; 29:81.

HOOD L.J. Auditory evoked potential differ at 50 milliseconds in right and left handed listeners. Hear Res 1990; 115: 22.

HUBIG DOC., COSTA FILHO OA. Otite média: consideraç̃os em relação à população de creche. In: LICHTIG, I.; CARVALLO, R.M.M. Audição: Abordagens Atuais. Ed. Pró-Fono 1997; cap. 5, p.89-117

HUMES LE. Masking of tone by modulated noise in normal, noise-masked normal, and hearing-impaired listeners. J Speech Hear Res 1990; 33:3-8.

HUNGRIA, H. Otorrinolaringologia. Ed. Gaunabara Koogan, cap.41, p. 375, 1991.

JACOBSON,J.T.; HALL III, J.W. Newborn and infant auditory brainstem response applications In: Handbook of Auditory Response. Hall III J.W. Cap. 13, p.313-44, 1992. 
JASPER H.H. The tem-twenty electrode system of the Internacional Federation. Eletroenceph. Clin. Neurophysiol. 1958; 10: $371-5$.

JERGER J. Clinical experience with impedance audiometry I Normal and sensorioneural ears. Arch.Otolaryng. 1970; (92):311 citado em SANTOS TM., RUSSO ICP. A Prática da Audiologia Clínica 1991, cap. VI, p. 113-45.

JERGER J.F., JERGER S.W. Auditory findings in brainstem disorders. Arch Otolaryngol. 1974; 99:342-49

JERGER J.F., JERGER S.W. Clinical validity of central auditory tests. Scand Audiol. 1975; 4:147-63.

JERGER S., JERGER J. Tumores intracranianos que afetam o sistema auditivo central. In: JERGER S., JERGER J Alterações auditivas. 1992; cap.12, p. 87-104.

JERGER J., MUSIEK F. Report of Consensus Conference on the Diagnosis of Auditory Processing Disorders in School-Aged Children. J Am Acad Audiol 2000; $11: 467-74$.

JIRSA R.E., CLONTZ K.B. Long latency auditory event-related potencials from children with auditory processing disorders. Ear Hear 1990; 11(3): 222-32.

JIRSA R.E. The clinical utility of the P3, AERP in children with auditory processing disorder. J Speech Hear Res. 1992; 35: 903-12.

JUNGERT S. Auditory pathways in the brainstem. A neurophisiologic study. Acta Otolaryngol. 1958; 138 (Suppl)

JUNQUEIRA C.A.O., FRIZZO A.C.F. Potenciais Evocados Auditivos de Curta, 
Média e Longa Latência In: AQUINO A.M.C.M. Processamento auditivo Eletrofisiologia \& Psicoacústica. Ed. Lovise 2002, cap.4., p.63-86.

KALIL D.M., ZILIOTTO K.N., ALMEIDA C.I.R. SSI em Portugüês. In: PEREIRA LD. SCHOCHAT E. Processamento Auditivo Central. Ed. Lovise, 1997; Parte 2, cap. 4, p. 129-33.

KATZ J., TILLERY KL. An Introduction to Auditory Processing. In: LICHTIG, I.; CARVAllO, R.M.M. Audição: Abordagens Atuais. Pró fono 1997; cap. 6, p. 119-72.

KATZ J., WILDE L. Desordem do processamento auditivo central. In: KATZ, J. Tratado de Audiologia Clínica. Ed. Manole 1999; cap. 32, p. 486-98.

KEIDEL W., KALLERT S., KORTH M., HUMES L.The phisiological basis of hearing. New York: Thieme-Stratton 1983.

KEITH RW. Tests of central auditory processing. In: Auditory Disorders in school children - The law - identification - remediation. Thieme Medical Publishers, Inc. $1995 ; 3^{\circ}$ ed., cap.5, p. 101-16.

KIMURA D. Some effects of temporal lobe damage on auditory perception. Can J Psychol. 1961; 15: 166-71.

KRAUS N., KILENY P., McGEE T. Potenciais auditivos evocados de média latência. In: KATZ, J. Tratado de Audiologia Clínica. Ed. Manole 1999; cap. 26, p. $384-402$.

KRAUS N., McGEE T. Potenciais auditivos evocados de longa latência. In: KATZ, J. Tratado de Audiologia Clínica. Ed. Manole 1999; cap. 27, p. 403-20. 
LASKY E., KATZ J. Perspctives on auditory processing. In: LASKY, E.; KATZ, J. Central auditory processing disorders. Baltimore, University Park Press 1983; p.3-9.

LEWIS M. Learning disabilities and prenatal risks. Urbana: University of Illinois Press citado em MUSIEK FE., BARAN JA., PINHEIRO ML. Neuroauditory disorders In: Neuroaudiology - Case Studies Singular Publishing Group 1994 p. $29-43$.

MACHADO A. Anatomia macroscópica do diencéfalo. In: Neuroanatomia funcional $\mathrm{Ed}$. Atheneu $2^{\mathrm{a}}$ ed. 1998; p.55-8

MACHADO LP., PEREIRA LD. Desordem do processamento auditivo central. In: PEREIRA LD., SCHOCHAT E. Processamento Auditivo Central. Ed. Lovise $1997 ;$ p. 61-68.

MAINARDES J. Ciclos: Ainda um desafio para os sistemas de ensino In: FRANCO C. Avaliação, ciclos e promoção na educação. Porto Alegre Ed. Artmed Editora 2001.

MARGOLIS RH. Protocol 5 - Pediatric Central Auditory Processing Evaluation In: MAGOLIS, R.H. Audiology Clinical Protocols Ed. Allyn and Bacon 1997; p. 37-55.

McPHERSON DL. Long latency auditory evoked potecials. In: Late Potencials of the auditory system. Singular Publishing Group, Inc. 1996; p.7-21.

MEDICAL TECHNOLOGIES - 20/10/2002. [figuras on line $\}$ URL $<$ http://www.audiospeech.ubs.ca.haplab/aep.htm

MEIRELES S. O fracasso da escola pública Revista Aprendiz [periódico online] 
2003, p. 1-2. Disponivel em <URL:

http://www.uol com.br/aprendiz/n colunas/coluna livre/id070402.htm.

MENDELSON,T.; SALAMY, A. Maturational effects on the middle components of the averaged electroencephalic response. J Speech Hear Res 24: 140-44, 1981.

MOREST DK. The neuronal architecture of medial geniculate body of the cat. $\mathbf{J}$ Anat 1964; 98: 611-30.

MUNHOZ M.S.L., SILVA M.L.G., CAOVILLA H.H., GANANÇA M.M., FRAZZA M.M. Neuroanatomofisiologia da audição In: . MUNHOZ M.S.L., CAOVILla H.H., SILVA M.L.G., GANANÇA M.M Audiologia clínica. Ed. Atheneu 2000a; cap. 3, p. $19-43$.

MUNHOZ M.S.L., SILVA M.L.G., GANANÇA M.M., CAOVILlA H.H., FRAZZA M.M. Respostas auditivas de média latência In: . MUNHOZ M.S.L., CAOVILlA H.H., SILVA M.L.G., GANANÇA M.M Audiologia clínica. Ed. Atheneu 2000b; cap. 13, p. $221-30$.

MUSIEK FE., PINHEIRO ML., BARAN JA. Auditory pattern perception in splitbrain patients. Arch Otolaryngol 1980; 106: 610-12.

MUSIEK FE., KIBBE K., BARAN JA. Neuroaudiological results from split-brain patients. Sem Hear 1984a; 5(3): 219-29.

MUSIEK F., GEURKINK N.A., WEIDER D.J., DONNELLY K. Past, Present, and Future Applications of the Audiometry Middle Latency Response. Laryngoscope. 1984b; 94: 1.545-53.

MUSIEK FE., REEVES A., BARAN JA. Release from central auditory competition in the split-brain patient. Neurology. 1985; 35: 983-7. 
MUSIEK F., KIBBE-MICHAL K, GEURKINK N., JOSEY A., GLASSCOCK III $\mathrm{M} A B R$ results in patients with posterior fossa tumors and normal puro tone hearing. Otolaryngol Head Neck Surg 1986; 94: 568-73.

MUSIEK FE., BARAN JA. Neuroanatomy, neurophysiology, and central auditory assessment. Part I: Brain stem Ear Hear. 1986; 7 (4): 207-19.

MUSIEK FE. Neuroanatomy, neurophysiology, and central auditory assessment. Part II: The cerebrum Ear Hear. 1986a., 7 (5):. 283-94.

MUSIEK FE. Neuroanatomy, neurophysiology, and central auditory assessment. Part III: Corpus callosum and efferent pathways. Ear Hear. 1986b; 7 (6): 349-58.

MUSIEK FE . Aplicação de testes auditivos centrais - Uma abordagem geral. In: KATZ J. Tratado de Audiologia Clínica. Ed. Manole 1989a; cap. 17, p. 323-39.

MUSIEK FE. Probing brain function with acoustic stimuli ASHA 1989b, 31: 100 06.

MUSIEK FE., BARAN JA., PINHEIRO ML. P300: results in patients with lesions of the auditory areas of the cerebrum. J Am Acad Audiol 1992; 3(1): 5-15.

MUSIEK FE., BARAN JA., PINHEIRO ML. Introduction to Case Studies in Neuroaudiology. In: Neuroaudiology - Case Studies. Ed. Singular Publishing Group 1994.

MUSIEK FE., LAMB L. Avaliação auditiva central: Uma visão geral. In: KATZ,J. Tratado de Audiologia Clínica. Ed.Manole 1999; cap. 14, p. 195-209.

MUSIEK FE., BORENSTEIN S.P., HALL III J.W., SCHWABER M.K. 
Audiometria de tronco encefálico ( $\mathrm{ABR}$ ): neurodiagnóstico e aplicações intraoperatórias. In: KATZ, J. Tratado de Audiologia Clínica. Ed. Manole 1999; cap. 24, p. 349-71.

NOBACK CR. Neuroanatomical correlates of central auditory function. In: PINHEIRO ML., MUSIEK FE. Assessment of central auditory dysfunction: foundations and clinical correlates. Baltimore: Williams \& Wilkins 1985; p. 7-21

NASCIMENTO G. Ensino polêmico - projeto propõe suspensão de sistema que impede repetência Revista Isto é Online [periódico online] agosto, 2001.

Disponivel em (30/01/2003) <URL:

http://www.terra.com.br/istoe/1665/educação/1665 ensino polemico. htm

NORTHERN J.L.; GERKIN,K.P. New technology in infant hearing screening. Otolaryngol Clin North Am Fev, 1989, 22.(1).

ORTIZ KZ., PEREIRA LD. Desordem do processamento auditivo central e distúrbios da produção fonoarticulatória In: LICHTIG, I.; CARVALLO, R.M.M. Audição Abordagens Atuais. Ed. Pró-Fono 1997; cap. 7, p. 175-86.

OSTERNE F.J., COSTA S.A., PEREIRA L.D., BORGES A.C.L.C. Teste de identificação de frases sintéticas (SSI): aplicação em adultos com audição normal. Anais do IX Encontro Internacional de Audiologia p. 88, 1994.

OZDAMAR O., KRAUS N. Auditory middle latency responses in humans. Audiology 1983, 22:34-49.

PAGE JM. Central auditory disorders in children. Otolaryngol Clin North Am. $1985 ; 18(2): 323-35$. 
PALUDETTI, G.; MAURIZI, M.; D'ALATRI, L.; GALLI, J. - Relationships between middle latency auditory response (MLR) and speech discrimination tests in the elderly. Acta Otolaryngol (Stockh) Suppl. 476: 105-9, 1991.

PANDYA DN., ROSENE DL. Some observation on trajectories and topography of commissural fibers. In: REEVES AG. - Epilepsya and the corpus callosum. New York: Plenun Press 1985.

PANDYA DN., SELTZER B. The topography of commissural fibers. In: LEPORE, F.; PITITO M., JASPER HH. - Two hemispheres - one brain: functions of the corpus callosum. New York: Alan R Liss, Inc. 1986

PARTHASARATHY T.K. Electrophysiologic assessment of CAPD: a review of the basics. Hearing Journal. 2000, April.

PEN M.G., MANGABEIRA-ALBERNAZ P.L. Desenvolvimento de testes para logoaudiometria: discriminação vocal. Anales del II Congresso Pan Americano de Otorrinolaringologia Lima, 1973, 2: 223-26.

PENROD J.P. Logoaudiometria. In: KATZ, J. Tratado de Audiologia Clínica. Ed. Manole 1999; cap. 10, p. 146-62.

PEREIRA LD. Identificação de desordem do processamento auditivo central através do observação comportamental: organização de procedimentos padronizados. In: SCHOCHAT E. Processamento Auditivo. São Paulo, Lovise, 1996; p.43-56.

PEREIRA LD. Processamento auditivo central: abordagem passo a passo. In: PEREIRA LD. SCHOChAT E. Manual de Avaliação do Processamento Auditivo Central. Ed. Lovise, 1997; Parte 1, cap. 5, p. 49-60. 
PEREIRA LD. SCHOCHAT E. Manual de Avaliação do Processamento Auditivo Central. Ed. Lovise, 1997.

PERISSINOTO J., PEREIRA LD., PAGOTTO AP., SILVA E., ALVES E., LEITE GSF., RODRIGUES MGP. Processamento auditivo central: sensibilizando professores que atuam em alfabetização. In: LAGROTTA, M.G.M; CÉSAR, C.P.H.A.R A fonoaudiologia nas instituições. 1997; cap. 16, p.111-21.

PFEIFFER RR. Classification of response patterns of spike discharges for units in the cochlear nucleus. Tone-burst stimulation. Exp Brain Res 1966; 1: 220-35.

PHILIPS DP. Central auditory processing: a view from auditory neuroscience. Am J Otology. 1995; $16(3)$ : 338-52.

PICTON T.W., HILLYARD S.A., KRAUSZ H.I., GALAMBOS R. Human auditory evoked potential. I Evaluation of components. Electroenceph Clin Neurophysiol 1974, $36 ; 179-90$.

RINTELMANN W. Monoaural speech tests in the detection of central auditory disorders. In: MUSIEK FE., PINHEIRO ML. Assessment of central auditory dysfunction: Foundations and clinical correlates. Baltimore: Williams \& Wilkins, 1985 ; p. 173-200.

RHODE W. The use of intracellular techniques in the study of the cochlear nucleus. J Acoust Soc Am. 1985; 78: 320-7.

RUPP. R The audiologist's role in the evaluation of auditory perceptual and processing abilities in young school-age children. In: BRADFORD, L. Audiology: An Audio Journal for Continuing Education New York, Grune \& Stratton, Inc, 1978 
RUTH R.A., LAMBERT P.R. Auditory evoked potencials. Otolaryngol Clin 1991; 24(2): 349-70.

SCHOCHAT E. Percepção da fala. In: Processamento Auditivo. Ed. Lovise, 1996; vol. II, cap. 1, p.15-42.

SCHOCHAT E, PEREIRA LD. Fala com Ruido. In: PEREIRA LD., SCHOCHAT E. Processamento Auditivo Central. Ed. Lovise 1997, Parte 2, cap. 1, p.99-102.

SCHOCHAT E., SCHEUER, C.I., ANDRADE, E.R. ABR and auditory P300 findings inchildren with ADHD. Arq. Neuro-Psiquiatr. [online]. Sept. 2002, vol.60, no.3B [citado em Novembro 2002], p.742-747. Disponível para World Wide Web: URL $<$

http://www.scielo.br/scielo.php?script=sci_arttext\&pid=S0004282X200200050001 $2 \& \operatorname{lng}=$ en\&nrm=iso $>$. ISSN 0004-282X.

SCHUMAN-GALAMBOS,C.; GALAMBOS,R. Brain stem auditory-evoked response in premature infants. J Speech Hear Res., v.18, p.456-65, 1975.

SLOAN C. Introduction: What is auditory processing? Why is it important? In: Treating auditory processing difficulties in children. Singular Publishing Group 1991; cap. 1, p. 1-4.

SPEAKS C., JERGER J. Method for measurement of speech identification. J Speech Hear Res 1965, 8:185-94.

SMEYERS P. Studies of evoked potentials in children with the syndrome of attention deficit and hyperactivity. Rev Neurol. 1999; Feb.(Suppl.)28: 173-6.

STANOVICH K.E. Beginning eeading and phonological awareness [texto online] . 
Language Arts Disponivel em (30/01/2003) <URL:

http://www.kidsource.com/kidsource/content2/disability.phonologicalhtml

STROMINGER NL., STROMINGER AL. Ascending brain stem projections of the anteroventral cochlear nucleus in the rhesus monkey. J Comp Neurol 1971; $143: 217-32$.

STROMINGER NL., HURWITZ JL. Anatomical aspects of the superior olivary complex. J Comp Neurol 1976; 170:485-97.

TARNOPOL L., TARNOPOL M. Distúrbios da leitura: uma perspectiva internacional. Editora da Universidade de São Paulo 1981; p.1-22.

TOBIN H. Binaural interaction tasks. In: MUSIEK, F.E; PINHEIRO, M.L. Assessment of central auditory dysfunction: Foundations and clinical correlates. Baltimore: Williams \& Wilkins 1985; 155-71.

TUCKER DA., RUTH RA. Effect of age, signal level, and signal rate on the auditory middle latency response. J Am Acad Audiol 1996; 7(2): 83-91.

TUCKER DA., DIETRICH S., McPHERSON DL., SALAMAT MT. Effect of stimulus intensity level on auditory middle latency response brain maps in human adults. J Am Acad Audiol 2000; 12(5); 223-32.

VISIOLI-MELO JF., ROOTTA NT. Avaliação pelo P300 de crianças com e sem epilepsia e rendimento escolar. Arq Neuropsiquiatr. 2000; 58(2-B): 476-84

WADDINGTON M. Atlas of human intracranial anatomy. Rutland, VT: Academy Books 1984.

WARR WB. Fiber degeneration following lesions in the anterior ventral cochlear 
nucleus of the cat. Exp Neurol. 1966; 14:453-74.

WEBSTER DB. Projection of the cochlea the cochlear nuclei im Merriam's kangaroo rat. J Comp Neurol 1971; 143: 323-40.

WEBSTER DB., WEBSTER M. Mouse brainstem auditory nuclei development. Ann Otolaryngol Rhinol Laryngol 1980; 89(68): 254-6.

WINER JA. The human medial geniculate body. Hearing Research. 1984; 15: 225-47.

WHITFIELD IC. The auditory pathway. Baltimore, Williams e Wilkins 1967

WILLEFORD J.A., BURLEIGH J.M. Testes Centrais: procedimentos utilizando sentenças. In: KATZ, J. Tratado de Audiologia Clínica. Ed. Manole 1999; cap. 18, p.254-66.

WHAT ARE AUDITORY EVOKED POTENTEIAL AND AUDITORY EVENTRELATED POTENTIAL. 20/10/2002 - [figuras on line] URL $<$ http://www.cf.ac.uk/biosi/staff/jacob/teaching/sensory/aepl.html

WOOD D.L., ALAIN C., COVARRUBIAS D., ZAIDEL O. Middle latency auditory evoked potential to tones of different frequency. Hearing Research. 1995; 85: 69-75. 
IDENTIFICACÃO:

Nome:

Escolaridade:

Endereço:

Informante:

\section{DADOS FAMILIARES:}

Nome do pai

ocupação

Nome do nãe

ocupação

Imãos?

Nome

Nome

Nome

Como é o relacionamento com os irmãos?

E com outras crianças?

E com os pais?

A criança é ( ) destra ou
MOTIVO PARA A AVALIACÃO

( ) Problemas escolares

( ) Problemas de leitura/escrita

\section{ASPECTOS GESTACIONAIS E DE NASCIMENTO}

1. Problema pré-natal?

2. Uso de álcool na gravidez?

3. Drogas ou medicamentos?

Quais

4. Doenças

Quais

12. Teve toxoplasmose, nubéola, citomegalovírus, herpes ou sífilis?

Idade

Idade

Idade

DN:

Cidade/Estado

Sexo:

Data: Idade: CEP escolaridade

idade

escolaridade

idade

) $\operatorname{sim}($ ) não

escolaridade escolaridade escolaridade
Sexo Sexo

Sexo

( ) canhota?

) Problemas auditivos

( ) Problemas de atenção

( ) Outros:

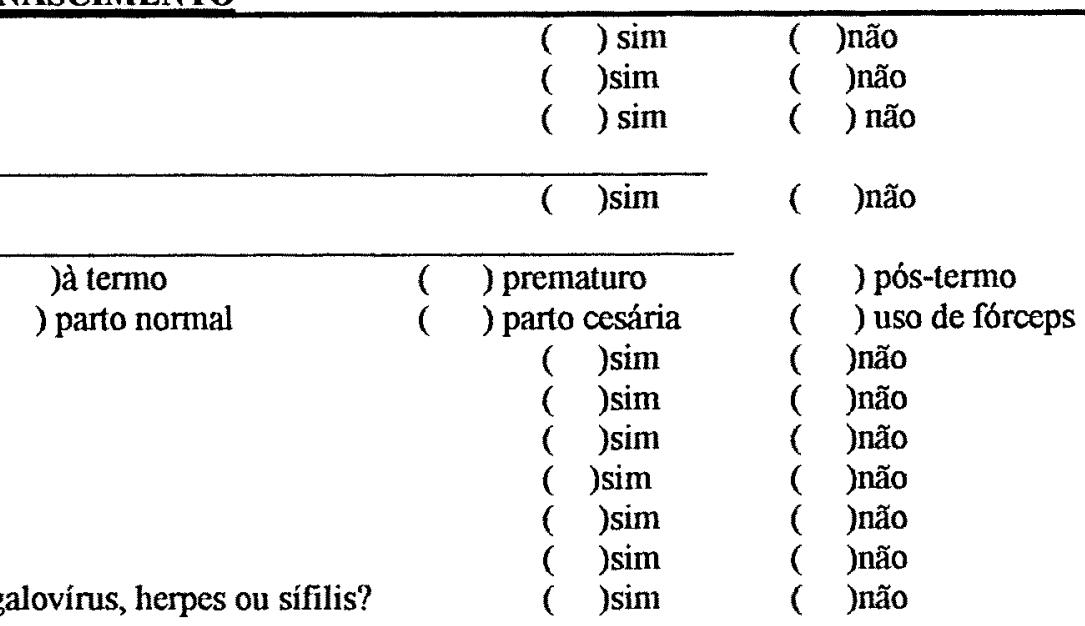

( ) $\operatorname{sim}$ ( )não

( ) $\operatorname{sim}($ )não

( ) sim $($ )กลัก

( ) sim

(

)กล̃o
5. Nasceu

6. Chorou logo que nasceu?

7. Apresentou-se cianótico?

8. Apresentou ictericia?

9. Ficou internado?

10.Em incubadora?

11 Fez transfusão sanguínea?

Quais

13. Peso no nascimento

HISTÓRIA MÉDICA:

1.Está em algum tratamento médico atualmente?

Qual?

2. Está tomando algum medicamento?

Qual?

3. Trauma craniano?

4. Mal-formações?

5. Convulsões?

Quando

6. Dores de cabeça?

7. Doenças? Quais?

8.Outros problemas neurológicos?

Quais?

9. Cirurgias?

Quais?

10. Ficou intemado?

HISTÓRIA AUDIOLÓGICA

1. Acha que seu filho(a) ouve bem?

2. Seu filho(a) queixa-se de barulho no ouvido ou cabeça?

3. Seu filho(a) tem tonturas ou vertigens?

4. Seu filho(a) teve ou tem dores de ouvido?

( ) à termo

Quando?

( ) Problemas de fala/linguagem 
5. Fez cirurgias no ouvido?

Quando?

6. Usa aparelho auditivo?

( ) sim

( )não

EXAMES ANTERIORES

1. Já fez testes auditivos?

Quando? Quais os resultados?

2.Já fez avaliação da fala e linguagem? $\quad() \operatorname{sim} \quad$ ( )não

Quando? Quais os resultados?

3.Exames de visão?
Quando? Quais os resultados?

4.Exames neurológicos (EEG)?

Quando? Quais os resultados?

5.Testes psicológicos

Quando? Quais os resultados?

\section{HISTÓRIA FAMILIAR}

Alguém na família tem:

1. Problemas neurológicos?

2. Problemas de fala?

3. Problemas de aprendizagem?

4. Doenças hereditárias?

Quais
5. Problemas Auditivos?

6. Parentesco entre os pais

( ) $\operatorname{sim}$

( )não

\section{CARACTERÍSITICAS EMOCIONAIS}

1. Tem desconforto a sons intensos?

2. Tem dificuldade de entender em lugar nuidoso?

3. É distraído?

4. Esquece o que é dito?

5. Prefere brincar com crianças mais jovens?

6. Fica cansado facilmente nas atividades?

7. Pede para repetir constantemente? (Hã? Hum?)

8. Perde a atenção facilmente?

9. É hiperativo, muito agitado?

10. É desobediente?

11. Irrita-se facilmente?

12. Gosta de ir à escola?

13.Tem problemas de localizar os sons?

14. Tem problemas com conceitos de tempo (ontem, hoje, anteontem)?

15. Problemas com obediência, seguir regras?

16. Frusta-se facilmente?

17. Falta de auto-confiança?

$\begin{array}{llll}( & \text { )sim } & ( & \text { Inão } \\ ( & \text { )sim } & ( & \text { )não } \\ ( & \text { )sim } & ( & \text { )não } \\ ( & \text { ) }) \operatorname{sim} & ( & \text { )não }\end{array}$

( ) sim ( ) não

( ) sim ( )não

\section{PROBLEMAS DE FALA/LINGUAGEM}

1.Atrasou para falar?

2.Tem vocabulário pobre?

3. Apresenta problemas para formar frases complexas?

4. Sua fala é facilmente entendida?

5. Entende o que os outros falam?

6. Faz ou fez terapia de fala/linguagem?

7. Tem problemas escolares?

\begin{tabular}{|c|c|}
\hline )sim & ( \\
\hline )sim & ( \\
\hline )sim & ( \\
\hline )sim & ( \\
\hline )sim & ( \\
\hline )sim & ( \\
\hline )sim & ( \\
\hline )sim & ( \\
\hline )sim & ( \\
\hline )sim & ( \\
\hline )sim & ( \\
\hline )sim & ( \\
\hline )sim & ( \\
\hline )sim & ( \\
\hline Jsim & c \\
\hline )sim & ( \\
\hline )sim & 8 \\
\hline
\end{tabular}

* Anamnese modificada de MARGOLIS, 1997.

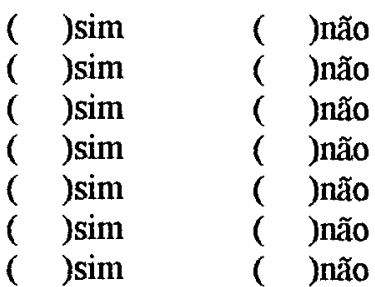




\title{
ESTUDO DA DESORDEM DO PROCESSAMENTO AUDITIVO CENTRAL EM ESCOLARES DE 9 A 11 ANOS DE IDADE,
} NA CIDADE DE BAURU - SP (ANEXO 2)

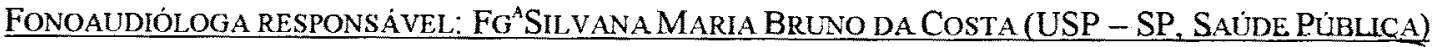

\author{
Tel. Para contato: 234-6412 (Instituto de Comunicação e Audição)
}

\section{Orientador da Pesquisa: Dr^ Maria Regina Alves Cardoso (USP- SP, DePart. de Saúde Pública) Co-orientador: Dr. Orozimbo Alves da Costa F ${ }^{\circ}$ ( USP - Bauru, Depart. De Fonoaudiologia)}

A audição é muito importante para a aprendizado e a comunicação dos individuos. Nós sabemos que ouvimos por meio dos ouvidos, porém não podemos esquecer que é o cérebro que faz uso da informação que escutamos. Assim, se algo nesse trajeto, da orelha até o cérebro, impede que a mensagem seja transmitida corretamente, perdemos a informação. Algumas crianças e adolescentes tem dificuldade para aprender por meio das pistas auditivas, apesar da audição e nível intelectual normais. Elas precisam desenvolver certas habilidades. Estas habilidades fazem parte do Processamento Auditivo Central, que hoje temos testes especiais para avaliá-las (atenção, memória, discriminação auditiva e outras).

A identificação da desordem do processamento auditivo central tem recebido atenção especial nas últimas duas décadas por causa das evidências de que estas desordens podem estar relacionadas ao desempenho escolar e casos de infecções no ouvido, principalmente nos $1^{\circ} \mathrm{s}$ anos de vida.

Por este motivo, este estudo tem por objetivo estimar a prevalência desta desordem em escolares e identificar possiveis associaçôes entre as características da criança e do ambiente com esta desordem, auxiliando nas orientações e encaminhamentos.

A avaliação audiológica unida ao do uso de testes para avaliar.o processamento auditivo central é o.primeiro passo para identificar crianças com desordens que possam prejudicar o desempenho escolar.

A realização destes testes, aliados aos sintomas observados pelos pais, tais como : criança muito distraida, atenção reduzida, dificuldade de leitura, escrita ou fala, baixo rendimento escolar e outros, serão muito importantes para detectar estas dificuldades.

Aos pais que mostrarem interesse na participação do estudo devem estar cientes que poderão suspender a participação a qualquer momento. Os testes e as orientações são gratuitas, pois são financiadas pela.FAPESPP (Fundação de Amparo à Pesquisa do Estado de São Paulo).

A bateria de testes é constituída de avaliação audiológica e avaliação com testes comportamentais especiais para Processamento Auditivo Central. Os resultados dos testes serão discutidos e entregues aos pais, que devem ser guardados, pois terão valor diagnóstico para o resto da vida da criança.

Salientamos que todos os dados da criança e da família serão mantidos em sigilo- Além disso, nenhum procedimento causará qualquer prejuizo à criança, pois são testes da rotina audiológica e não invasivos. Será enviado un cartão de agendamento para a realização dos testes.

Autorizo a participação de meu filho(a) nesta pesquisa e estou ciente que dos procedimentos utilizados, aguardo 0 agendamento 


\section{AUDIOGRAMA (anexo 3)}

Nome:

Idade:

OD

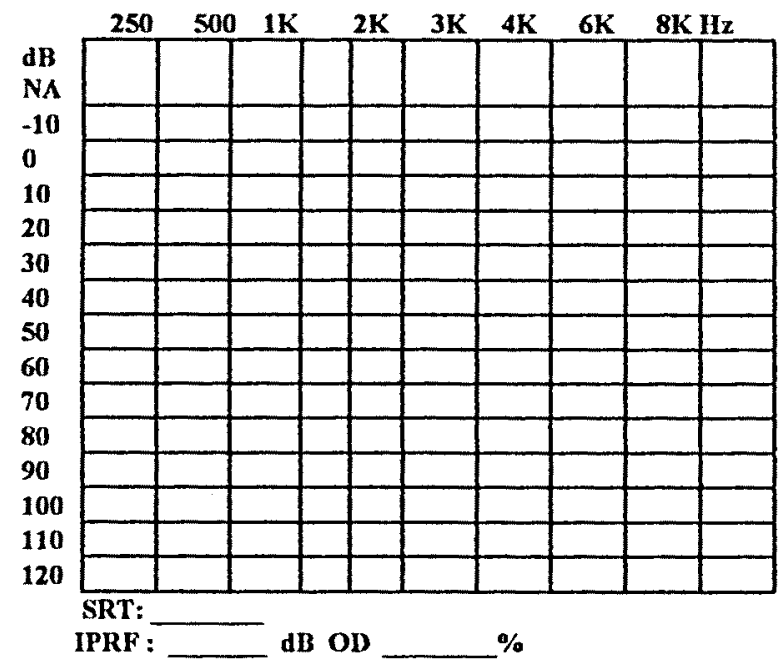

MASCARAMENTO

\begin{tabular}{l|l|l|} 
& OD & OE \\
\hline VA & & \\
\hline VO & & \\
\hline SRT & & \\
\hline LAF & & \\
\hline
\end{tabular}

OD

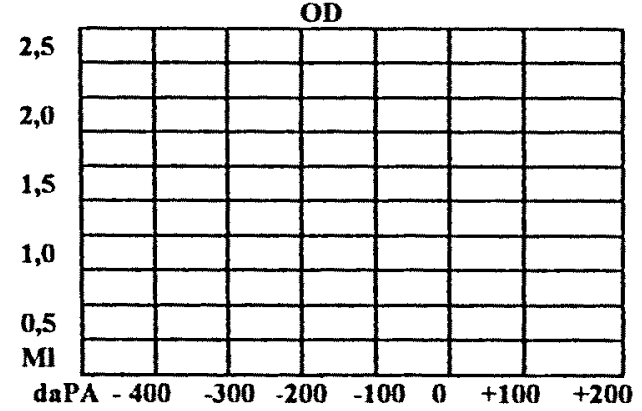

OE

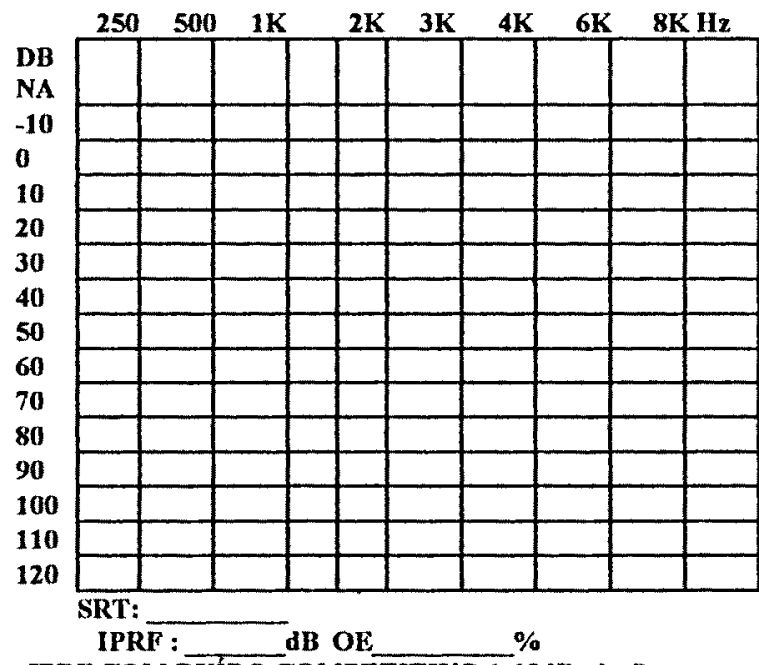
IPRF COM RUIDO COMPETITIVO (+10dB - ipsi):

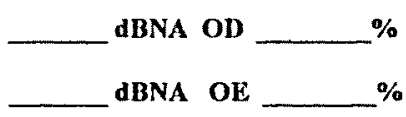

IPRF COM RUIDO COMPETITIVO (0dB - contra): dBNA OD $\%$ IBNA OE $\%$

\section{TIMPANOGRAMA}

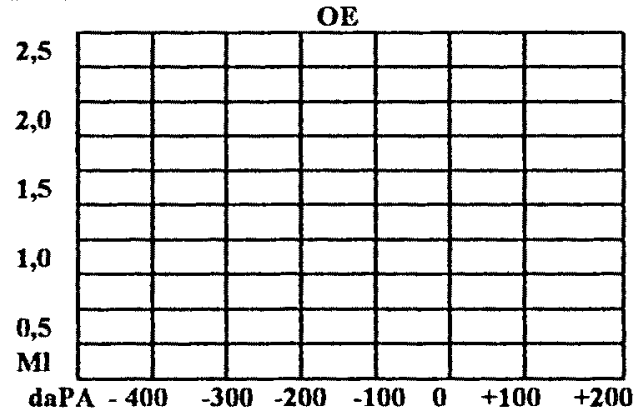

\begin{tabular}{|l|c|c|}
\hline \multicolumn{2}{|c|}{ COMPLACENCIA ESTÁTICA } & OE \\
\hline Pressão & OD & \\
\hline Máx. relaxamento & & \\
\hline +200daPa & & \\
\hline Complacência & & \\
\hline
\end{tabular}

REFLEXO ACÚSTICO

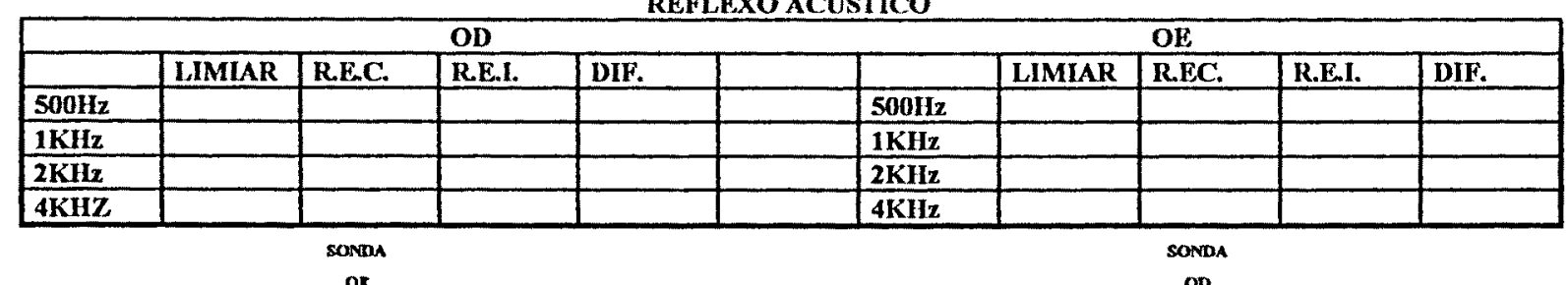


ANEXO 4 - AVALIACÃO DO PROCESSAMENTO AUDITIVO CENTRAL

IDADE:

DATA:

TESTE - Teste de identificacão de sentecas sintéticas com mensagem comnetitiva-

SSI em português

(avaliação da habilidade de figura-fundo )

Início: a 40dBNS (média de 500, 1000 e

Mensagem competitiva: Texto

$2000 \mathrm{~Hz}$ )

Avaliação

- Contralateral - tarefa dicótica

Relação S/R: OdB ; $-40 \mathrm{~dB}$ (contra)

- Ipsilateral - tarefa monótica

- com fones

OdB ; -10dB (ipsi)

Material: lista de sentenças sintéticas

Nome:

Idade:

D.N.:

DATA:

\begin{tabular}{|c|c|c|c|c|c|c|c|c|c|c|c|c|c|c|c|c|}
\hline Série & $\begin{array}{c}\text { O.testada } \\
\text { NA }\end{array}$ & $\begin{array}{c}\text { M. } \\
\text { dBNA }\end{array}$ & $\begin{array}{c}\text { MC } \\
\text { dBNA }\end{array}$ & $\begin{array}{c}\text { R. } \\
\text { S/R }\end{array}$ & & & & & & & & & & & & \\
\hline 1 & OD & & & 0 & MCC & 1 & 2 & 5 & 3 & 4 & 7 & 8 & 9 & 10 & 6 & \\
\hline 2 & OD & & & -40 & MCC & 3 & 7 & 9 & 6 & 5 & 8 & 10 & 1 & 2 & 4 & \\
\hline 3 & OE & & & 0 & MCC & 2 & 10 & 3 & 6 & 7 & 5 & 1 & 8 & 9 & 4 & \\
\hline 4 & OE & & & -40 & MCC & 2 & 1 & 6 & 10 & 3 & 9 & 8 & 5 & 7 & 4 & \\
\hline 5 & OD & & & 0 & MCI & 7 & 4 & 1 & 10 & 6 & 5 & 8 & 2 & 9 & 3 & \\
\hline 6 & OD & & & -10 & MCI & 10 & 2 & 3 & 8 & 7 & 1 & 9 & 6 & 4 & 5 & \\
\hline 7 & OE & & & 0 & MCI & 7 & 4 & 3 & 9 & 1 & 8 & 10 & 6 & 2 & 5 & \\
\hline 8 & OE & & & -10 & MCI & 1 & 2 & 9 & 4 & 8 & 10 & 6 & 5 & 3 & 7 & \\
\hline
\end{tabular}




\section{Anexo 5 \\ RELATÓRIO DE AVALIAÇÃO DO PROCESSAMENTO AUDITIVO \\ CENTRAL}

3auri, de de 200

1. Testes especiais realizados:

- Teste de escuta monótica e dicótica

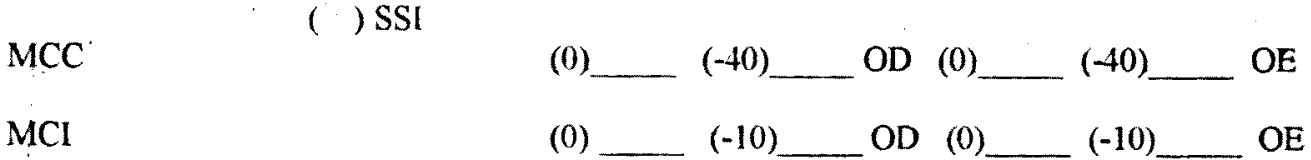

- Teste de fala com nuído - com palavras

$\mathrm{MCC}$

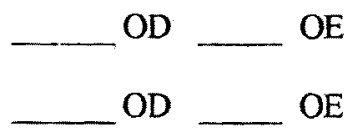

MCI

2. Medidas eletrofisiológicas - resultados

- BERA (80dBNAn) - análise das latências

- MLR (70dBNAn) - análise das latências

$\begin{array}{llll} & \text { I } & \text { III } & \text { V } \\ \text { OD } & & & \\ \text { OE } & & \\ \text { OD } & \mathrm{Na} & \mathrm{Pa} \\ \mathrm{OE} & & \end{array}$

- $\quad$ P300 (75dBNAu)

Resultado:

Conduta: 


\section{AUDIOGRAMA}

Nome:

Idade:

OD DATA:

OE

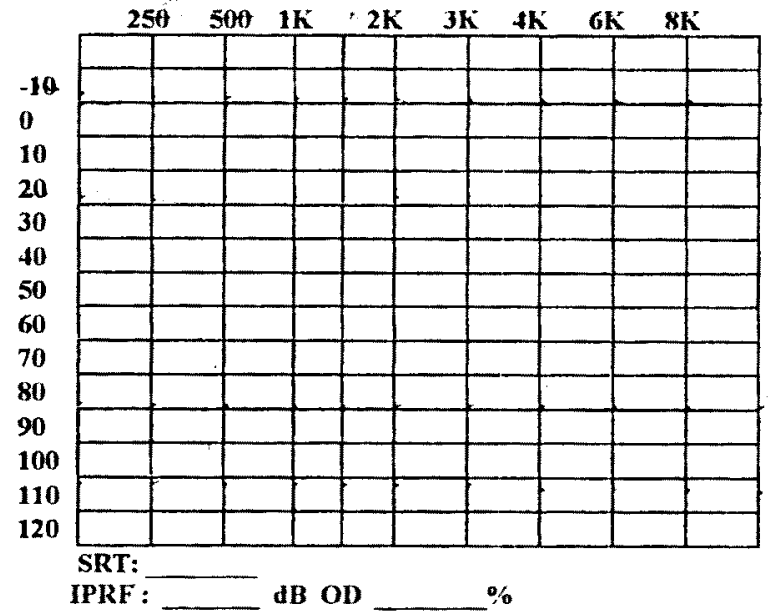

MASCARAMENTO

\begin{tabular}{l|l|l|} 
& OD & $\mathrm{OE}$ \\
\hline VA & & \\
\hline VO & & \\
\hline SRT & & \\
\hline IPRF & & \\
\hline LAF & & \\
\hline
\end{tabular}

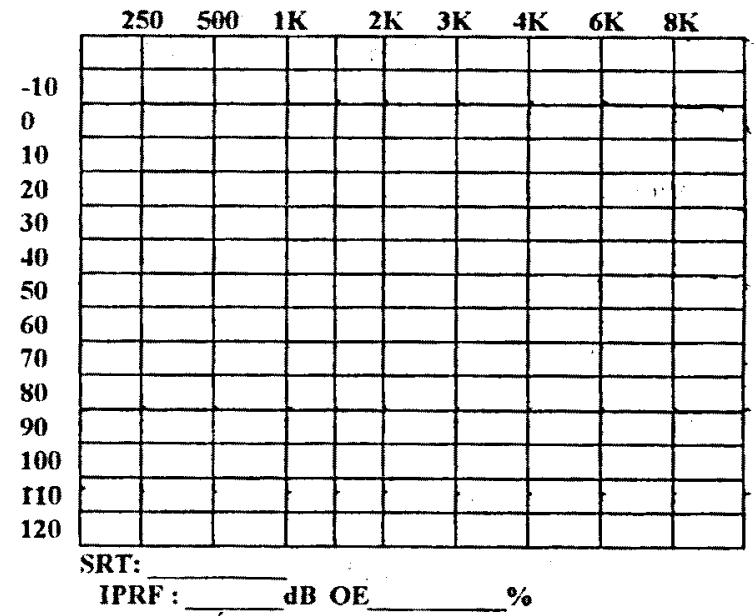
IPRF COM RUÍDO COMPETITIVO (+10dB - ipsi):

$\begin{array}{r}\text { IBNA OD } \\ \square \\ \hline\end{array}$

IPRF COM RUÍDO COMPETITIVO (+10dB - contra):

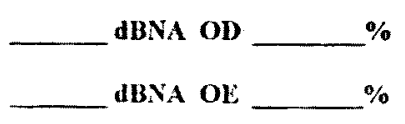

TIMPONOGRAMA
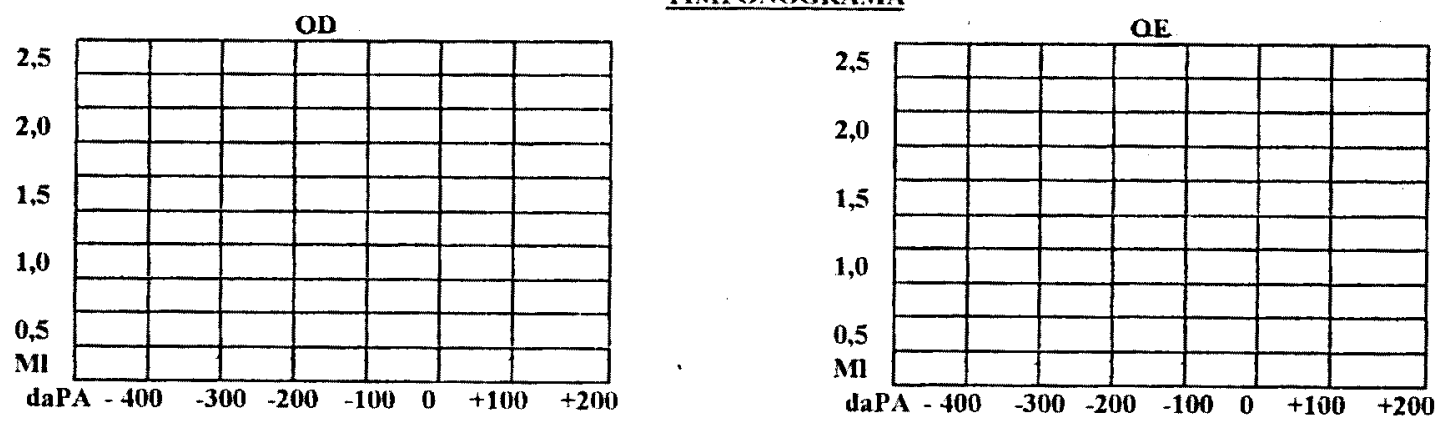

\begin{tabular}{|l|c|c|}
\hline \multicolumn{3}{|c|}{ CONTLACANCTA ESTATICA } \\
\hline Pressão & OD & OE \\
\hline Máx. relaxamento & & \\
\hline +200daPa & & \\
\hline Complacência & & \\
\hline
\end{tabular}

REFLEXO ACÚSTICO

\begin{tabular}{|c|c|c|c|c|c|c|c|c|c|}
\hline \multicolumn{6}{|c|}{ OD } & \multicolumn{3}{|c|}{ OE } & 1 \\
\hline & LINUAR & REC. & R.E.I. & DFF. & & LHMHAR & R.EC. & R.E.I. & DfF. \\
\hline $500 \mathrm{~Hz}$ & & & & & $500 \mathrm{~Hz}$ & & & & \\
\hline $1 \mathrm{KHz}$ & & & & & $1 \mathrm{KHL}$ & & & & \\
\hline $2 \mathrm{KHz}$ & & & & & $2 \mathrm{~K} 1 \mathrm{~L}$ & & & & \\
\hline $4 \mathrm{KHZ}$ & & & & & $4 \mathrm{KIIz}$ & & & & \\
\hline
\end{tabular}


DEDALUS - Acervo - FSP 